Bolm Inst. oceanogr. S Paulo, 20 (2): 1-70, 1971

\title{
DIVERSIFICAÇÃO FISIOLÓGICA E MORFOLÓGICA DE MICROPOGON FURNIERI (DESMAREST, 1822) AO SUL DE CABO FRIO, BRASIL*
}

(Recebido em $24 / 8 / 1971$ )

A.E.A. de A. VAZZOLER

Instituto Oceanográfico da Universidade de são Paulo

\section{SYNOPSIS}

This paper deals with some aspects of faunistic diversification and refers to part of the distribution area of a sciaenid $f$ ish Micropogon furnieri (Desmarest, 1822) Jordan \& Evermann 1884, widely distributed. Such species is characteristic of the tropical area and occurs along the Brazilian coast with highest abundance south of Cabo Frio.

The analysis of variations of six meristic characters and eight body proportions and of some reproduction and growth features has shown that along the coast between latitudes $230 \mathrm{~S}$ and $330 \mathrm{~S}$ diversification occurs within the species; such diversification implies in the existence of two populations, one occupying the area between 2305 and $290 \mathrm{~S}$ (area I) and the other between $290 \mathrm{~S}$ and $330 \mathrm{~S}$ (area II). The ecological differences between the two mentioned areas according to our point of view is the reason for the species diversification in the whole area under observation.

The differences recorded as the characteristics studied were sufficient enough to illustrate the existence of two populations reproductively isolated suggesting that some gene exchange, if any, between both populations occurs in a very low rate.

Our results show that abundance estimates of $M$. furnieri in this area must be made for each population as a whole until further studies on genetic characters are developed which may confirm the existence of gene exchange and if so, the gene flow rate.

As the present study does not cover the total area of occurrence of Micropogon furnieri no hypothesis is extended to the general pattern of diversification (eventual presence of sub-species) and no systematic "status" and names are given to the populations identified.

\section{INTRODUÇÃO}

Tanto do ponto de vista teórico, relativo à diversificação das faunas, quanto do prático, nos estudos quantitativos para estimativa do tamanho dos estoques, é de fundamental importância determinar se cada espécie é homogênea em toda sua ārea de distribuição, ou se há diferenciação geográfica e, na presença desta, quais as feições mais importantes. Podem ocorrer apenas variações nos caracteres por influência do meio ambiente (variações individuais, fenotípicas), ou ocorrer diferenciação geogräfica com base genética, culminando com - isolamento reprodutivo, constituindo-se, então, cada grupo em uma população reprodutivamente isolada.

* Tese de doutoramento apresentada ao Departamento de Zoologia do Instituto de Biociências da Universidade de São Paulo. Parte do trabalho foi realizado com apoio financeiro da Fundação de Amparo à Pesquisa do Estado de São Pau10.

PUBL. NQ 311 DO INST. OCEAN. DA USP. 
No presente estudo abordamos alguns aspectos do problema, tendo por objeto parte da ārea de um sciaenideo de ampla distribuição geogräfica, característico da região tropical, Micropogon furnieri (Desmarest,1822) Jordan \& Evermann, 1884 .

Micropogon furnieri (Fig. 1) ocorre em toda a costa do Brasil, sendo mais abundante ao sul de Cabo Frio. Dedicamo-nos ao estudo dessa espécie desde 1962 , e os resultados que obtivemos até o presente sugerem que, dentro da ārea compreendida pelas 1 atitudes $23^{\circ} \mathrm{S}$ e $33^{\circ} \mathrm{S}$, a espécie não se comporta como um todo uni forme.

$\mathrm{Na}$ ärea entre $23^{\circ} \mathrm{S}$ e $26^{\circ}-28^{\circ} \mathrm{S}$ (Cabo Frio-ilha de Santa Catarina) a densidade da população é homogênea durante todo o ano, com abundância relativa em torno de 1 quilo/hora lance. Na zona mais ao sul, entre $28^{\circ} \mathrm{S}$ e $34^{\circ} \mathrm{S}$ (ilha de Santa Catarina-Chuí), não ocorre o mesmo. Formam-se concentrações densas no verão e inverno, em āreas diferentes. No outono e primavera há dispersão dessas concentrações, que se distribuem entre as latitudes extremas da ārea. Durante o verão (janeiro a março) as concentrações localizam-se na altura de $32^{\circ} \mathrm{S}$; no inverno (julho a setembro) na altura de $28^{\circ} 30^{\prime} \mathrm{S}$; a abundância relativa média nessa ārea é de 8 quilos/hora lance (Vazzoler, 1963a, 1965). Tais deslocamentos sazonais parecem estar relacionados às condições hidrográficas da região, acompanhando os deslocamentos da convergência Sub-Tropical (Emilsson, 1961). Estudo posterior mais detalhado de tais movimentos (Vazzoler \& Santos, 1965) mostrou que, realmente, M. furnieri realiza deslocamentos ao longo da costa sul do Brasil. atingindo a latitude $29^{\circ} \mathrm{S}$ como limite norte e

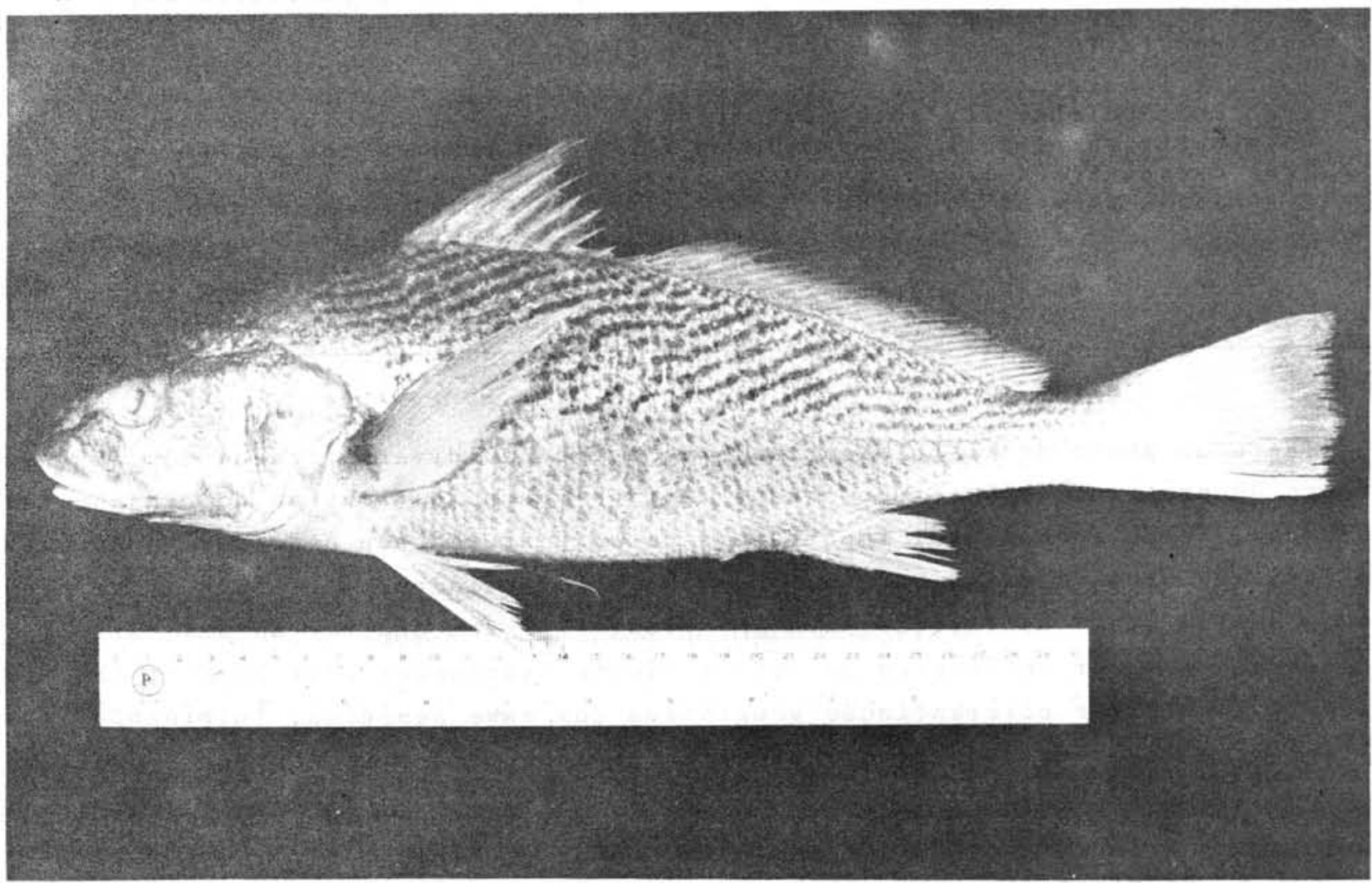

FIG. 1 - Exemplar de Micropogon furnieri (Desmarest, 1822) Jordan \& Evermann, 1884 
$32^{\circ} 30^{\prime} \mathrm{s}$, como sul. A determinaçäo mais precisa de um limite meridional é prejudicada pela inexistência de dados de regiões ao sul de $35^{\circ}$ s.

Alguns aspectos gerais sobre a biologia dessa espécie, tais como reprodução, crescimento e hābitos alimentares jā foram estudados, considerada a espécie como um todo uniforme (Vazzoler, G., 1962; Franco, 1959; Vannucci, 1963; Vazzoler, 1962, 1969; Paiva 1958a, b; Rodrigues, 1968). Numerosas outras referências existem sobre a espēcie (cf. Nomura, 1965); entretanto, por não terem sido as conclusões ou afirmações baseadas em estudo sistemático, mas em observações esparsas deixamos de referí-1as.

os resultados sintetizados acima sugeririam que $M$. furnieri não se constitui em um grupo homogêneo na ärea entre $23^{\circ} \mathrm{S}$ e $33^{\circ} \mathrm{S}$, parecendo tratar-se de duas populações; entretanto, não são suficientes para confirmar tal suposição. A distribuição da espécie é contínua nessa àrea; não há nenhuma barreira geográfica separando as duas supostas populações; assim, o unico fator que poderia funcionar como barreira é a convergência Sub-tropical, atuando como barreira oceanogrāfica.

A importância da ação dos fatores ambientais (temperatura, salinidade e outros) sobre a morfologia dos peixes é atualmente reconhecida e as variaçós intra-específicas determinadas por esses fatores são interpretadas de modo distinto do que se fazia hả algumas dēcadas. Ainda na primeira metade do sécu10, tais variações eram interpretadas como sendo sempre causadas por diferenças genéticas e muitas formas reconhecidas como espécies ou sub-espécies, sem maior investigação.

Schmidt $(1917,1919,1921)$ e Hubbs $(1921,1922,1924,1926,1928,1941)$ realizaram os primeiros trabalhos procurando esclarecer a natureza das variações morfolögicas em peixes; mostraram que tanto proporções corporais como caracteres merísticos podem variar em função da distribuição latitudinal dos peixes, devido às consequentes variações das condições ambientais, principalmente temperatura. Trabalhos posteriores como os de Schultz (1927), V1adykov (1934), Gabrie1 (1944), Molander \& Molander-Swedmark (1957), Heuts (1947a,b;1949;1956), Táning (1952) e outros, revistos e discutidos por Barlow (1961), contribuiram para esclarecer a questão.

Não só caracteres merísticos e proporções corporais, mas tambem processos fisiológicos, tais como crescimento e reprodução, sofrem grande influência do meio ambiente.

o problema da divergência genética entre e dentro de populações de espēcies de peixes havia recebido pouca atenção até recentemente (para os aspectos fisiológicos, ver Gordon, 1957). Nos ültimos 10 a 15 anos tem ele sido abordado de modo sistemātico atravēs do estudo de aspectos bioquímicos determinados geneticamente, tais como grupos sanguíneos e padróes de hemoglobina (Sindermann, 1959, 1961; Sindermann \& Honey, 1963; Sick, 1961, 1962, 1965a, b; Sick et al., 1963; Cushing, 1964; Frydenberg et al., 1965; Rattazzi \& Pik, 1965; Mф1ler \& Naevda1, 1969).

Dos estudos realizados ficou demonstrado que as condições ambientais podem Bolm Inst. oceanogr. S Paulo, 20 (2): 1-70, 1971 
atuar apenas sobre o fenotipo dos indivíduos e, como fator de seleção, determinando variações genēticas e isolamento reprodutivo, com consequente quebra da unidade da espécie; este ültimo caso é importante nos estudos sobre evolução.

A quase totalidade dos estudos sobre diversificação de espécies de peixes marinhos refere-se ao hemisfério norte.

0 objetivo do presente estudo é obter informações mais consistentes sobre a possível não homogeneidade de Micropogon furnieri na ärea compreendida entre $23^{\circ} \mathrm{S}$ e $33^{\circ} \mathrm{S}$ (Fig. 2), pela anālise de dados sobre proporções corporais, caracteres merísticos e aspectos do crescimento e reprodução.

\section{CARACTERIZAÇÃO DA ÅREA ESTUDADA}

A ārea estudada sofre a influência de duas grandes massas de āgua: (1) da Corrente do Brasil, um ramo da Corrente sul Equatorial, com àguas quentes e salinas, e (2) da Corrente das Malvinas, ramo da corrente do cabo Horn, com àguas frias e pouco salinas.

A nomemclatura por nós adotada para as massas de água da região em estudo, é a de Emílsson (1961).

Āguas quentes e salinas (temperaturas acima de $25^{\circ} \mathrm{C}$ e salinidade acima de $\left.36,5^{\circ} / 0 \circ\right)$ são transportadas para o sul pela Corrente do Brasil, misturando-se com águas de baixa salinidade e temperatura, originando uma massa de àgua temperada acima de $20^{\circ} \mathrm{C}$ e salinidade acima de $36^{\circ} / 00$ denominada "Água Tropical". Esta, continuando seu deslocamento para o sul perde calor para a atmosfera aumentando de densidade e sofrendo um afundamento (constitui a zona norte da convergência Sub-tropica1); mistura-se depois com águas do sul ("Āgua Sub-Antārtica"), de baixa salinidade e temperatura, resultando uma massa de água de temperatura entre $10^{\circ} \mathrm{C}$ e $200^{\circ}$ e salinidade de $350 / 00-360 / 00$. Parte dessa água volta para o norte, na forma de contra-corrente, sob a "Āgua Tropical", constituindo uma massa de água denominada "Água Sub-tropical".

A Corrente do Brasil, em seu fluxo para o sul, segue a borda da plataforma continental (que na região de Santos tem cerca de $100 \mathrm{mn}$ de extensão e no Rio Grande do Sul $150 \mathrm{mn}$ ) até cerca de $30^{\circ} \mathrm{S}$, onde se afasta do continente. Aos $42^{\circ} \mathrm{S}$ desvia-se para leste em direção às costas da Āfrica.

A massa de água transportada pela Corrente das Malvinas, denominada "Āgua Sub-tropical", com salinidade inferior a $340 / 00$ e temperatura entre $4{ }^{\circ} \mathrm{C}$ e $20^{\circ} \mathrm{C}$ (durante as estações do ano), ocorre em superfície até cerca de $300^{\circ}$; entretanto, em regiões mais profundas parece atingir até $23^{\circ} \mathrm{S}$.

A região de encontro das äguas sub-tropicais com as sub-antärticas, constitui uma zona denominada convergência Sub-tropical. 0 limite norte dessa zona, na parte oeste do oceano, oscila aproximadamente entre as latitudes de $30^{\circ} \mathrm{S}$ e $40^{\circ} \mathrm{s}$.

Sobre a plataforma continental são encontradas äguas que sofrem grande influência da "Água Sub-tropical" e que resultam da mistura desta com a "Āgua Tropical" e äguas costeiras, bem como de aquecimento por radiação solar; essas 
águas são denominadas "Āgua de Plataforma". Nessa ārea, de modo geral, apesar do regime pluviométrico ser tropical, ou sub-tropical, a contribuição de água doce vinda do continente é pequena devido ao fato dos grandes rios fluirem em direção ao rio Paraná e, através deste, para o rio da Prata. Diante das costas do Rio de Janeiro, São Paulo e Paraná, salinidades abaixo de $34,50 / 00$ são comuns, não tendo sido registrados valores abaixo de $330 / 00$ longe dos estuários e baías fechadas. Na costa de Santa Catarina o contingente de água doce é menor ainda; apenas dois pequenos rios, o rio Aranranguá (290S) e o rio Mampituba $\left(29^{\circ} 20^{\prime} \mathrm{s}\right)$ desaguam nessa região. Nessa área a salinidade é relativamente mais elevada $(35 \% / 00-35,5 \% / 00)$, pois a Corrente do Brasil flui mais próxima à costa, aumentando a influência da "Água Tropical". Na região costeira mais ao sul (cerca de $32^{\circ} \mathrm{S}$ ), entretanto, há influência de grandes quantidades de água doce provenientes da lagoa dos Patos, sendo que essa região também sofre influencia do rio da Prata, determinando uma área de baixa salinidade (em torno de $33,5 \% / 00)$. Uma zona de grande transição de salinidade e temperatura, considerada como a extremidade ocidental da convergência sub-tropical ocorre ao norte dessa região, sendo que sua posição oscila devido às fortes correntes de deriva que fluem sobre a rasa e larga plataforma continental. Segundo Emílsson (1961) pode-se considerar, como regra geral, que essa zona de transição está situada diante da costa do Uruguai no verão, podendo, no inverno, alcançar o norte da ilha de Santa Catarina.

Na região que se estende do Espírito Santo (20\%S) ao Paraná (260S) ocorre uma ressurgência que tem máximo de intensidade na região de Cabo Frio, e máximo anual no verão.

Etchichury \& Remiro (1963) analisando as associações de minerais dos sedimentos, na mesma área, chegam à conclusão de que minerais da associação Pampeano-patagônica, característica da região do rio da Prata, atingem até 23030 's, transportados pela Corrente das Malvinas.

Bo1tovskoy $(1959,1964,1968)$, estudandoa hidrologia do At lântico Sul Ocidental, com base em indicadores biológicos (foraminíferos bentônicos e planctônicos), conclui que o ponto mais setentrional que sofre influência da Corrente das Malvinas, localiza-se a $220 \mathrm{~S}$; conclui,entretanto, que o aporte das águas malvinenses até essa latitude é insignificante e ocorre só no inverno, Constatou que a massa principal de águas sub-tropicais puras, transportadas pela Corrente do Brasil, atinge no verão as 1 atitudes $35^{\circ}-36^{\circ} \mathrm{S}$ e no inverno $29^{\circ}$ $30^{\circ} \mathrm{S}$, sendo esse o limite setentrional da zona de convergência. o citado autor considera, com base na análise da fauna bentônica de foraminíferos, que o Uruguai e o sul do Brasil, até aproximadamente $290 \mathrm{~S}$, pertencem à mesma província zoogeogräfica que a Argentina, a Província Patagônica e que, mais ao norte, até os $230 \mathrm{~S}$, ocorre outra província; a região até $29 \circ \mathrm{s}$ sofre influência da área do rio da Prata.

Stuardo (1964), estudando a distribuição de moluscos marinhos litorais da América Latina, conclui que entre Rio de Janeiro e Santa Catarina parece existir uma zona de transição que separaria as províncias Caribeana (ou Antilhana) e Argentina (ou Patagônica) e que a Província Argentina se estende até Santa 
Catarina e cabo de Santa Marta Grande, na costa brasileira (28028's), incluindo toda costa do Uruguai e Rio Grande do Sul.

Segundo Carcelles (1944) a Província Antilhana estende-se até o cabo de Santa Marta Grande, aos $28028^{\prime} \mathrm{S}$, sendo sua fauna (moluscos) tipicamente tropical.

Balech (1954, 1964) diz que as àguas sub-antärticas, transportadas para o norte pela Corrente das Malvinas parecem desaparecer da superfície, durante o verão e outono, próximo ao rio da Prata, admitindo, entretanto, que seguem muito mais ao norte, pelo fundo, pois no sul do Brasil ainda ocorrem elementos (sub-superficiais) do plâncton, típicos malvinenses ou sub-antārticos. Admite que a Província Argentina atinge o sul do Brasil até aproximadamente $30^{\circ}-32^{\circ} \mathrm{S}$, latitude na qual termina a influência da Corrente das Malvinas, sendo possível que esta, ocasionalmente, atinja os $28^{\circ} \mathrm{S}$.

Boschi (1964) analisando a distribuição e frequência de Penaeidae no Atlântico Sul, considera duas äreas: $22^{\circ} \mathrm{S}$ a $28^{\circ} \mathrm{S}$ e de $28^{\circ} \mathrm{S}$ a $33^{\circ} \mathrm{S}$. Hymenopenaeus muelzeri e Artemesia Zonginaris, espécies de äguas temperadas, raramente ocorrem ao norte de $28^{\circ} \mathrm{S}$; esses dois crustáceos, segundo Boschi, são os mais típicos e importantes da Província Argentina. Espécies de āguas tropicais e sub-tropicais, como Penaeus brasiliensis,Penaeus schmitti e Xiphopenaeus kroyeri, atingem até os $26^{\circ} \mathrm{S}$. Considera a zona das costas do Uruguai e sul do Brasil como uma zona de transição.

Os resultados obtidos no presente trabalho mostram que a região estudada pode ser dividida em duas áreas: uma de $23^{\circ} \mathrm{S}$ a $29^{\circ} \mathrm{S}$ e outra de $29^{\circ} \mathrm{S}$ a $33^{\circ} \mathrm{S}$, 0 que está de acordo com o verificado por outros autores, antes discutidos.

MATERIAL E METODOS DE COLETA DOS DADOS

0 material utilizado neste estudo foi coletado: (1) de barcos da frota pesqueira com base em Santos, que operam na área considerada, (2) pelo barco de pesquisa "Emília" e (3) no litoral de Santa Catarina, de pequenas embarcações que capturam essa espécie. Somente foram coletadas amostras quando os barcos da frota comercial operaram em regiões bem delimitadas, dentro da ārea considerada. Cuidados especiais foram tomados a esse respeito. Para complementar informações quanto à reprodução e crescimento, foram coletadas amostras com o N/Oc. "Prof. W. Besnard", no período de março-abril de 1969, na área compreendida entre $30^{\circ} \mathrm{S}$ e $33^{\circ} \mathrm{S}$.

Para assegurar o controle na obtenção de amostras, de modo que fossem coletadas ao longo de toda a ārea estudada, esta foi dividida em 5 sub-āreas, como segue (Fig. 2):

$$
\begin{array}{lll}
\text { Sub-ärea A: } & 23^{\circ} \mathrm{S} \text { a } 25^{\circ} \mathrm{S} \\
\text { Sub-ārea B: } & 25^{\circ} \mathrm{S} \text { a } 27^{\circ} \mathrm{S} \\
\text { Sub-ārea C: } & 27^{\circ} \mathrm{S} \text { a } 29^{\circ} \mathrm{S} \\
\text { Sub-ārea D: } & 29^{\circ} \mathrm{S} \text { a } 31^{\circ} \mathrm{S} \\
\text { Sub-ärea E: } & 31^{\circ} \mathrm{S} \text { a } 33^{\circ} \mathrm{S}
\end{array}
$$


TRECHO DA CARTA N\& 30 DA D.HN.

ESC. 1: 2376700 NA LAT. $29 \circ 30^{\prime}$
SÃO PAULO

R. DE JANEIRO
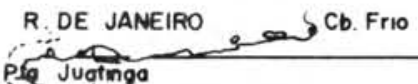
b. Frio

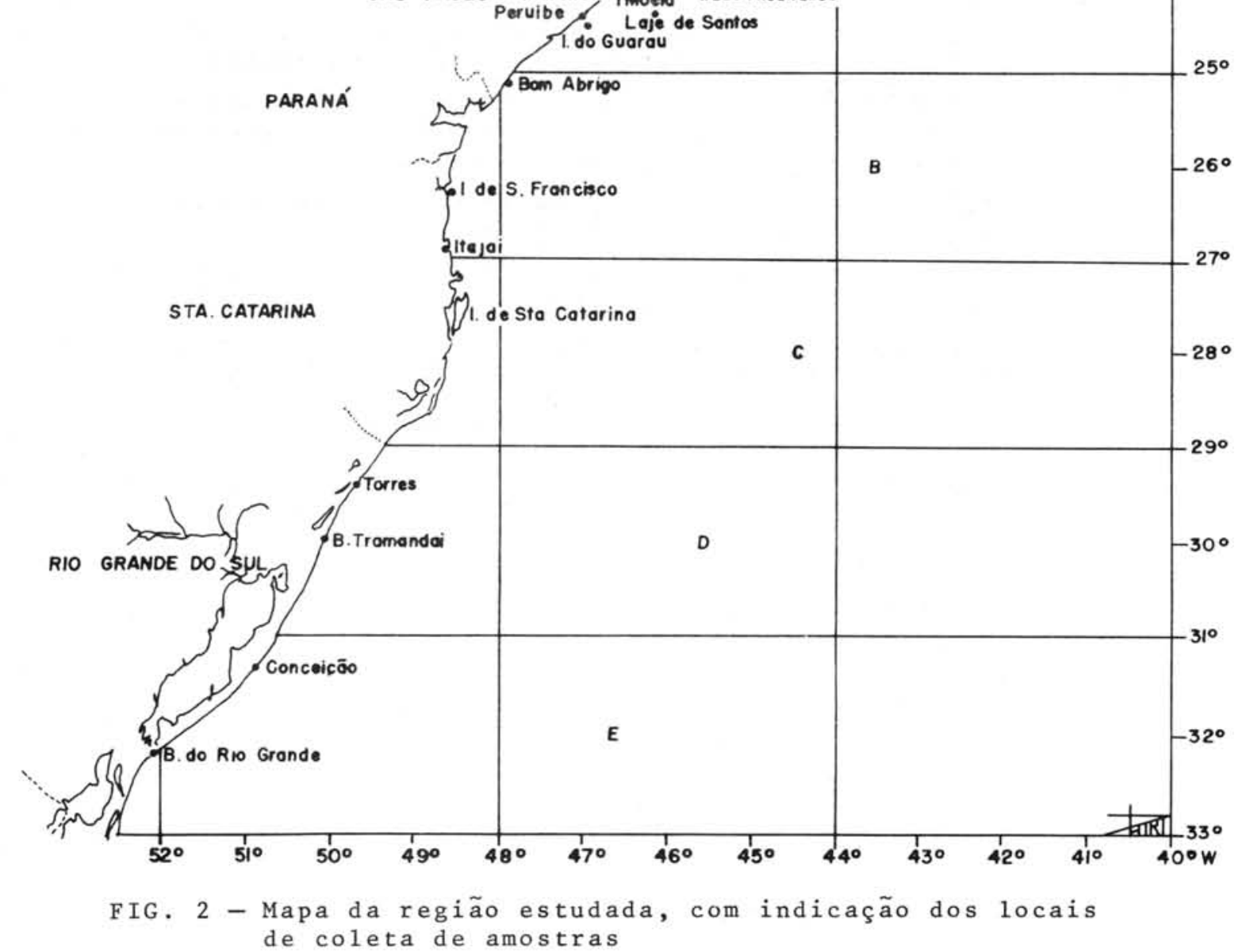

0 material foi coletado durante o período de junho de 1967 a março de 1968, procurando-se obter amostras bimensais dentro de cada uma das sub-äreas acima citadas.

As amostras sobre as quais estā baseado o presente estudo estão alistadas na Tabe 1 a I.

0 comprimento (medido da ponta do focinho à extremidade da cauda, 1igeiramente distendida) variou de 130 a $749 \mathrm{~mm}$.

Esse intervalo de comprimento foi dividido em classes de 50 mm, com grupamento dos comprimentos intermediários na classe imediatamente inferior (p.ex., de 150 a $199 \mathrm{~mm}$, na classe de $150 \mathrm{~mm}$ ), num total de 12 classes de comprimento, procurando-se coletar sempre dez exemplares por classe, por amostra, o que garantiu que todas as classes de tamanho estivessem igualmente representadas nas amostras.

Foram considerados os seguintes caracteres:

I - Proporções corporais (medidas em mm) (Fig. 3):

a - Comprimento tota 1: medida horizontal da ponta do focinho à extremidade da nadadeira caudal, levemente distendida. Lt

Bolm Inst. oceanogr. S Paulo, 20 (2): 1-70, 1971 
b - Cabeça: medida horizontal da ponta do focinho à borda óssea posterior do opérculo . . . . . . . . . . . . . . Lc

c - Tronco: comprimento total menos comprimento da cabeça. . Tr

d - Focinho: medida horizontal da ponta do focinho à margem anterior da órbita.. . . . . . . . . . . . . . . If

e - 01ho: medida do diâmetro horizontal do olho: distância entre as margens anterior e posterior da órbita . . . . Do

f - Altura: medida da distância vertica1, em ângulo reto com o eixo do peixe, entre o contorno dorsal e abdominal, na altura da origem da nadadeira dorsal. . . . . . . . . $H$

g - Distância pré-dorsal: medida horizontal da ponta do focinho à origem da primeira nadadeira dorsal. . . . . . . Ld

h - Distância pré-anal: medida horizontal da ponta do focicinho à origem da nadadeira anal . . . . . . . . . . . . La

i - Comprimento da escama: medida vertical do foco ao bordo oposto superior da escama (Fig. 11B). . . . . . . . . E

II - Relativos ao crescimento e à reprodução:
a - Peso total (gramos) . . . . . . . . . . . . . . . Wt
b - Sexo. . . . . . . . . . . . . . . . . . . . . . S
c - Estādio de maturidade . . . . . . . . . . . . . . . . . $M$
d - Peso dos ovārios (centigramos) . . . . . . . . . . . . . Wg
e - Idade (anos) . . . . . . . . . . . . . . . . . . I

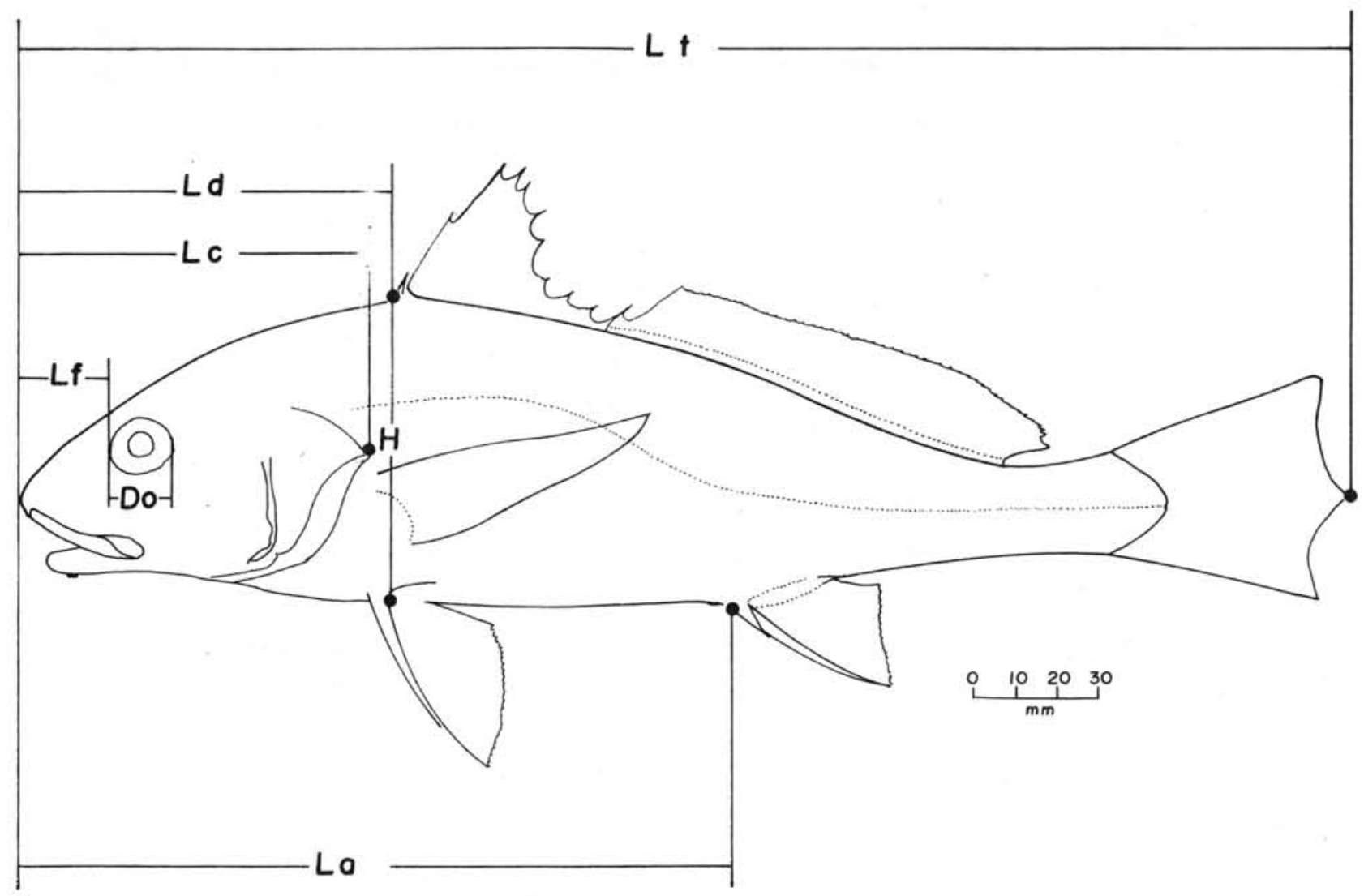

FIG. 3 - Indicação do critērio adotado para medição das proporçöes corporais 
III - Merísticos (Figs. 4 e 5):

a - Numero de raios da segunda nadadeira dorsal: os dois ü1timos raios, unidos na base, foram contados como um único. . . . . . . . . . . . . . . . . . . . . . Nr2d

b - Número de raios da nadadeira peitoral esquerda. . . . NrPe

c - Número de rastros do primeiro arco branquial esquerdo . Nr

d - Nümero de escamas na linha lateral: refere-se às escamas perfuradas que se estendem ao longo do corpo, até a base da nadadeira caudal . . . . . . . . . . . . . . .

NeL Z

e - Nümero de séries de escamas acima da linha lateral: refere-se às escamas de uma fileira vertical, com origem na base da primeira nadadeira dorsal até a linha lateral, exclusive. . . . . . . . . . . . . . . . . .

f - Nümero de vértebras: desde o atlas, inclusive, até o uróstilo, exclusive. . . . . . . . . . . . . . . . . NV

Os dados relativos aos exemplares estudados, referentes aos caracteres acima citados, encontram-se arquivados na Secção de Necton, Divisão de Oceanografia Biológica do Instituto Oceanogräfico da Universidade de São Paulo.

Os dados relativos às proporções corporais, à reprodução e crescimento foram coletados de exemplares antes da fixação, para evitar que variações no período de preservação introduzissem vícios ("bias") (Pimentel, 1958).

As medições foram executadas sobre um ictiômetro, ao qual foi ajustado um papel milimetrado recoberto por uma placa de vidro, adotando-se como unidade o milímetro, com aproximação para a unidade inferior. Cada exemplar foi colocado com o flanco direito sobre o ictiómetro, como focinho encostado ao braço ver-

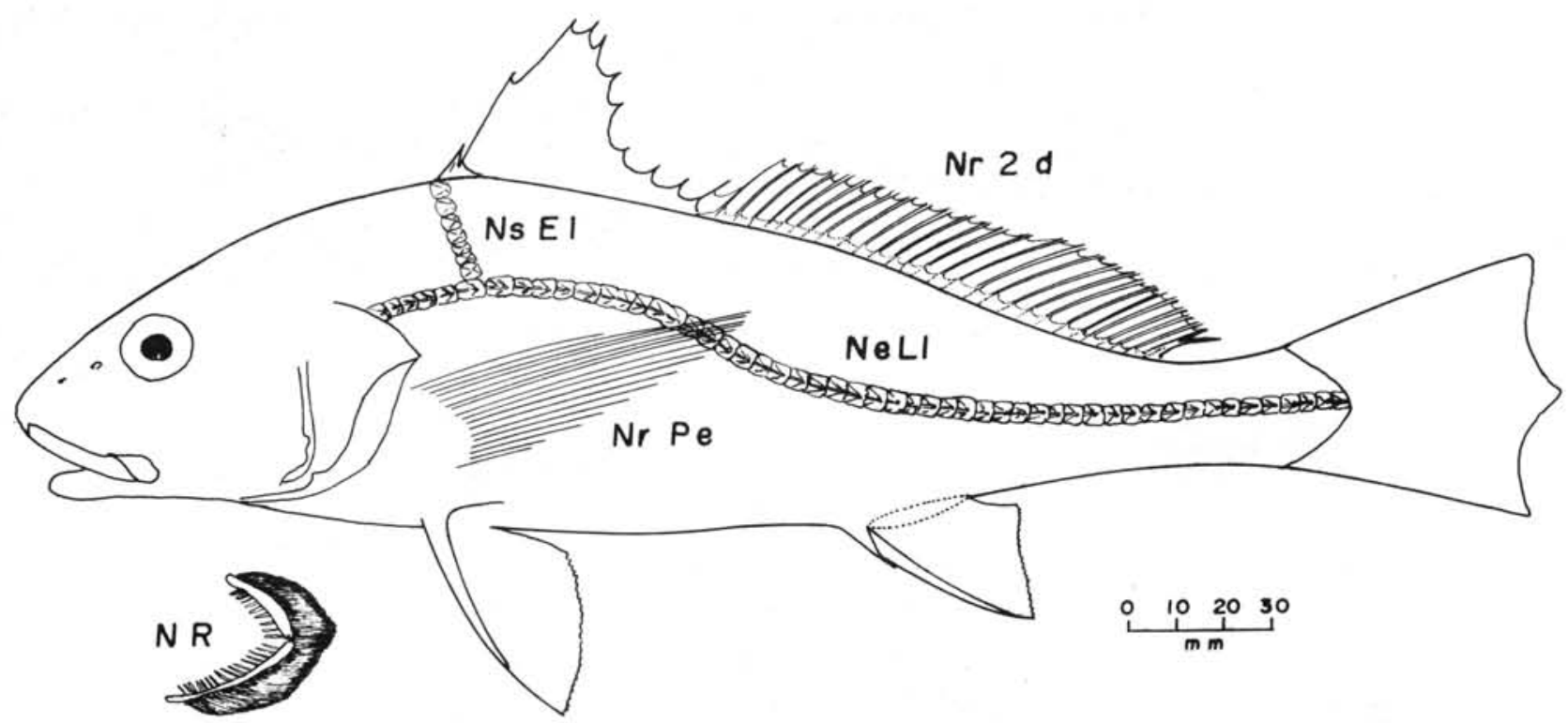

FIG. 4 - Indicação do critērio adotado para contagem dos caractéres merísticos 
tical do aparelho e, desta forma, todas as medições realizadas em projeção horizontal (Figs. 3 e 6), com exceção do diâmetro do ôlho e do comprimento das escamas. o diâmetro do ôlho foi medido com o auxilio de um compasso de ponta sêca. A técnica utilizada para medição das escamas será descrita mais adiante.

A seguir, cada exemplar foi pesado (em gramos), aberta sua cavidade abdominal para determinação do sexo e estádio de maturidade (cuja escala será apresentada mais adiante), e pesados os ovários em uma balança Mettler p 1200 (aproximação a centigramo). Foram, a seguir, retiradas algumas escamas da região acima da axila da nadadeira peitoral direita, para medida do comprimento e determinação da idade do exemplar. As escamas foram conservadas a seco, em envelope de papel, até a montagem (método descrito mais adiante).

Na etapa seguinte foram efetuadas as contagens de escamas na linha lateral e de séries de escamas entre a linha lateral e a origem da primeira nadadeira dorsal, do lado esquerdo do animal (Fig. 4) e retirado o primeiro arco branquial esquerdo,fixado em álcool a $70 \%$ para contagem dos rastros (Figs. 4 e 7). Com o auxilio de um estilete foi contado o número de raios da segunda nadadeira dorsal e da peitoral esquerda.

A seguir, os exemplares foram separados ( 2 exemplares por classe de comprimento) para determinação do número de vértebras e preservados em álcool a $70 \%$.

A contagem de rastros (incluidos também os rudimentares) foi feita sob estereomicroscōpio Wild M5 e com auxílio de agulhas de dissecção (Fig. 7).
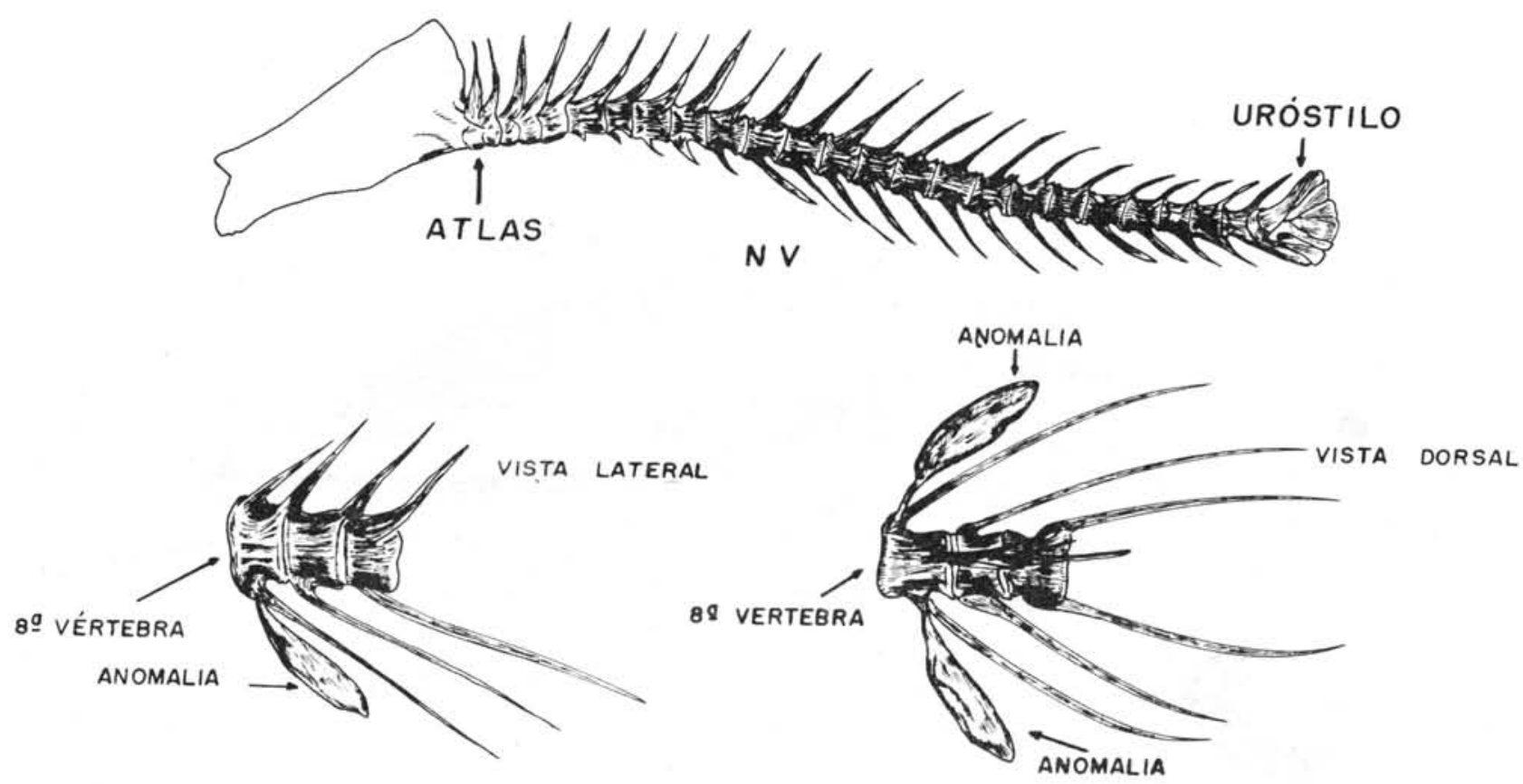

FIG. 5 - Indicação do critério adotado para contagem de vértebras e esquemas de formações ósseas anômalas 


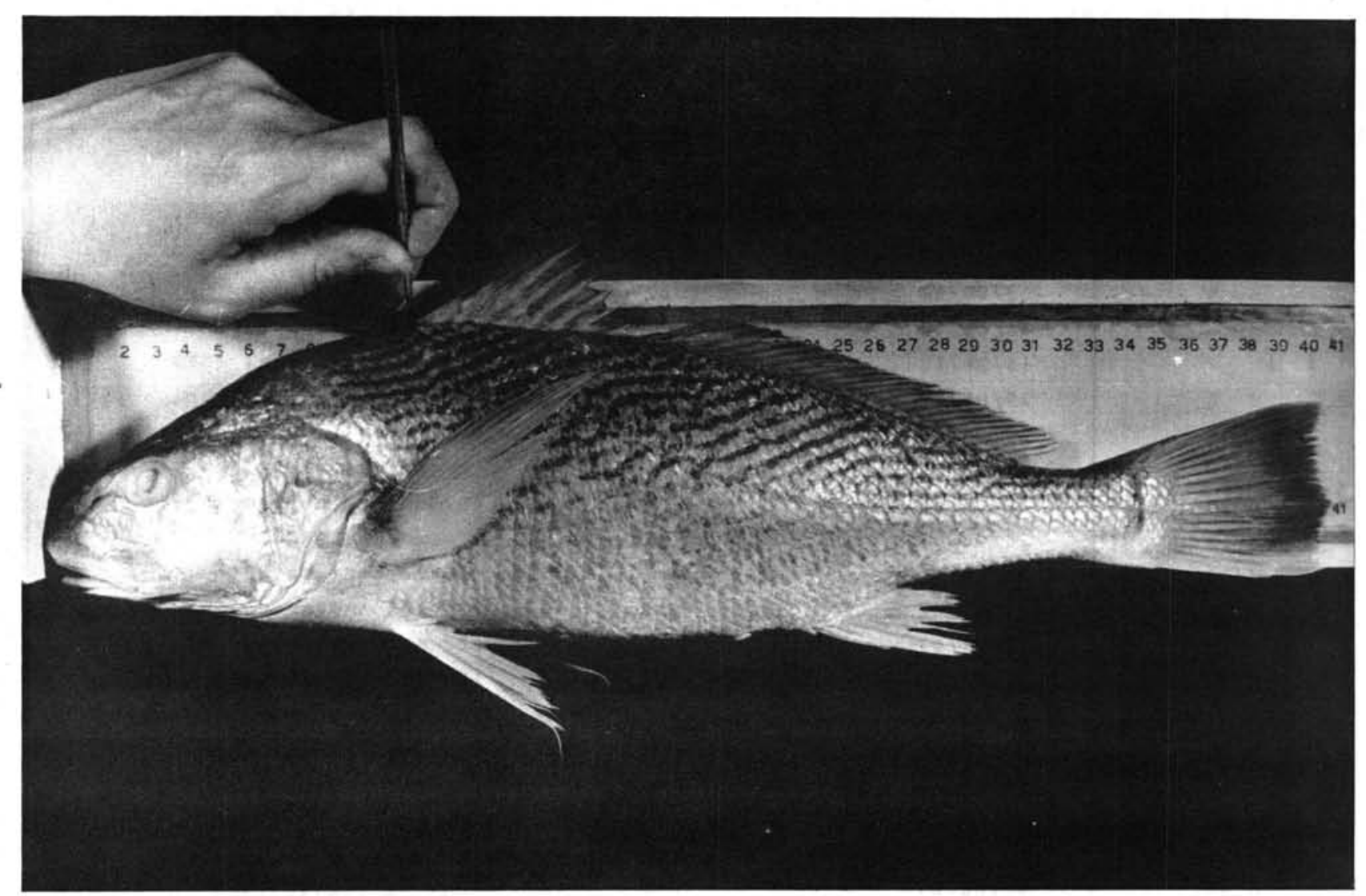

FIG. 6 - Exemplar de M. furnieri sobre o ictiômetro

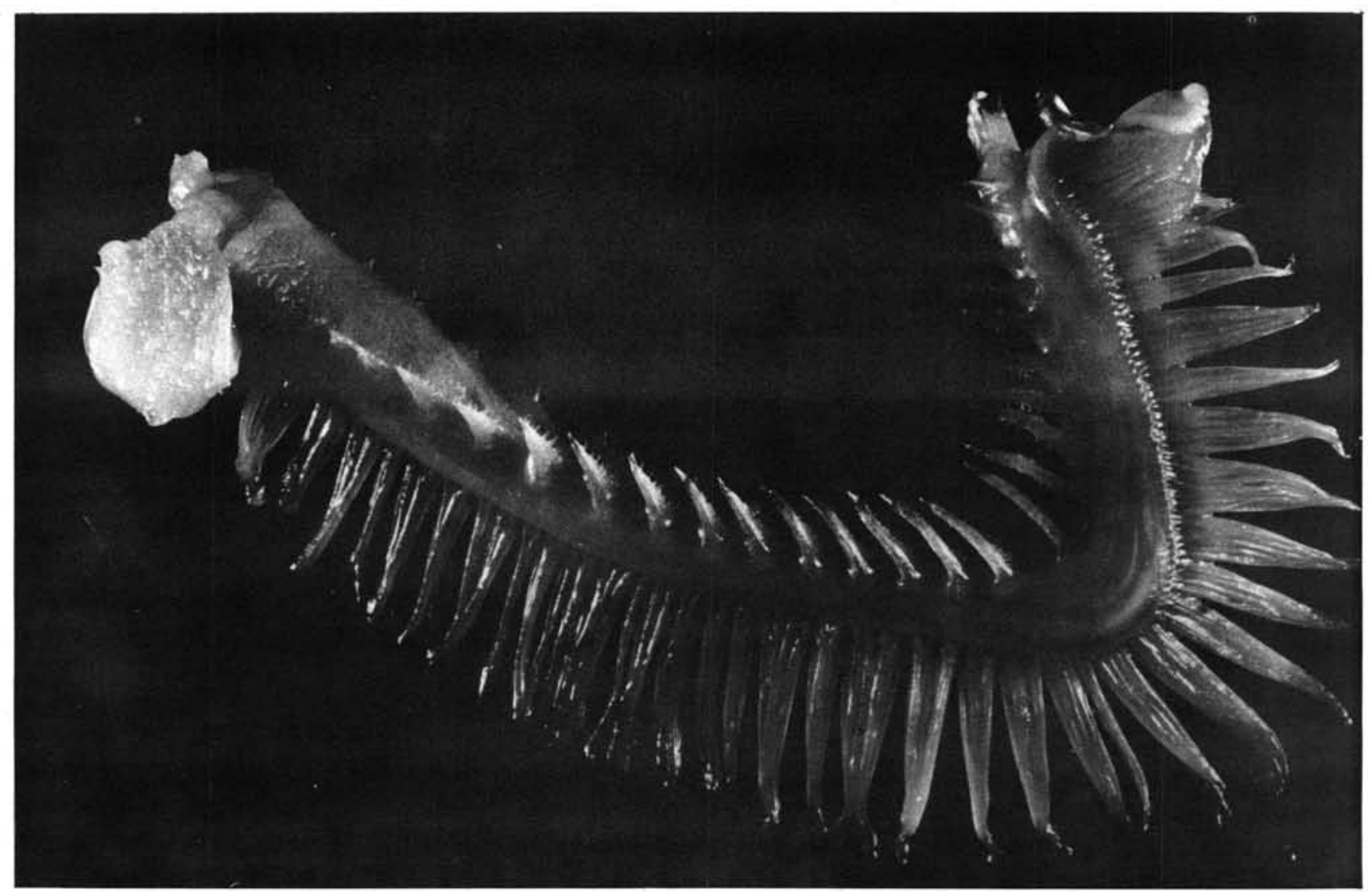

FIG. 7 - Primeiro arco branquial esquerdo de exemplar de $M$. furnieri mostrando os rastros, inclusive os rudimentares

Bolm Inst. oceanogr. S Paulo, 20 (2): 1-70, 1971 
TABELA I - Lista das amostras de Micropogon furnieri sıbre as quais estā baseado o presente estudo

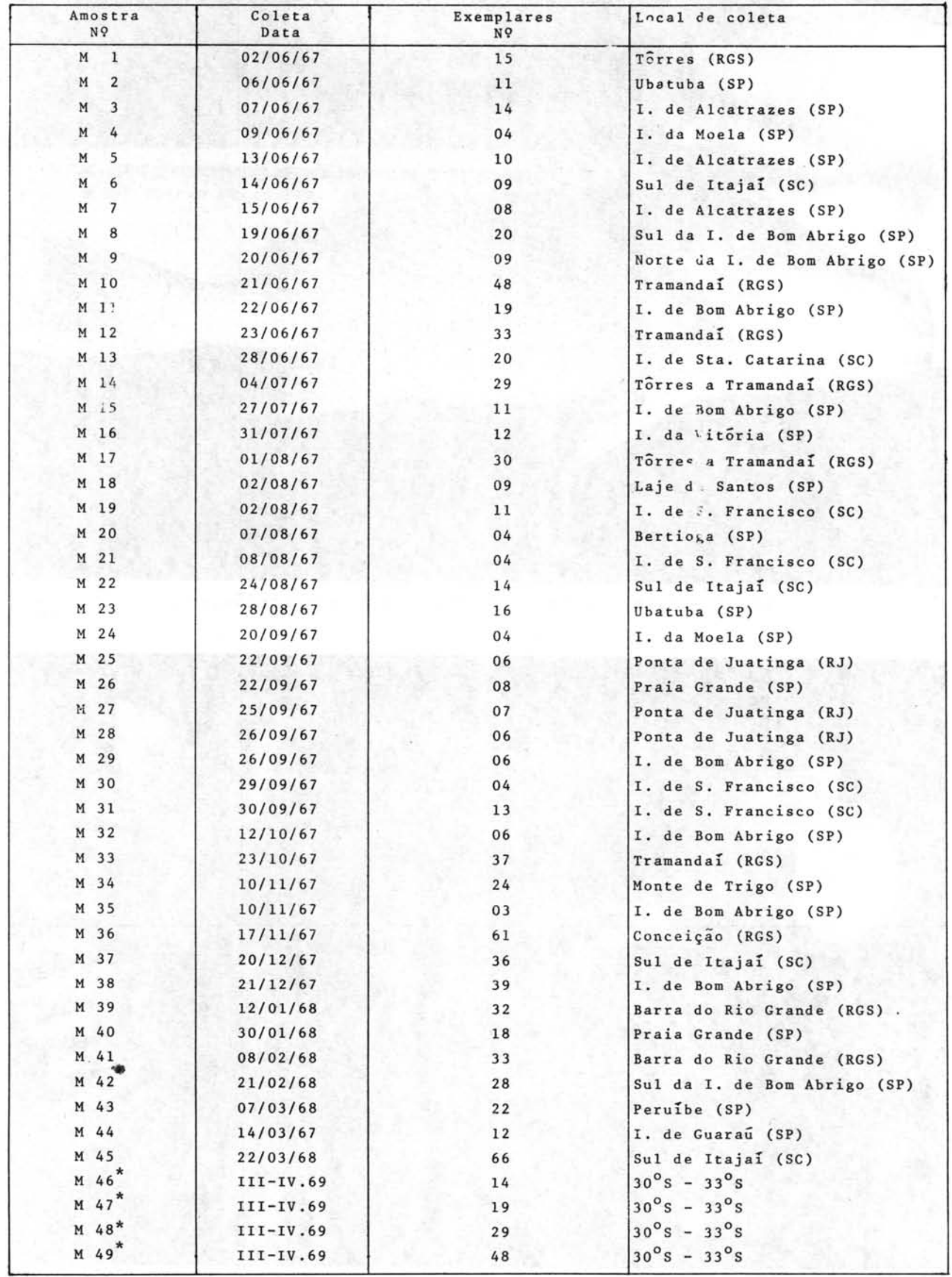

* Amostras coletadas com o N/Oc. "Prof. W. Besnard". 
Para contagem de vértebras os exemplares foram radiografados utilizando-se chapas de $30 \times 40 \mathrm{~cm}$ (Gevaert, Curix FW Blue Base), com distância fixa de $80 \mathrm{~cm}$ entre o foco e a chapa. A radiação (KV) a que foi submetido cada exemplar e o tempo de exposição (mAS) variaram de acordo com o seu tamanho (relacionado com espessura) ( $\mathrm{Tab}$. II).

A contagem das vértebras foi realizada com auxílio de um negatoscōpio, considerando-se as vērtebras desde o atlas, inclusive, até o uróstilo, exclusive (Figs. 5 e 8). Durante o exame das radiografias para contagem de vértebras foram observadas formações ósseas anômalas, que passaram a ser analisadas (Figs. 5, 9A e B, 10A e B). Foi anotada a presença ou ausência dessas formações, o nümero e a localização das mesmas.

As escamas foram montadas entre duas lâminas de vidro, como segue:

1 - As escamas foram lavadas em āgua corrente e selecionadas as duas mais perfeitas;

2 - Foram limpas em solução de $\mathrm{KOH}$ a $4 \%$ por alguns segundos;

3 - A seguir, lavadas em ägua corrente e colocadas em solução de fenol a $10 \%$, como fungostātico;

4 - Foram lavadas rapidamente em àgua corrente para tirar o excesso de fenol e fixadas em uma lâmina de vidro com adesivo Cascolar. A 1 âmina foi rotulada na extremidade esquerda, com indicação do número da amostra e do exemplar e coberta por outra lâmina, sendo colocadas uma à outra com o mesmo adesivo.

TABELA II - Radiação e tempo de exposição utilizados para radiografar exemplares de $M$. furnieri de diferentes comprimentos totais (mm)*

\begin{tabular}{|c|c|c|c|c|c|c|c|c|c|c|c|c|}
\hline $\operatorname{Rad} i \mathrm{ação}$ & \multicolumn{6}{|c|}{$8 \mathrm{Kv}$} & \multicolumn{6}{|c|}{$10 \mathrm{Kv}$} \\
\hline \multirow{2}{*}{$\begin{array}{c}\text { Comprimento } \\
\text { tota } 1 \\
(\mathrm{~mm})\end{array}$} & \multicolumn{6}{|c|}{$\begin{array}{c}\text { Tempo de exposição } \\
(m A s)\end{array}$} & \multicolumn{6}{|c|}{$\begin{array}{c}\text { Tempo de exposição } \\
\text { (mAs) }\end{array}$} \\
\hline & 36 & 37 & 38 & 39 & 40 & 42 & 41 & 42 & 43 & 44 & 45 & 46 \\
\hline 250 & $\mathrm{x}$ & & & & & & & & & & & \\
\hline 300 & $\mathrm{x}$ & $\mathrm{x}$ & & & & & & & & & & \\
\hline 350 & $\mathrm{x}$ & $\mathrm{x}$ & $\mathrm{x}$ & $\mathrm{x}$ & $\mathrm{x}$ & & $\mathrm{x}$ & & & & & \\
\hline 400 & & $\mathrm{x}$ & $\mathrm{x}$ & $\mathrm{x}$ & $\mathrm{x}$ & & $\mathrm{x}$ & & $\mathrm{x}$ & $\mathrm{x}$ & & \\
\hline 450 & & & $\mathrm{x}$ & & $\mathrm{x}$ & $\mathrm{x}$ & & $\mathrm{x}$ & $\mathrm{x}$ & $\mathrm{x}$ & $\mathrm{x}$ & \\
\hline 500 & & & & & $\mathrm{x}$ & $\mathrm{x}$ & & & & $\mathrm{x}$ & $\mathrm{x}$ & $\mathrm{x}$ \\
\hline 550 & & & & & & & & & & & $\mathrm{x}$ & $\mathrm{x}$ \\
\hline
\end{tabular}

(*) - Exemplares fixados em ā 1 cool a $70 \%$.

Bolm Inst. oceanogr. S Paulo, 20 (2): 1-70, 1971 


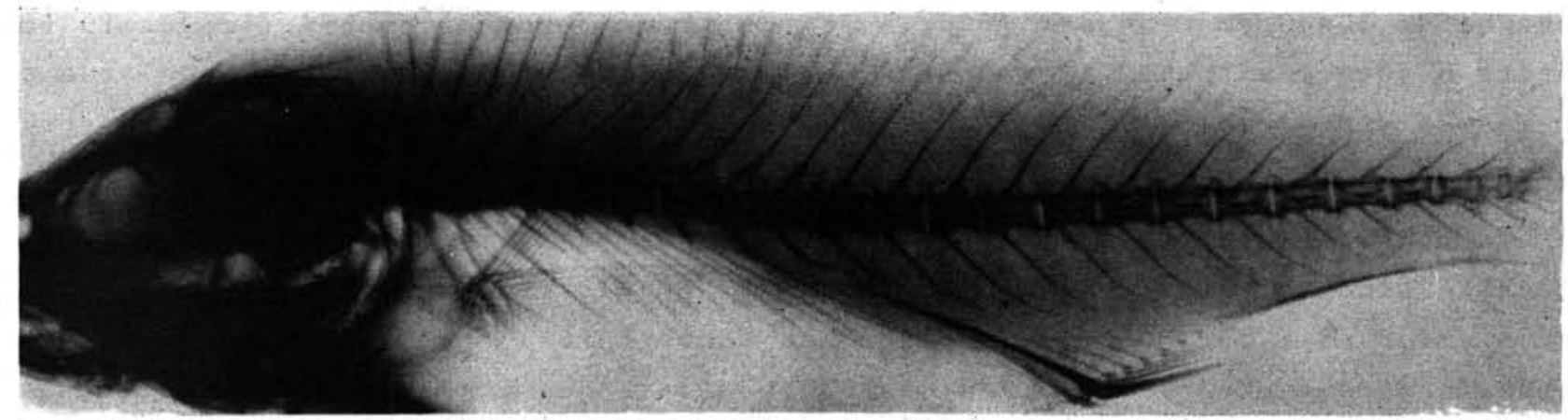

FIG. 8 - Cópia de uma radiografia de $M$. furnieri mostrando a coluna vertebral

Tramandai $-23 / 10 / 67$
Macho Lt $=294 \mathrm{~mm}$

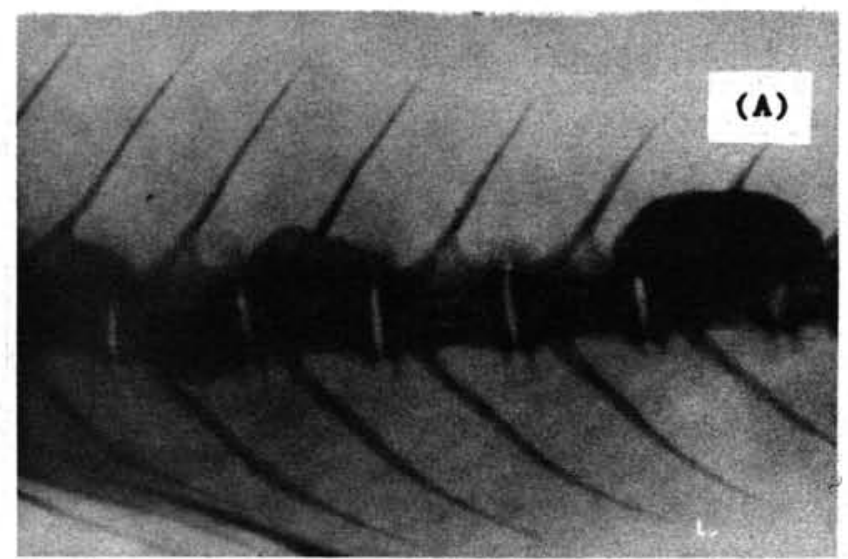

I. de Bom Abrigo - 21/12/1967

Fêmea Lt $=448 \mathrm{~mm}$

(B)

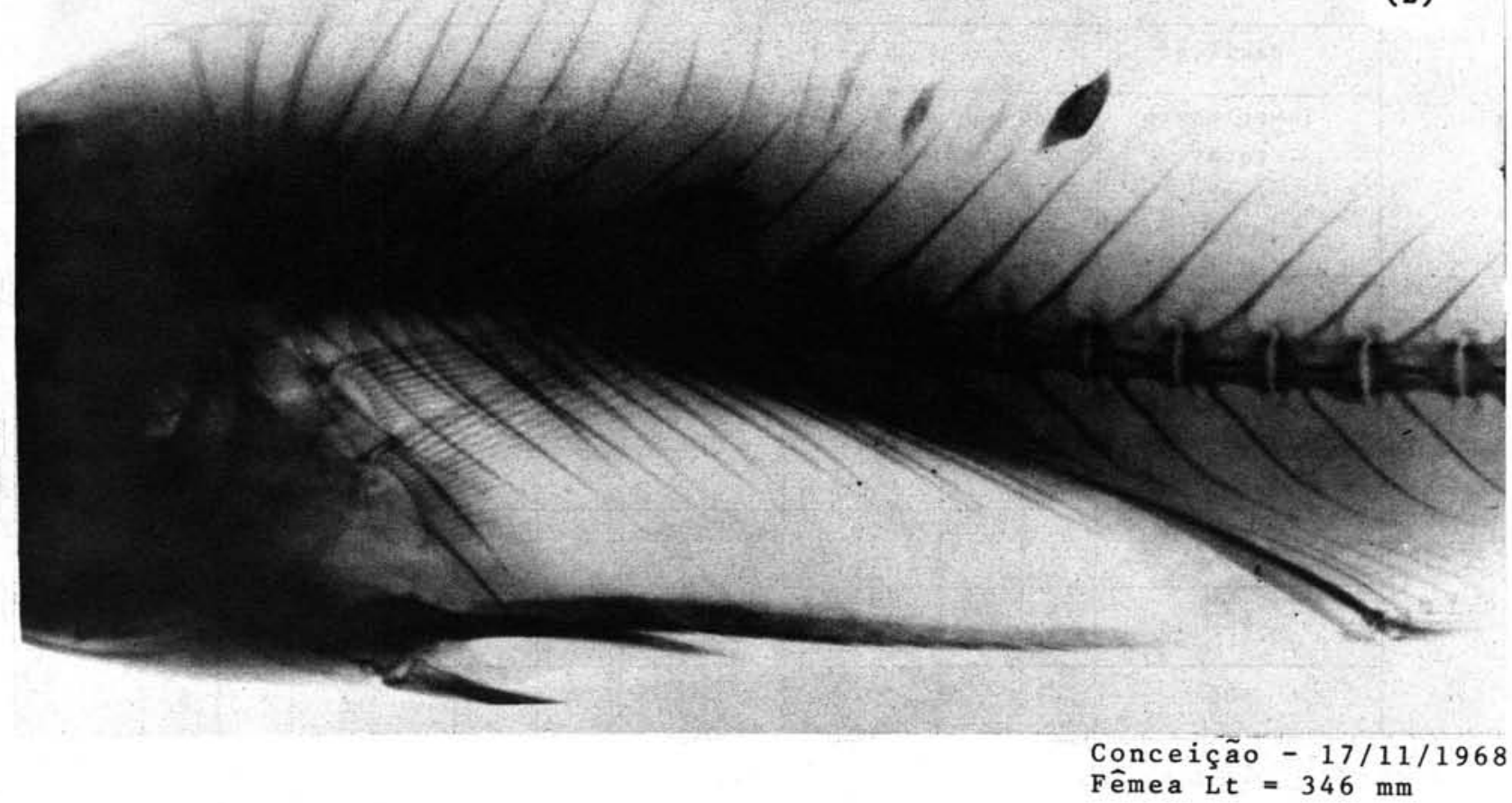

FIG. 9 - Cōpias de radiografias de $M$. furnieri mostrando formações ós seas, anômalas em diferentes locais do esqueleto 


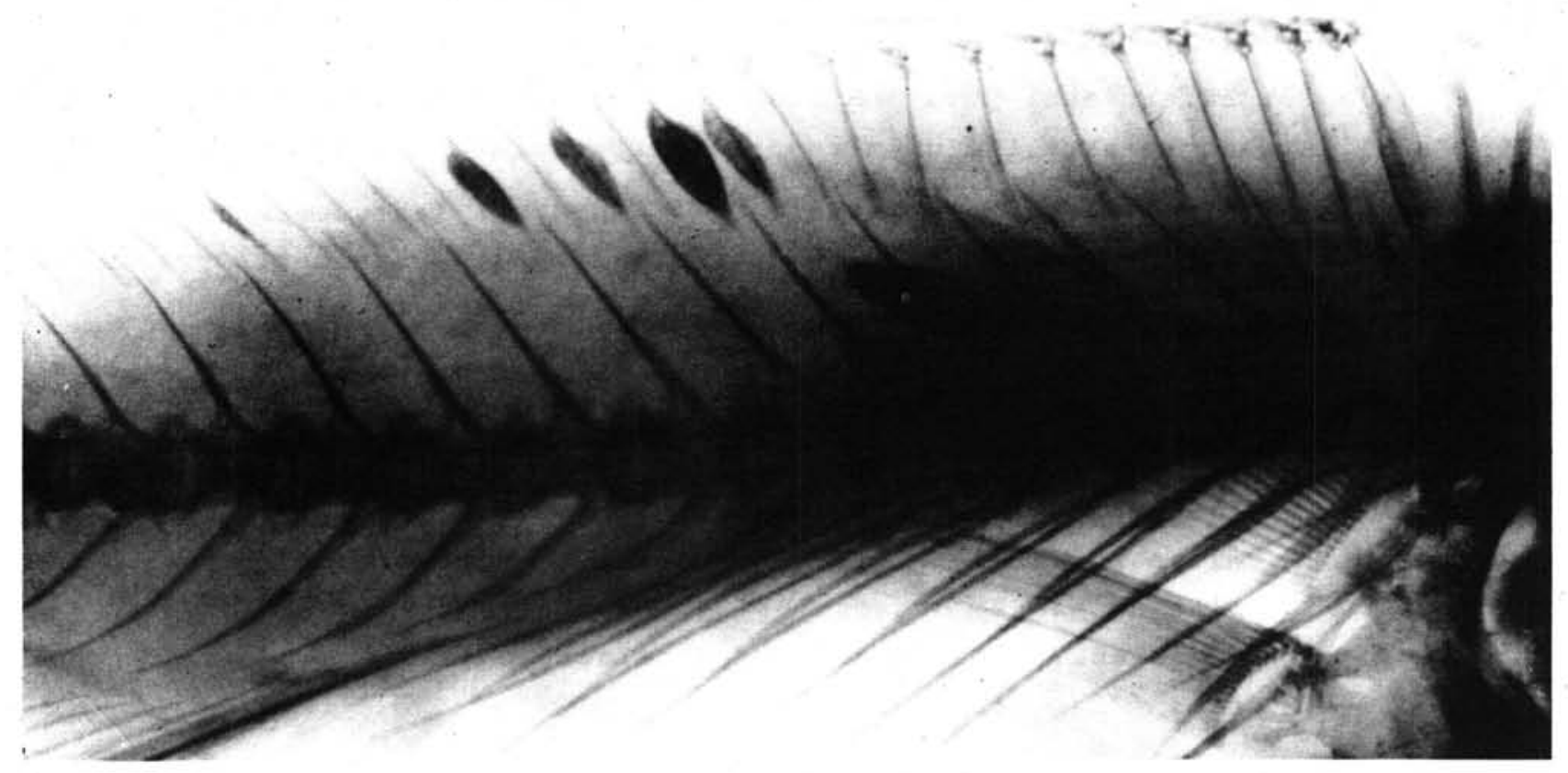

FIG. 10 (A) - Cópia de uma radiografia de M. furnieri mostrando formações ósseas anômalas em diferentes fases de desenvolvimento

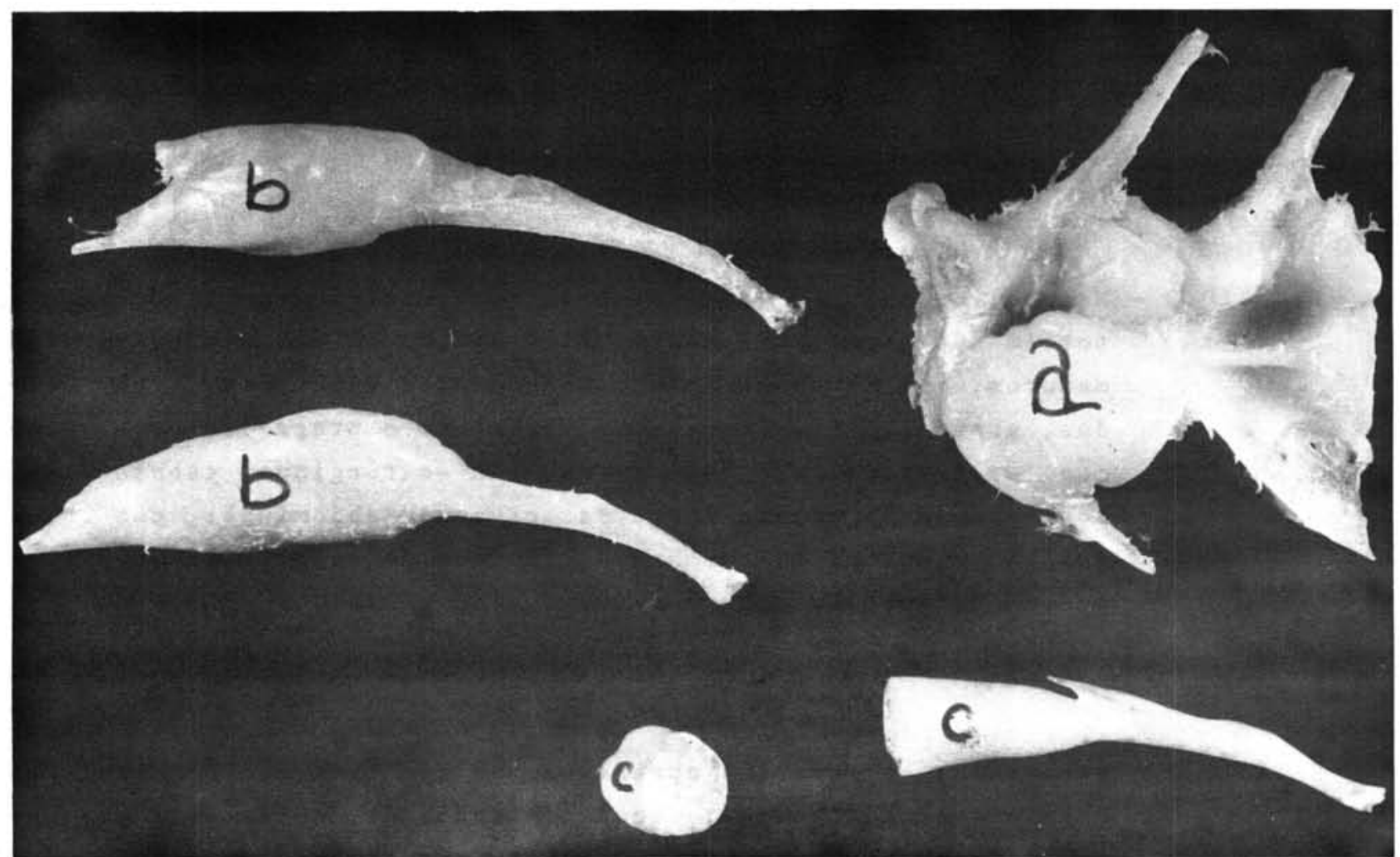

FIG. 10 (B) - Fotos de formações ósseas anômalas: a) sobre vértebras; b) isoladas da $8 a$. vértebra; c) corte transversal mostrando a estrutura interna 
A medida do comprimento das escamas (Fig. 11A) foi feita em estereomicroscópio Wild M5, com ocular micrométrica, tendo-se considerado a média do comprimento de duas escamas de cada exemplar.

A idade foi determinada pela contagem dos anéis de crescimento das escamas (Fig. 11B), usando-se para tal um microprojetor Wetzlar Leitz (aumento $14 \mathrm{X}$ ).

Devido a peculiaridades na maturação de $M$. furnieri (estudos em progresso) adotamos uma escala de quatro estádios, em vez dos oito usualmente considerados (Naier cit. in Buckmann, 1929), apresentados em Laevastu (1965).

Os quatro estādios considerados foram os seguintes:

ESTĀDIo A - Imaturo: os ovārios são filiformes, translúcidos, de tamanho muito reduzido, colocados bem junto da coluna vertebral; a olho nú não se observa os óvulos. Os testículos também são bem reduzidos, filiformes, com colocação semelhante à dos ovārios (Figs. $12 \mathrm{~A}$ e $13 \mathrm{~A}$ ).

ESTĀDIO B - Em maturação: os ovārios apresentam-se ocupando cerca de $1 / 3$ a $2 / 3$ da cavidade abdominal, com intensa rede capilar; a olho nú observam-se grânulos opacos de tamanho variável, os óvulos. Os testículos, do mesmo modo que os ovārios, apresentam-se desenvolvidos, com forma lobulada, sendo que, com uma certa pressão, sua membrana rompe-se, eliminando um esperma leitoso, viscoso (Figs, 12B e 13B).

ESTĀDIO C - Maduro: os ovārios apresentam-se tūrgidos, ocupando quase que totalmente a cavidade abdominal; a olho nú observam-se óvulos maduros, que se apresentam como grânulos esféricos, translúcidos, grandes; sua frequência varia com o progresso da maturação. Os testículos também apresentam-se türgidos, esbranquiçados, ocupando grande parte da cavidade abdominal; com fraca pressão rompe-se sua membrana, fluindo um esperma menos viscoso que no estädio anterior (Figs. $12 \mathrm{C}$ e 13C);

ESTĀDIO D - Esvaziado: os ovārios apresentam-se com aspecto hemorrágico, completamente flácidos, ocupando menos de $1 / 3$ da cavidade abdominal; observam-se poucos óvulos, em estado de reabsorção. os testículos também apresentam-se flácidos, com aspecto hemorrāgico; a membrana não se rompe sob pressão fraca (Figs.12D e $13 \mathrm{D})$. 


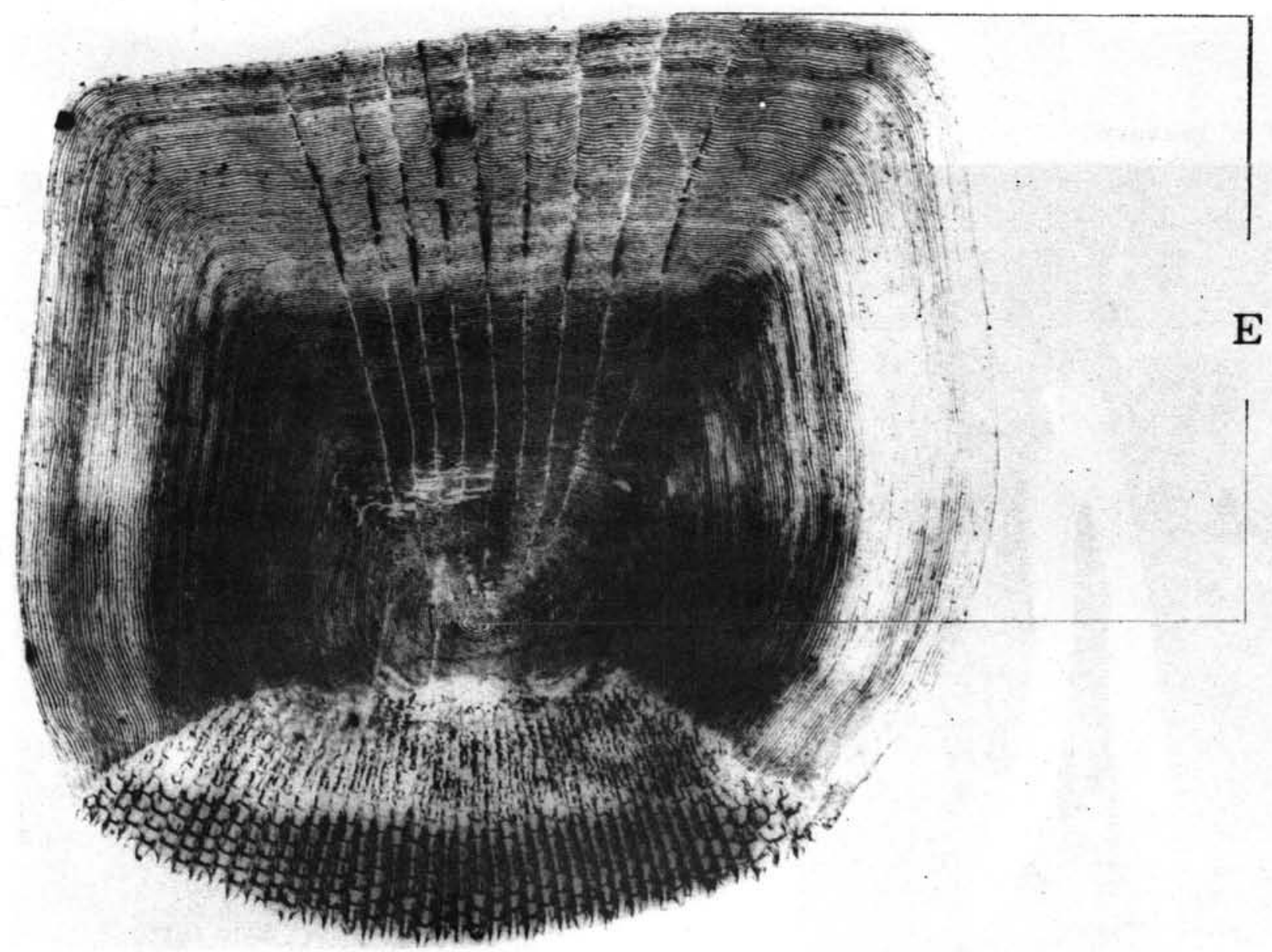

(A) - Indicação da medida considerada como comprimento da escama (E)

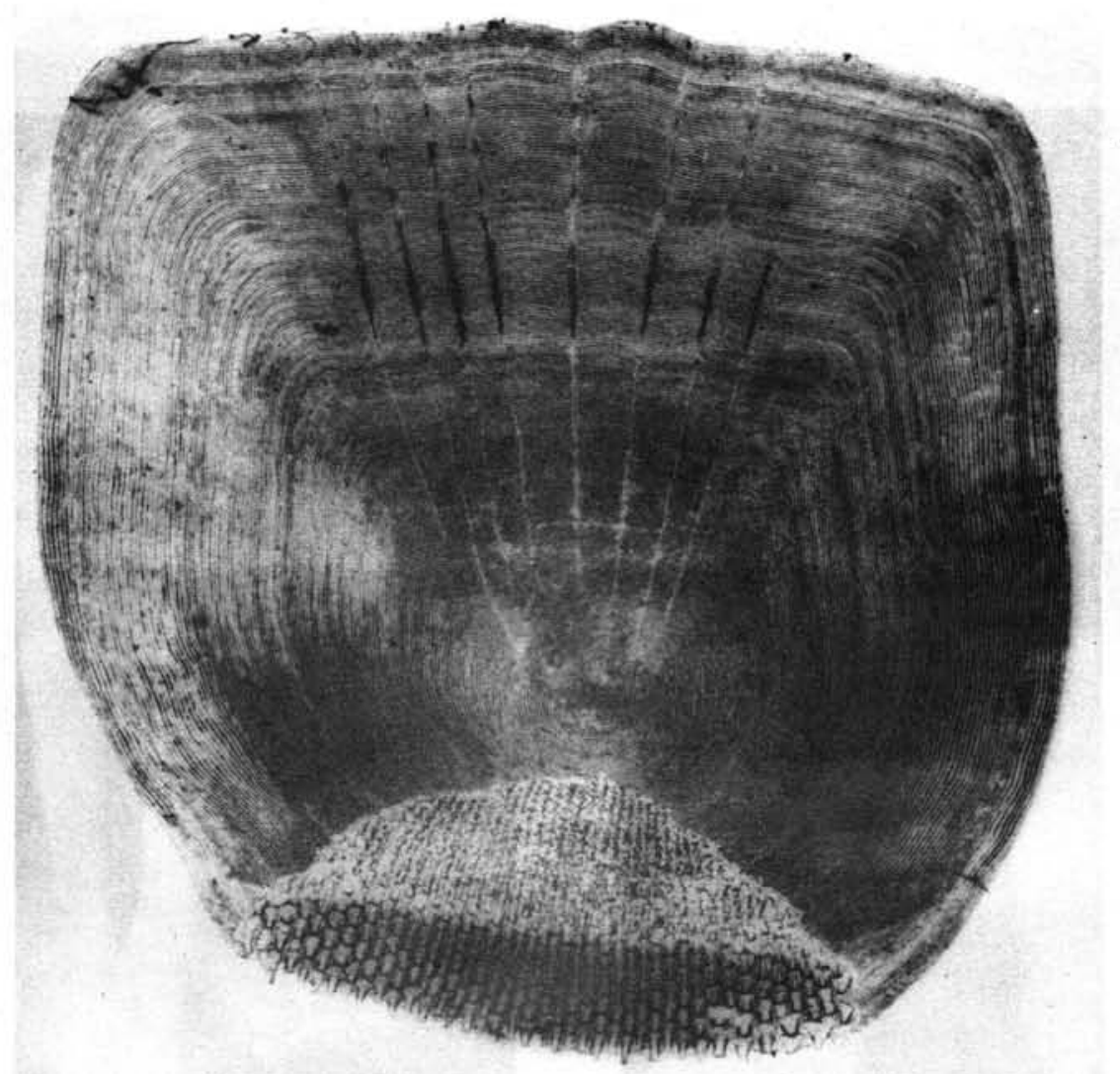

(B) - Escama mostrando anēis de crescimento

FIG. 11 - Fotos de escamas de $M$; furnieri

Bolm Inst. oceanogr. S Paulo, 20 (2): 1-70, 1971 
(A) - Imaturo

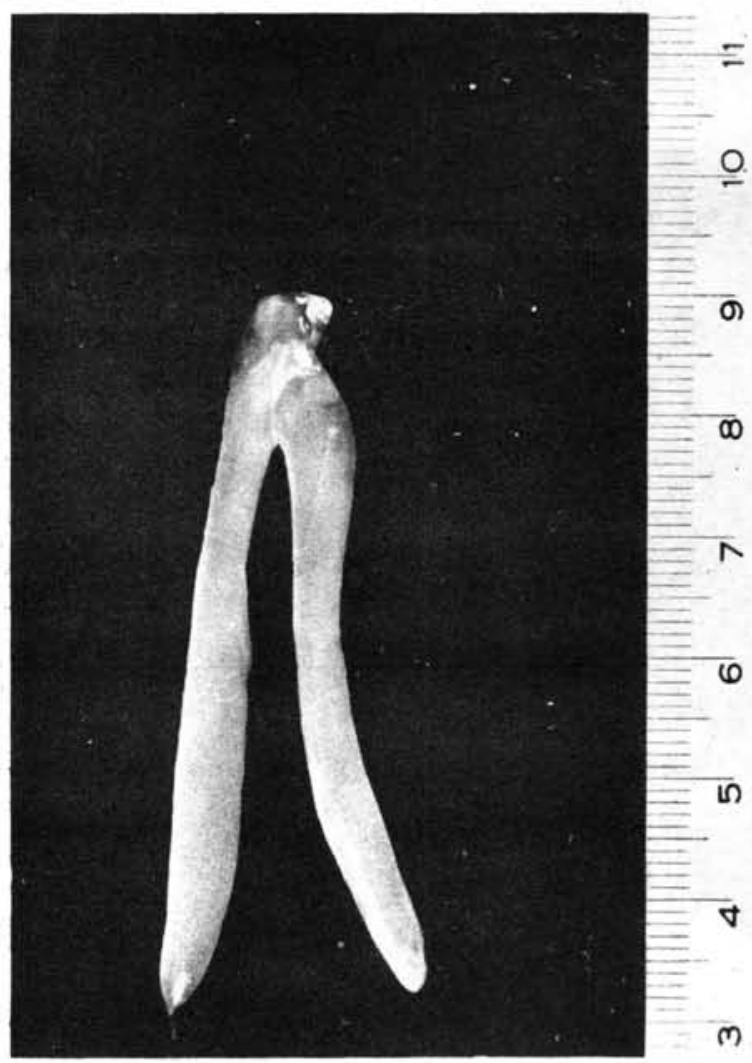

(C) - Maduro

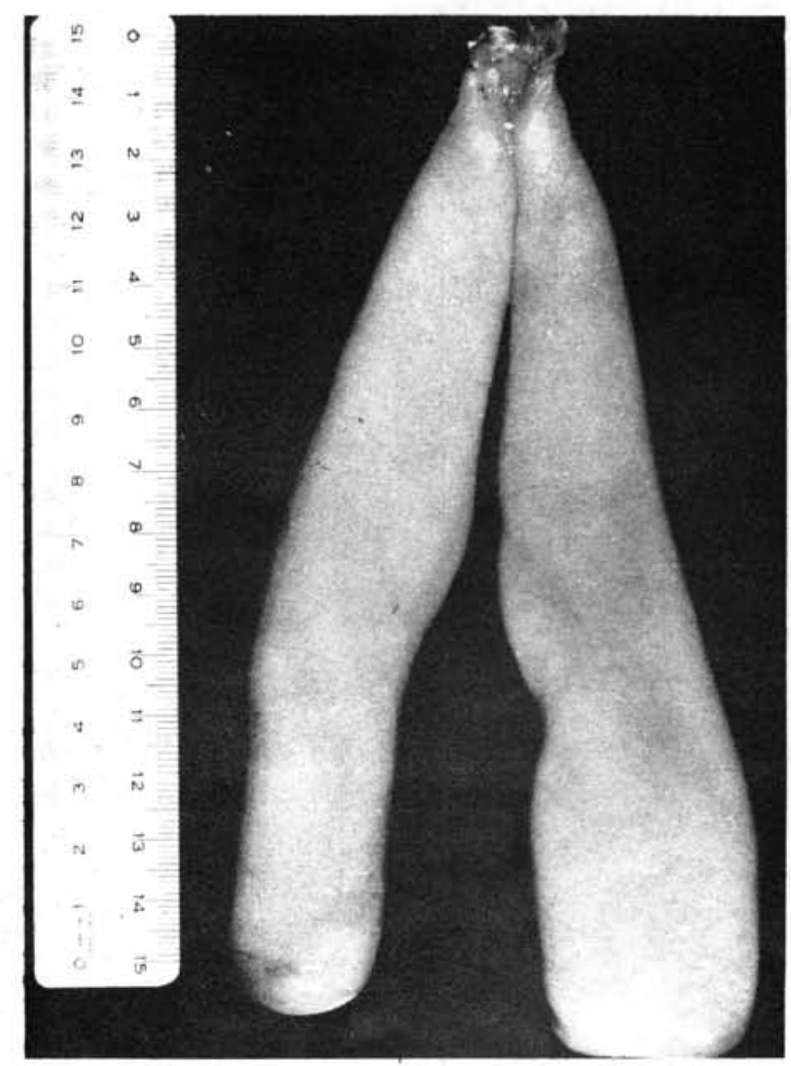

(B) - Em maturação

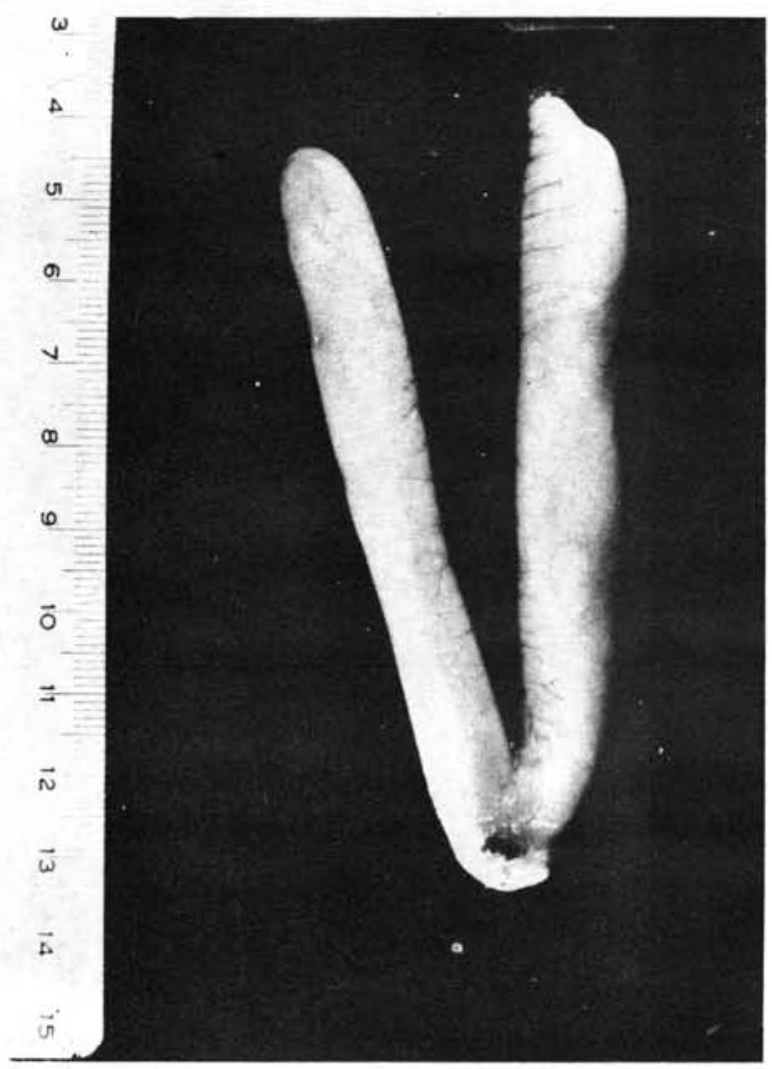

(D) - Esvaziado

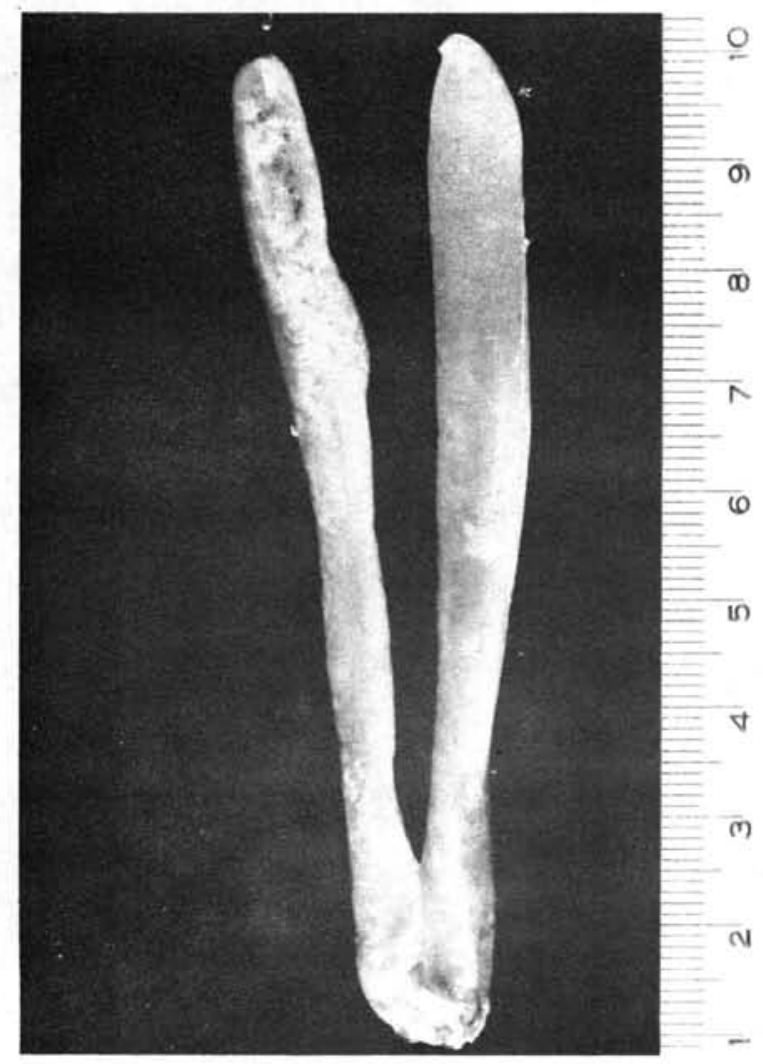

FIG. 12 - Ovários nos diferentes estádios de desenvolvimento 


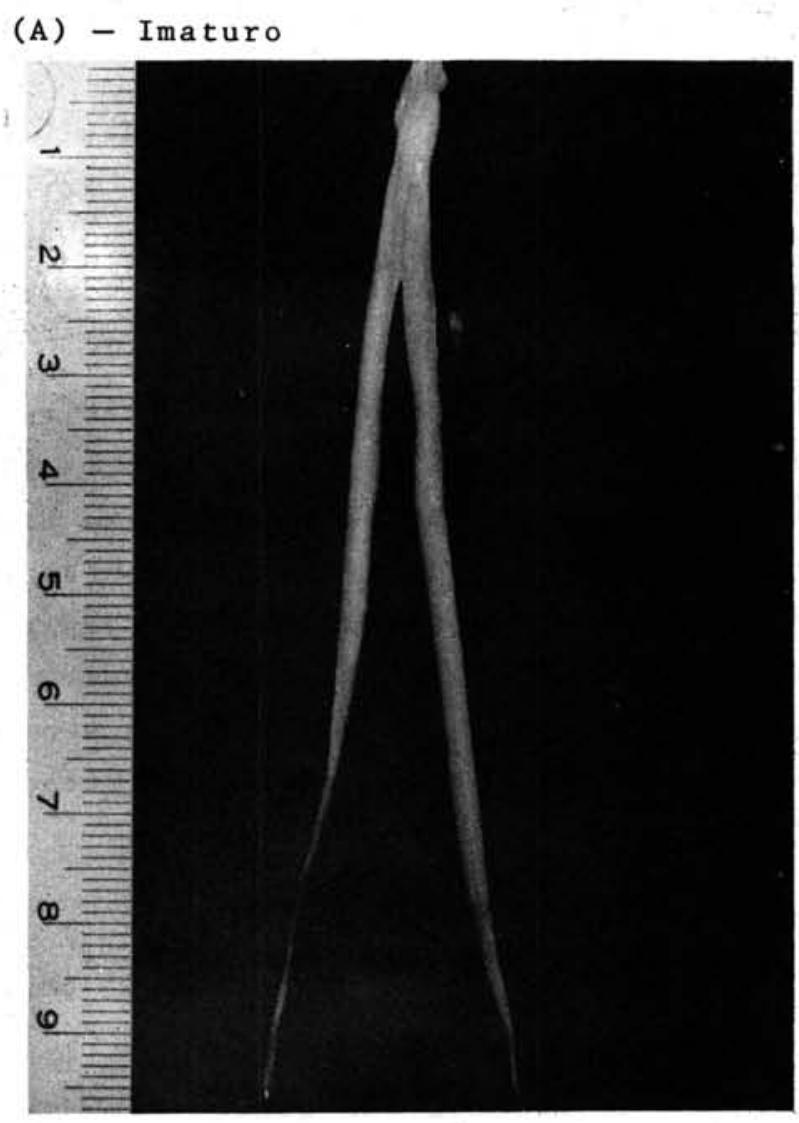

(B) - Em maturação

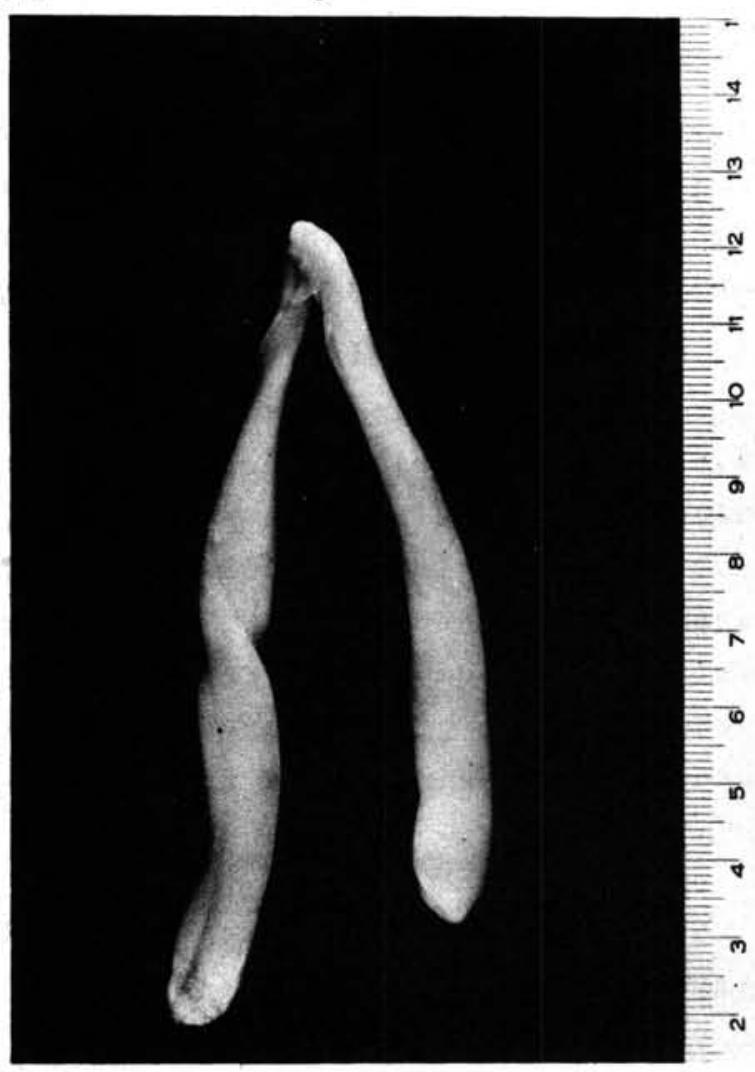

(C) - Maduro

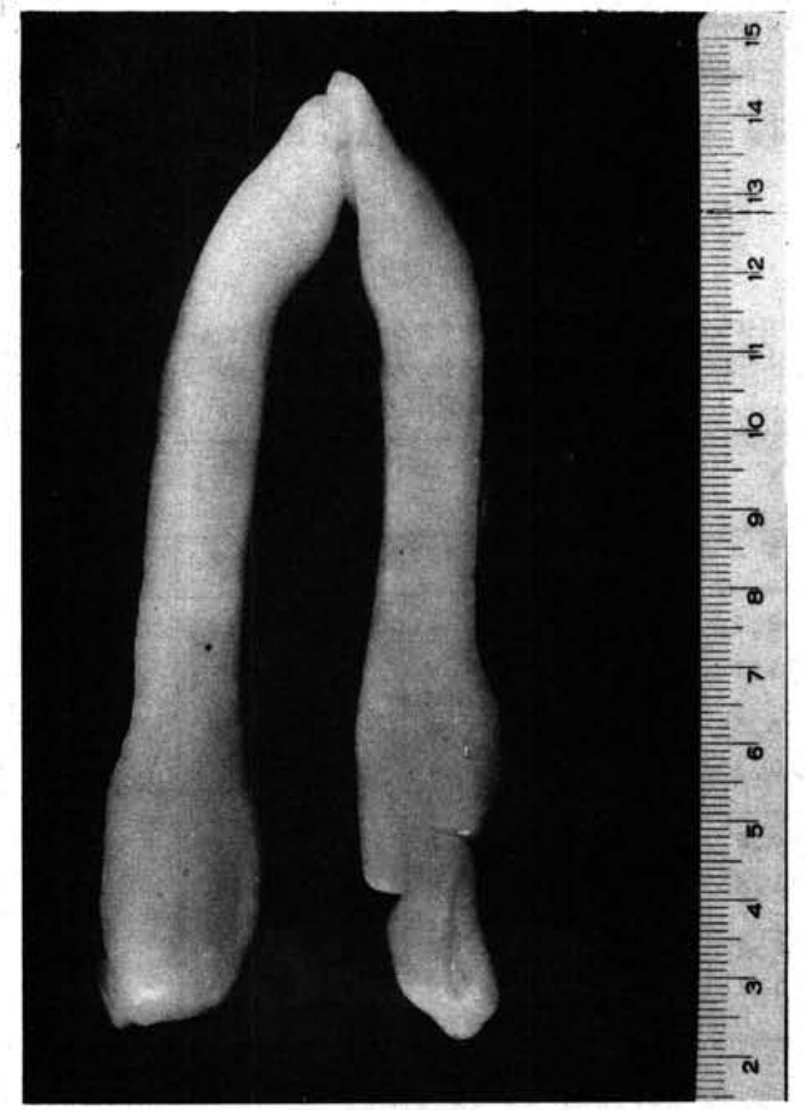

(D) - Esvaziado

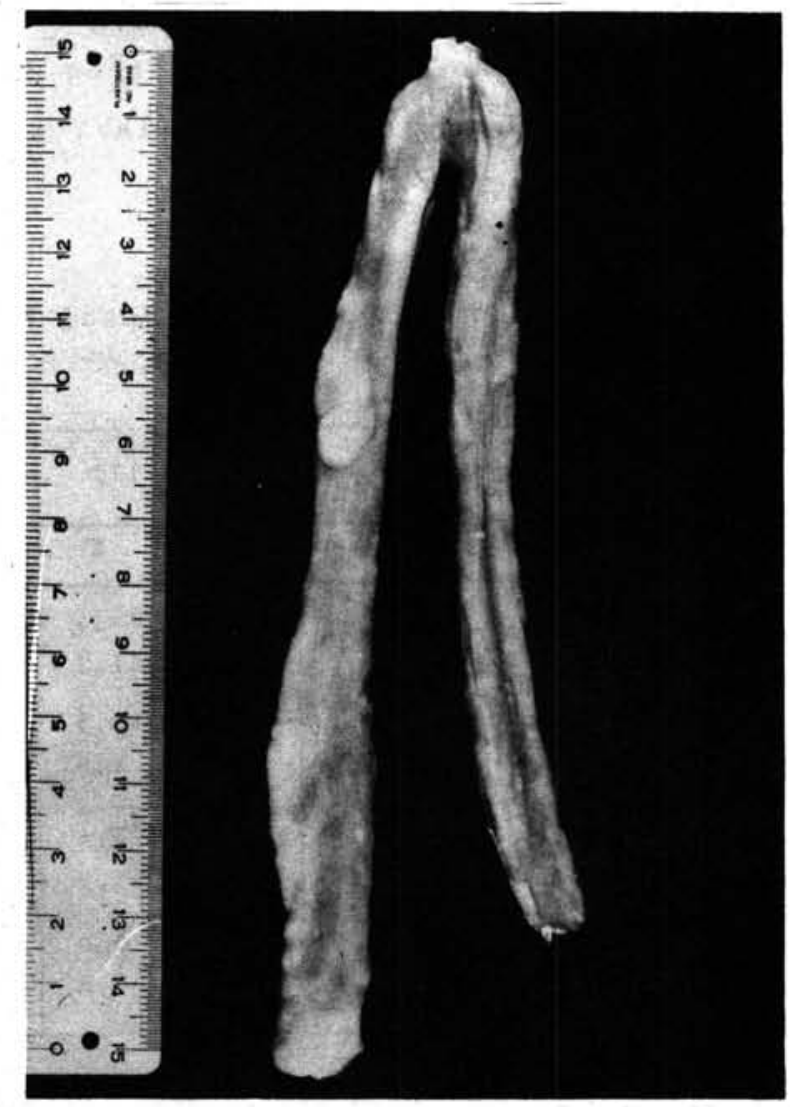

FIG. 13 - Testículos nos diferentes estädios de desenvolvimento 
Os dados relativos a cada um dos caracteres estudados foram grupados bimensalmente, por sub-ārea e por sexo, após testada sua homogeneidade. Foram considerados os bimestres maio-junho, julho-agosto, setembro-outubro, novembro-dezembro, janeiro-fevereiro, março-abril. A homogeneidade entre as várias amostras foi testada através da anālise de variância.

Os testes estatísticos foram aplicados apenas com o propósito de aceitar ou rejeitar uma hipótese, sendo a decisão baseada no nível de significância de $5 \%$. A hipótese inicial (nula) foi a de que os dados pertenciam a uma mesma população estatística, ou seja, de que eram homogêneos. Contudo, diferenças e semelhanças óbvias não foram testadas, sendo as conclusões baseadas na simples inspeção dos resultados. Quando esta, ou a resultado dos testes estatísticos, mostraram não haver diferença significativa entre os dados, estes foram sendo sucessivamente grupados. Para cada carāter, após o método de anālise, é citada apenas a grupagem final, ficando implícitas as fases intermediárias.

I - os dados referentes à reprodução e crescimento foram analisados como segue :

A - REPRODUÇÃo - Os dados relativos à ocorrência dos quatro estādios de maturidade foram distribuidos bimensalmente, por sexo, para cada uma das 5 sub-āreas consideradas e calculadas suas frequências relativas. A anāise dessas distribuições fornece indicações sobre as épocas de desova. Comparadas por simples inspeção, as distribuições foram grupadas para ambos os sexos e para as sub-āreas A, B, C e D, E (Tab. III, Fig.14). Não foram aqui considerados

TABELA III - Distribuição bimensal de frequência dos quatro estádios de maturidade, para os dois sexos grupados, para as äreas I e II

\begin{tabular}{|c|c|c|c|c|c|c|c|c|c|c|c|c|c|}
\hline \multirow{2}{*}{\multicolumn{2}{|c|}{$\begin{array}{l}\text { Bimestre } \\
\text { Frequência }\end{array}$}} & \multicolumn{2}{|c|}{$V-V I$} & \multicolumn{2}{|c|}{ VII - VIII } & \multicolumn{2}{|c|}{$I X-X$} & \multicolumn{2}{|c|}{$X I-X I I$} & \multicolumn{2}{|c|}{$I-I I$} & \multicolumn{2}{|c|}{$\operatorname{III}-\operatorname{IV}(*)$} \\
\hline & & No & $\%$ & No & $\%$ & No & $\%$ & No & $z$ & No & $z$ & No & $z$ \\
\hline \multirow{4}{*}{ Area I } & A & 29 & 29,0 & 27 & 35,5 & 4 & 6,7 & 6 & 6,0 & 9 & 19,6 & 30 & 31,8 \\
\hline & B & 56 & 56,0 & 39 & 51,3 & 43 & 74,1 & 62 & 62,0 & 9 & 19,6 & 47 & 49,8 \\
\hline & C & 3 & 3,0 & 8 & 10,5 & 5 & 8,5 & 2 & 2,0 & 0 & 0,0 & 0 & 0,0 \\
\hline & D & 12 & 12,0 & 2 & 2,6 & 6 & 10,3 & 30 & 30,0 & 28 & 60,9 & 17 & 18,0 \\
\hline \multirow{4}{*}{ Area II } & A & 30 & 36,6 & 15 & 25,4 & 6 & 19,4 & 13 & 21,3 & 16 & 28,1 & 28 & 37,8 \\
\hline & B & 22 & 26,8 & 14 & 23,7 & 16 & 51,6 & 36 & 59,0 & 28 & 49,1 & 34 & 45,9 \\
\hline & $\mathrm{c}$ & 0 & 0,0 & 0 & 0,0 & 8 & 25,8 & 10 & 16,4 & 1 & 1,8 & 1 & 1,4 \\
\hline & D & 30 & 36,6 & 30 & 50,8 & 1 & 3,2 & 2 & 3,3 & 12 & 21,0 & 11 & 14,9 \\
\hline
\end{tabular}

(*) Obs:- Area II, bimestre III-IV : dados obtidos de amostras coletadas com o N/Oc. "Prof. W. Besnard", em 1969. 
os indivíduos com sexo indeterminado. Os dados relativos ao bimestre marçoabril, sub-äreas D e E, referem-se a exemplares coletados em 1969, entre as 1atitudes $30^{\circ} \mathrm{S}$ e $33^{\circ} \mathrm{S}$, com o N/Oc. "Prof. W. Besnard", para efeito de complementação dos dados. Estes foram considerados apenas para a elaboração das Tabelas III, IV e V e obtenção da frequência de jovens no bimestre III-IV,na área II, representada na Figura 18 .

Daqui em diante, sempre que for feita referência às āreas I e II, significa que os dados foram grupados na forma citada; a ārea I é limitada pelas 1 atitudes $23^{\circ} \mathrm{S}$ e $29^{\circ} \mathrm{S}$, englobando as sub-äreas A, B e C; a àrea II é $1 i m i-$ tada pelas latitudes $29^{\circ} \mathrm{S}$ e $33^{\circ} \mathrm{S}$, englobando as sub-äreas D e E.

Para obter indicações sobre os locais de desova, os indivíduos com gônadas maduras (estādio C) foram distribuidos bimensalmente por sub-área (Tab. IV). A Figura 15 mostra a distribuição espacial e temporal desses indivíduos, sempre que a frequência tenha sido superior a $10 \%$ (devido à ocorrência de pequeno número de indivíduos com gônadas maduras).

A Tabela V dā a distribuição de frequência dos indivíduos com gônadas esvaziadas (estádio D), por sub-ärea e bimestre. A Figura 16 mostra a distribuição espacial e temporal desses indivíduos, sempre que a frequência tenha sido superior a $5 \%$.

Foi estimado o comprimento total médio em que $50 \%$ das fêmeas e machos da população atinge a primeira maturação sexual (mediana). Para tal, as fêmeas e machos foram grupados em imaturos (estádio A) e adultos (estädios B, C e D), e calculadas suas frequências por classes de comprimento total, por sub-ārea, para todo o período considerado. As frequências de fêmeas e de machos por classe de comprimento foram lançadas em gráfico e a mediana determinada graficamente.

A inspeção dos resultados levou ao grupamento dos dados referentes a fêmeas e machos para a área I e ärea II; os resultados finais estão mostrados nas Tabelas VI e VII, e Figura 17.

Para obter-se informações sobre o período em que se dá a entrada de indivíduos jovens para a população (recrutamento), foram analisadas as distribuições de frequência bimensais, por ärea, de indivíduos em que as gônadas estavam ainda indiferenciadas, não sendo possível determinar o sexo (Fig. 18), em relação ao número total de indivíduos amostrados por bimestre.

Os dados relativos ao peso dos ovários foram analisados para as áreas I e II; foi calculado o peso médio dos ovários nos diferentes estádios de maturidade, por classe de comprimento e área (Fig. 19).

B - CREscimento - A partir dos dados sobre idade e comprimento total, foram calculadas as médias bimensais de comprimento,por classe de idade e lançadas em gräfico para obtenção de indicações sobre a época de formação dos anéis de crescimento das escamas, por sub-ärea. Foram aqui considerados os dados obtidos das amostras coletadas durante o bimestre III-IV de 1969,

Bolm Inst. oceanogr. S Paulo, 20 (2): 1-70, 1971 
TABELA IV - Distribuição bimensal de frequência dos indivíduos com gônadas maduras (C; machos e fêmeas), por sub-ärea

Area I $\left(23^{\circ}-29^{\circ} \mathrm{S}\right)$

\begin{tabular}{|c|c|c|c|c|c|c|c|c|c|c|c|c|}
\hline & \multicolumn{2}{|c|}{$V-V I$} & \multicolumn{2}{|c|}{ VII - VIII } & \multicolumn{2}{|c|}{$I X-X$} & \multicolumn{2}{|c|}{$X I-X I I$} & \multicolumn{2}{|c|}{$I-I I$} & \multicolumn{2}{|c|}{ III - IV } \\
\hline & No & $\%$ & No & $\%$ & No & $\%$ & No & $z$ & N9 & $\%$ & No & $z$ \\
\hline $23^{\circ}-25^{\circ} \mathrm{s}$ & 0 & 0,0 & 1 & 5,6 & 2 & 11,1 & 1 & 5,6 & 0 & 0,0 & 0 & 0,0 \\
\hline $25^{\circ}-27^{\circ} \mathrm{S}$ & 2 & 11,1 & 6 & 33,3 & 3 & 16,6 & 1 & 5,6 & 0 & 0,0 & 0 & 0,0 \\
\hline $27^{\circ}-29^{\circ} \mathrm{S}$ & 1 & 5,6 & 1 & 5,6 & 0 & 0,0 & 0 & 0,0 & 0 & 0,0 & 0 & 0,0 \\
\hline
\end{tabular}

Area II $\left(29^{\circ}-33^{\circ} \mathrm{S}\right)$

\begin{tabular}{|c|c|c|c|c|c|c|c|c|c|c|c|c|}
\hline$B i$ & \multicolumn{2}{|c|}{$V-V I$} & \multicolumn{2}{|c|}{ VII - VIII } & \multicolumn{2}{|c|}{$I X-X$} & \multicolumn{2}{|c|}{$X I-X I I$} & \multicolumn{2}{|c|}{$I-I I$} & \multicolumn{2}{|c|}{ III - IV } \\
\hline & No & $\%$ & No & $\%$ & No & $\%$ & No & $\%$ & No & $\%$ & No & $\%$ \\
\hline $29^{\circ}-31^{\circ} \mathrm{S}$ & 0 & 0,0 & 0 & 0,0 & 8 & 40,0 & 0 & 0,0 & 0 & 0,0 & 1 & 5,0 \\
\hline $31^{\circ}-33^{\circ} \mathrm{s}$ & 0 & 0,0 & 0 & 0,0 & 0 & 0,0 & 10 & 50,0 & 1 & 5,0 & 0 & 0,0 \\
\hline
\end{tabular}

Obs:- Area II, bim. III-IV : dados obtidos de amostras coletadas em 1969, com o N/Oc. "Prof. W. Besnard".

TABELA V - Distribuição bimensal de frequência dos indivíduos com gônadas esvaziadas (D; machos e fêmeas), por sub-ärea

Ārea I $\left(23^{\circ}-29^{\circ} \mathrm{S}\right)$

\begin{tabular}{|c|c|c|c|c|c|c|c|c|c|c|c|c|}
\hline$B i$ & \multicolumn{2}{|c|}{$V-V I$} & \multicolumn{2}{|c|}{ VII - VIII } & \multicolumn{2}{|c|}{$I X-X$} & \multicolumn{2}{|c|}{$X I-X I I$} & \multicolumn{2}{|c|}{$I-I I$} & \multicolumn{2}{|c|}{ III - IV } \\
\hline & No & $\%$ & No & $\%$ & No & $\%$ & No & $\%$ & No & $\%$ & NO & $\%$ \\
\hline $23^{\circ}-25^{\circ} \mathrm{S}$ & 8 & 8,42 & 1 & 1,05 & 5 & 5,26 & 3 & 3,16 & 9 & 9,48 & 6 & 6,32 \\
\hline $25^{\circ}-27^{\circ} \mathrm{S}$ & 3 & 3,16 & 1 & 1,05 & 1 & 1,05 & 17 & 17,19 & 19 & 20,01 & 0 & 0,0 \\
\hline $27^{\circ}-29^{\circ} \mathrm{S}$ & 1 & 1,05 & 0 & 0,0 & 0 & 0,0 & 10 & 10,53 & 0 & 0,0 & 11 & 11,58 \\
\hline
\end{tabular}

Ārea II $\left(29^{\circ}-33^{\circ} \mathrm{S}\right)$

\begin{tabular}{|c|c|c|c|c|c|c|c|c|c|c|c|c|}
\hline Bim. & \multicolumn{2}{|c|}{$V-V I$} & \multicolumn{2}{|c|}{ VII - VIII } & \multicolumn{2}{|c|}{$I X-X$} & \multicolumn{2}{|c|}{$X I-X I I$} & \multicolumn{2}{|c|}{$I-I I$} & \multicolumn{2}{|c|}{ II - $-I V(\star)$} \\
\hline & No & $\%$ & No & 7 & No & $\%$ & No & $\%$ & No & $\%$ & No & $\%$ \\
\hline $29^{\circ}-31^{\circ} \mathrm{S}$ & 30 & 34,86 & 30 & 34,86 & 1 & 1,16 & 0 & 0,0 & 0 & 0,0 . & 0 & 0,0 \\
\hline $31^{\circ}-33^{\circ} \mathrm{s}$ & 0 & 0,0 & 0 & 0,0 & 0 & 0,0 & 2 & 2,33 & 12 & 13,96 & 11 & 12,79 \\
\hline
\end{tabular}

(*) Obs:- Área II - bimestre III-IV : dados obtidos de amostras coletadas em 1969 , com o N/Oc. "Prof. W. Besnard". 
TABELA VI - Distribuição de frequência de fêmeas imaturas (A) e adultas $(B+C+D)$, por classe de comprimento $\left(\mathrm{L}_{t}\right)$, para as āreas I e II

\begin{tabular}{|c|c|c|c|c|c|c|c|c|}
\hline \multirow{3}{*}{$\begin{array}{c}\text { C1asses Lt } \\
(\mathrm{mm})\end{array}$} & \multicolumn{4}{|c|}{ Area I $\left(23^{\circ}-29^{\circ} \mathrm{S}\right)$} & \multicolumn{4}{|c|}{ Area II $\left(29^{\circ}-33^{\circ} \mathrm{S}\right)$} \\
\hline & \multicolumn{2}{|c|}{ Imaturas } & \multicolumn{2}{|c|}{ Adu 1 tas } & \multicolumn{2}{|c|}{ Imaturas } & \multicolumn{2}{|c|}{ Adultas } \\
\hline & NO & $\bar{\gamma}$ & NO? & $\%$ & NO & $\%$ & NO & $\%$ \\
\hline $100-150$ & 1 & 100,0 & 0 & 0,0 & 0 & 0,0 & 0 & 0,0 \\
\hline $150-200$ & 9 & 100,0 & 0 & 0,0 & 0 & 0,0 & 0 & 0,0 \\
\hline $200-250$ & 29 & 87,9 & 4 & 12,1 & 5 & 100,0 & 0 & 0,0 \\
\hline $250-300$ & 13 & 50,0 & 13 & 50,0 & 20 & 90,8 & 2 & 9,1 \\
\hline $300-350$ & 10 & 19,2 & 42 & 80,6 & 23 & 79,1 & 6 & 20,6 \\
\hline $350-400$ & 2 & 3,7 & 52 & 96,2 & 2 & 9,1 & 20 & 90,8 \\
\hline $400-450$ & 2 & 3,8 & 51 & 95,9 & 0 & 0,0 & 27 & 100,0 \\
\hline $450-500$ & 0 & 0,0 & 28 & 100,0 & 0 & 0,0 & 20 & 100,0 \\
\hline $500-550$ & 0 & 0,0 & 11 & 100,0 & 0 & 0,0 & 20 & 100,0 \\
\hline $550-600$ & 0 & 0,0 & 3 & 100,0 & 0 & 0,0 & 14 & 100,0 \\
\hline $600-650$ & 0 & 0,0 & 1 & 100,0 & 0 & 0,0 & 4 & 100,0 \\
\hline $650-700$ & 0 & 0,0 & 0 & 0,0 & 0 & 0,0 & 0 & 0,0 \\
\hline $700-750$ & 0 & 0,0 & 0 & 0,0 & 0 & 0,0 & 1 & 100,0 \\
\hline TOTAL & 66 & - & 205 & - & 50 & - & 114 & - \\
\hline
\end{tabular}

TABELA VII - Distribuição de frequência de machos imaturos (A) e adultos $(B+C+D)$, por classe de comprimento $\left(L_{t}\right)$, para as äreas I e II

\begin{tabular}{|c|c|c|c|c|c|c|c|c|}
\hline \multirow{3}{*}{$\begin{array}{c}\text { Classes Lt } \\
(\mathrm{mm})\end{array}$} & \multicolumn{4}{|c|}{ Area I $\left(23^{\circ}-29^{\circ} \mathrm{S}\right)$} & \multicolumn{4}{|c|}{ Area II $\left(29^{\circ}-33^{\circ} \mathrm{S}\right)$} \\
\hline & \multicolumn{2}{|c|}{ Imaturos } & \multicolumn{2}{|c|}{ Adultos } & \multicolumn{2}{|c|}{ Imaturos } & \multicolumn{2}{|c|}{ Adultos } \\
\hline & NO & $\%$ & No & $\%$ & NO & $\%$ & NO & $\%$ \\
\hline $100-150$ & 0 & 100,0 & 0 & 0,0 & 0 & 0,0 & 0 & 0,0 \\
\hline $150-200$ & 5 & 100,0 & 0 & 0,0 & 0 & 0,0 & 0 & 0,0 \\
\hline $200-250$ & 12 & 57,1 & 9 & 42,8 & 1 & 100,0 & 0 & 0,0 \\
\hline $250-300$ & 18 & 43,7 & 23 & 55,9 & 13 & 92,8 & 1 & 7,1 \\
\hline $300-350$ & 3 & 5,8 & 49 & 94,1 & 10 & 55,6 & 8 & 44,4 \\
\hline $350-400$ & 2 & 3,9 & 49 & 96,0 & 5 & 19,2 & 21 & 80,6 \\
\hline $400-450$ & 0 & 0,0 & 22 & 100,0 & 1 & 3,1 & 31 & 96,7 \\
\hline $450-500$ & 0 & 0,0 & 9 & 100,0 & 0 & 0,0 & 18 & 100,0 \\
\hline $500-550$ & 0 & 0,0 & 1 & 100,0 & 0 & 0,0 & 13 & 100,0 \\
\hline $550-600$ & 0 & 0,0 & 1 & 100,0 & 0 & 0,0 & 3 & 100,0 \\
\hline $600-650$ & 0 & 0,0 & 0 & 0,0 & 0 & 0,0 & 0 & 0,0 \\
\hline $650-700$ & 0 & 0,0 & 0 & 0,0 & 0 & 0,0 & 0 & 0,0 \\
\hline $700-750$ & 0 & 0,0 & 0 & 0,0 & 0 & 0,0 & 0 & 0,0 \\
\hline TOTAL & 40 & - & 163 & - & 30 & - & 95 & - \\
\hline
\end{tabular}


na ärea II, com o N/Oc. "Prof. W. Besnard". A anālise dos resultados, por simples inspeção, resultou no grupamento dos dados referentes a área I e área II (Tab. VIII e Fig. 20).

Foram calculadas as curvas de crescimento para fêmeas e para machos, por sub-ärea, ajustando-se aos dados de comprimento total médio ( $\bar{L}_{t}$ ) e idade (I), a expressão de von Bertalanffy- $L_{t}=L_{\infty}\left[1-e^{-K\left(t-t_{0}\right)}\right]$, pelo método de Ford-Walford (Beverton \& Holt, 1957). Comparados os resultados, por simples inspeção, os dados da ārea I e ärea II foram grupados (Tab. IX), e calculadas as curvas de crescimento.

Testados os resultados (Tab. X-A), através do teste de "t", verificou-se ocorrer diferenças significativas entre sexos dentro de cada ārea e entre áreas para cada sexo (Tab. X-B).

A Figura 21 mostra as relações entre os valores de $L_{t+1}$ e $L_{t}$ entre sexos por área e entre áreas por sexo, e a Figura 22, as curvas de crescimento em comprimento, por sexo, para as äreas I e II.

A partir dos dados sobre pesos totais médios ( $\bar{W}_{t}$ ) por classe de idade (I) (Tab. XI) foram calculadas as regressões entre logarítmo natural do pêso médio ( $1 \mathrm{n} \overline{\mathrm{W}}_{\mathrm{t}}$ ) e logarítmo natural de idade ( $1 \mathrm{n}$ I), por sexo, para as áreas I e II (Tab, XII-A). Testados os resultados, através do teste de "t", verificou-se não ocorrer diferenças significativas entre sexos por ārea e entre áreas por sexo (Tab. XII-B); os dados foram grupados por ärea (Tab. XII-A) e testados, não ocorrendo diferenças significativas entre as áreas (Tab. XII-B). A Figura 23 mostra as relações entre $1 \mathrm{n}$ I e $1 \mathrm{n} \overline{\mathrm{W}}_{\mathrm{t}}$ por ärea, para sexos grupados.

Foram estudadas as regressões entre peso total ( $\mathrm{W}_{\mathrm{t}}$ ) e comprimento total $\left(L_{t}\right)$, por sexo e por sub-ārea, ajustando-se aos dados a expressão $W_{t}=a L_{t}^{b}, p^{-}$ 1o mētodo dos mínimos quadrados, após transformação logarítmica (logarítmos na turais); os dados foram grupados para as äreas I e II (Tab. XIII). Os resultados foram testados (Tab. XIII-B), através do teste de "t", e os dados grupados para ambos os sexos, para as äreas I e II (Tab.XIII-A, Fig. 24).

II - Os dados relativos à ocorrência de exemplares portadores de formações ósseas anômalas foram analisados:

a) quanto à frequência (\%) de portadores por classe de comprimento e por área (Fig. 25);

b) quanto ao número médio de formações por exemplar, por classe de comprimento e área (Fig. 26);

c) quanto à frequência (\%) de exemplares portadores por sexo e bimestre, e grupados para as äreas I e II (Tab. XIV-A, Fig. 27);

d) quanto ao número de formações por exemplar portador, por sexo e bimestre e também grupados por ärea I e II (Tab. XV-A, Fig. 28):

Os resultados foram testados através do teste do $\chi^{2}$, com correção de continuidade (Tabs. XIV-B e XV-B), verificando-se ocorrer diferenças significativas apenas quanto à frequência de fêmeas portadoras entre áreas, o que determina a diferença entre as äreas I e II (Tab. XIV-B);

e) quanto à frequência (\%) de portadores por bimestre e ärea (Tab. XIV-A, Fig. 29). 
TABELA VIII - Comprimentos totais médios $\left(\overline{\mathrm{L}}_{t}\right)$ bimensais por classe de idade, para $M$. furnieri das áreas I e II

Área I $\left(23^{\circ}-29^{\circ} \mathrm{S}\right)$

\begin{tabular}{|c|c|c|c|c|c|c|c|c|c|c|c|c|}
\hline \multirow{2}{*}{$\begin{array}{l}\text { Bimestre } \\
\text { Idade }\end{array}$} & \multicolumn{2}{|c|}{$V-V I$} & \multicolumn{2}{|c|}{ VII - VIII } & \multicolumn{2}{|c|}{$I X-X$} & \multicolumn{2}{|c|}{$X I-X I I$} & \multicolumn{2}{|c|}{$I-I I$} & \multicolumn{2}{|c|}{ III - IV } \\
\hline & No & $\bar{L}_{t}$ & No & $\overline{\mathrm{L}} \mathrm{t}$ & No & $\overline{\mathrm{L}}_{\mathrm{t}}$ & No & $\bar{L}_{t}$ & $\mathrm{NO}$ & $\overline{\mathrm{L}} \mathrm{t}$ & No & $\overline{\mathrm{L}}_{\mathrm{t}}$ \\
\hline 0 & 43 & 219,6 & 19 & 197,6 & 7 & 234,3 & 0 & - & 0 & - & 15 & 212,5 \\
\hline 1 & 26 & 281,3 & 33 & 269,9 & 11 & 255,8 & 8 & 308,5 & 6 & 327,8 & 28 & 272,6 \\
\hline 2 & 25 & 339,3 & 14 & 331,5 & 16 & 366,0 & 26 & 341,4 & 15 & 355,1 & 21 & 348,5 \\
\hline 3 & 9 & 382,1 & 12 & 382,8 & 15 & 392,7 & 43 & 403,4 & 8 & 418,0 & 17 & 407,4 \\
\hline 4 & 9 & 417,7 & 0 & - & 3 & 413,7 & 11 & 451,2 & 8 & 474,6 & 5 & 440,6 \\
\hline
\end{tabular}

Ārea II $\left(29^{\circ}-33^{\circ} \mathrm{S}\right)$

\begin{tabular}{|c|c|c|c|c|c|c|c|c|c|c|c|c|}
\hline \multirow{2}{*}{$\begin{array}{l}\text { Bimestre } \\
\text { Idade }\end{array}$} & \multicolumn{2}{|c|}{$V-V I$} & \multicolumn{2}{|c|}{ VII - VIII } & \multicolumn{2}{|c|}{$I X-X$} & \multicolumn{2}{|c|}{$X I-X I I$} & \multicolumn{2}{|c|}{$I-I I$} & \multicolumn{2}{|c|}{ III - IV (*) } \\
\hline & No & $\overline{\mathrm{L}} \mathrm{t}$ & No & $\overline{\mathrm{L}} \mathrm{t}$ & No & $\overline{\mathrm{L}} \mathrm{t}$ & No & $\bar{L} t$ & No & $\overline{\mathrm{L}} \mathrm{t}$ & No & $\bar{L} t$ \\
\hline 0 & 0 & - & 0 & - & 2 & 283,5 & 0 & - & 6 & 244,3 & 23 & 212,2 \\
\hline 1 & 6 & 271,8 & 6 & 305,3 & 6 & 296,0 & 5 & 306,4 & 10 & 295,2 & 30 & 287,3 \\
\hline 2 & 14 & 294,5 & 8 & 334,1 & 6 & 306,0 & 17 & 358,0 & 7 & 361,3 & 11 & 320,9 \\
\hline 3 & 18 & 353,8 & 14 & 389,1 & 10 & 407,1 & 15 & 377,6 & 11 & 410,5 & 14 & 362,4 \\
\hline 4 & 8 & 404,2 & 9 & 447,7 & 2 & 405,0 & 5 & 435,6 & 6 & 459,7 & 11 & 403,7 \\
\hline 5 & 9 & 435,9 & 9 & 475,4 & 0 & - & 1 & 470,0 & 4 & 562,5 & 9 & 469,0 \\
\hline
\end{tabular}

(*) Obs:- Ārea II, bim. III-IV : dados obtidos de amostras coletadas em 1969, com o N/Oc. "Prof. W. Besnard".

TABEla IX - Comprimentos totais médios $\left(\bar{L}_{t}\right)$ por classe de idade, por sexo, para $M$. furnieri das āreas I e II

\begin{tabular}{|c|c|c|c|c|c|c|c|c|}
\hline \multirow{3}{*}{ Id ade } & \multicolumn{4}{|c|}{ Area I $\left(23^{\circ}-29^{\circ} \mathrm{S}\right)$} & \multicolumn{4}{|c|}{ Area II $\left(29^{\circ}-33^{\circ} \mathrm{S}\right)$} \\
\hline & \multicolumn{2}{|c|}{ Fêmeas } & \multicolumn{2}{|c|}{ Machos } & \multicolumn{2}{|c|}{ Fêmeas } & \multicolumn{2}{|c|}{ Machos } \\
\hline & No & $\overline{\mathrm{L}}_{\mathrm{t}}$ & No & $\overline{\mathrm{L}}_{\mathrm{t}}$ & No & $\overline{\mathrm{L}}_{\mathrm{t}}$ & No & $\overline{\mathrm{L}}_{\mathrm{t}}$ \\
\hline 0 & 40 & 221,6 & 16 & 221,9 & 3 & 254,3 & 2 & 274,0 \\
\hline 1 & 43 & 284,4 & 60 & 277,8 & 17 & 291,4 & 11 & 317,2 \\
\hline 2 & 59 & 349,4 & 58 & 342,9 & 20 & 349,0 & 20 & 339,6 \\
\hline 3 & 64 & 408,2 & 40 & 385,4 & 33 & 374,0 & 34 & 395,4 \\
\hline 4 & 24 & 450,2 & 12 & 429,8 & 18 & 439,9 & 12 & 424,2 \\
\hline 5 & 6 & 467,2 & 2 & 470,5 & 10 & 494,0 & 13 & 460,2 \\
\hline 6 & - & - & - & - & 15 & 518,5 & 7 & 513,0 \\
\hline 7 & - & - & - & - & 6 & 521,2 & 3 & 522,3 \\
\hline TOTAL & 236 & - & 188 & - & 122 & - & 102 & - \\
\hline
\end{tabular}


TABELA X - A) Dados das regressões entre $L_{t+1}$ e $L_{t}$ de $M$. furnieri, por sexo, para as áreas I e II;

B) Resultados do teste de "t" aplicado às regressões da tabela anterior $(\mathrm{X}-\mathrm{A})$.

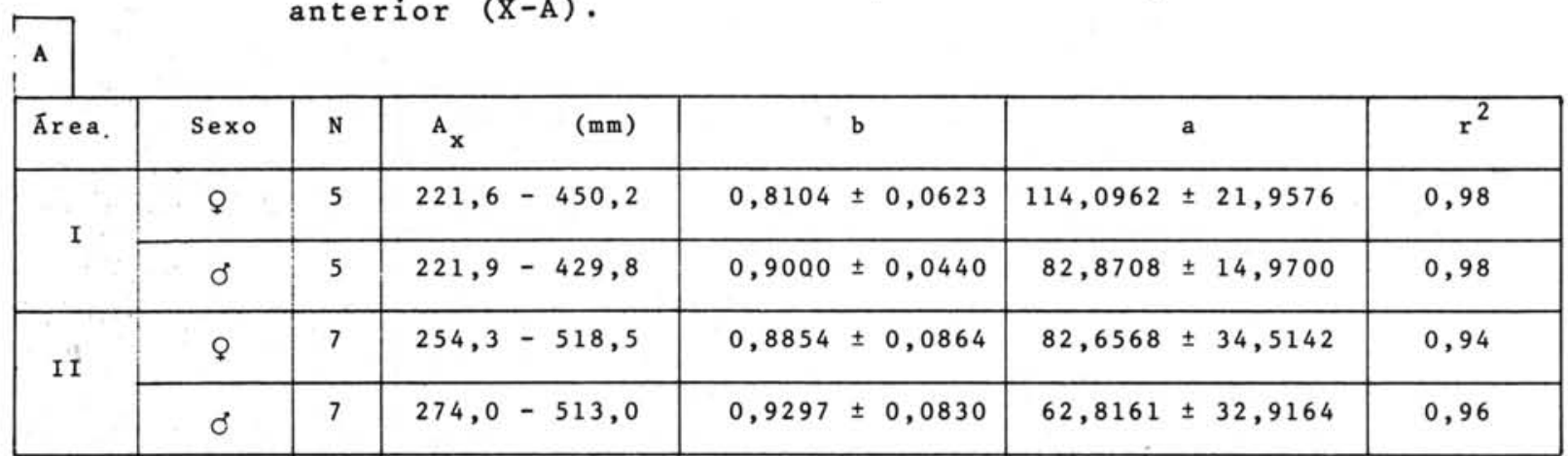

$\mathrm{N}=$ número de exemplares

$A_{x}=$ amplitude da variāvel x (menor - maior)

$\mathrm{b}=$ valor do coeficiente de regressão \pm seu desvio padrão

$a=$ valor da constante de regressão \pm seu desvio padrão

$\mathrm{r}^{2}=$ coeficiente de determinação

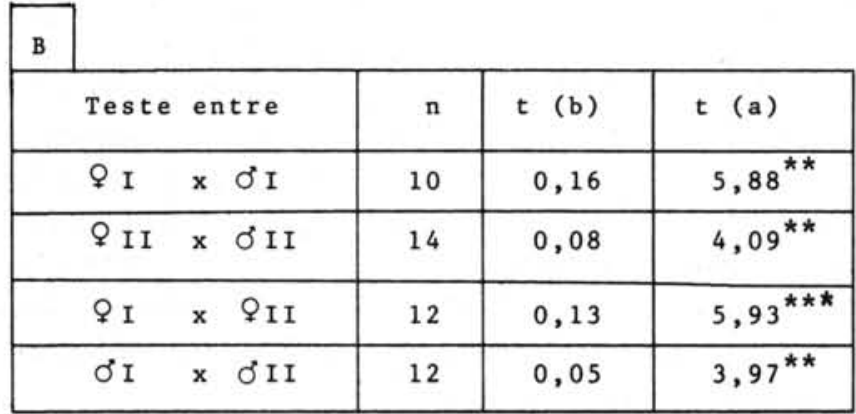

$\mathrm{n}=$ número total de exemplares

** = significativo ao nível de $1 \%$

$* * *=$ significativo ao nivel de $0,1 \%$

TABELA XI - Pesos totais médios $\left(\bar{W}_{t}\right)$ por classe de idade, por sexo e para - total, para $M$. furnieri das áreas I e II

\begin{tabular}{|c|c|c|c|c|c|c|c|c|c|c|c|c|c|c|c|c|}
\hline \multirow[b]{3}{*}{ Id ade } & \multicolumn{8}{|c|}{ Area I $\left(23^{\circ}-29^{\circ} \mathrm{S}\right)$} & \multicolumn{8}{|c|}{ Area II $\left(29^{\circ}-33^{\circ} \mathrm{s}\right)$} \\
\hline & \multicolumn{2}{|c|}{ Fêmeas s } & \multicolumn{2}{|c|}{ Machos } & \multicolumn{2}{|c|}{ Indeterm. } & \multicolumn{2}{|c|}{ Total } & \multicolumn{2}{|c|}{ Fêmeas } & \multicolumn{2}{|c|}{ Machos } & \multicolumn{2}{|c|}{ Indeterm.* } & \multicolumn{2}{|c|}{ Total } \\
\hline & x? & $\bar{w}_{t}$ & so & $\bar{w}_{t}$ & No & $\bar{w}_{t}$ & Ne & $\bar{w}_{t}$ & $\mathrm{x} 9$ & $\overline{\mathrm{v}}_{\mathrm{t}}$ & se & $\bar{w}_{t}$ & No & $\bar{w}_{t}$ & so & $\bar{w}_{t}$ \\
\hline 0 & 40 & 118,2 & 16 & 118,9 & 28 & 80,3 & 84 & 105,7 & 3 & 176,7 & 2 & 217,5 & 3 & 146,0 & 8 & 175.4 \\
\hline 1 & 43 & 249,0 & 60 & 233,4 & 9 & 152,0 & 112 & 232,9 & 17 & 277.2 & 11 & 367,4 & s & 199,4 & 33 & 295,5 \\
\hline 2 & 59 & 450,0 & 58 & 436,8 & 0 & - & 117 & 443.4 & 20 & 484,8 & 20 & 437,7 & 12 & 249,3 & 52 & 412,3 \\
\hline 3 & 64 & 717.6 & 40 & 609,8 & 0 & - & 104 & 676,2 & 33 & 618,4 & 34 & 713,1 & 1 & 255,0 & 68 & 660,4 \\
\hline 4 & 24 & 989,1 & 12 & 824,9 & 0 & - & 36 & 934,4 & 18 & 975,4 & 12 & 909,1 & 0 & - & 30 & 948,9 \\
\hline 5 & 6 & 1095,3 & 2 & 1140,5 & 0 & - & 8 & 1106,6 & 10 & 1428,1 & 13 & 1173,9 & 0 & - & 23 & 1284,4 \\
\hline 6 & 2 & 1625,0 & 0 & .. & 0 & - & 2 & 1625,0 & 15 & 1629,2 & 7 & 1569,3 & 1 & 1621,0 & 23 & 1683,8 \\
\hline 7 & 0 & - & 0 & - & 0 & - & 0 & - & 6 & 1567.5 & 3 & 1545,0 & 0 & - & 9 & 1360,0 \\
\hline Tota 1 & 238 & - & 188 & - & 37 & - & 463 & - & 122 & - & 102 & - & 22 & - & 246 & - \\
\hline
\end{tabular}

(*) Obs:- Exemplares aqui constantes, com sexo indeterminado, englobam os jovens (em que as gônadas eram injife renciadas) e aquêles em que por motivos värios não foi possivel determinar o sexo. 
III - Os dados referentes aos caracteres merísticos foram analisados comparando-se suas distribuições bimensais de frequência, por sub-ärea. Foram calculadas as médias, seus desvio-padrão e o coeficiente de variabilidade. Os dados foram grupados para ambos os sexos, pois a simples inspeção dos mesmos mostra claramente não haver diferenças. Os resultados foram testados através de anālise de variância entre sub-āreas dentro de cada bimestre e entre bimestre dentro de cada sub-ärea, e grupados os dados referentes à ārea I e área II, para todo o período estudado. Os resultados foram testados através de análise de variância (Tab. XVI, Figs. 30 a 32 ).

TABELA XII - A) Dados das regressões entre logarítmo do pêso médio (1n $\bar{W}_{t}$ ) e logaritmo da idade (In I) de $M$. furnieri, por sexo e para o total, para as äreas I e II;

B) Resultados do teste de "t" aplicado às regressões da tabela anterior (XII-A).

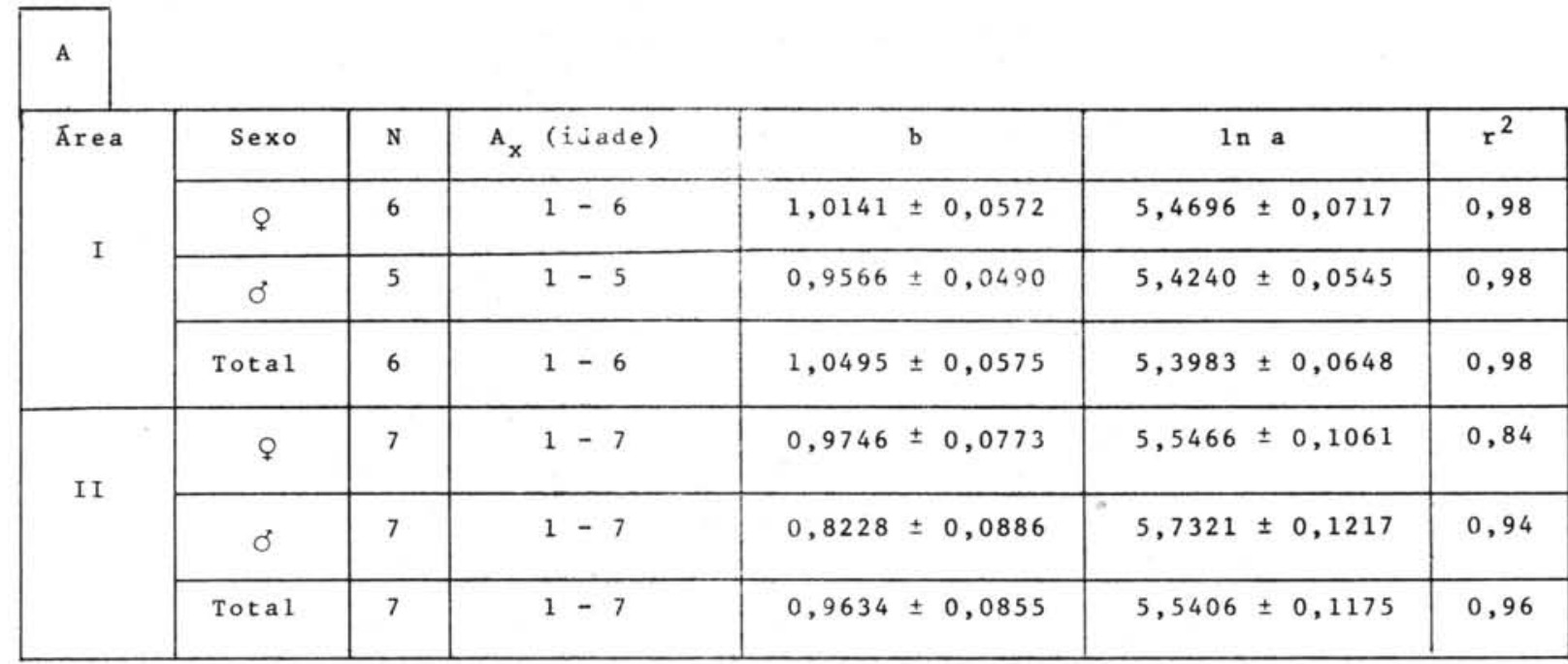

$\mathrm{N}=$ nümero de exemplares

$A_{x}=$ amplitude da variāvel $x$ (menor - maior)

$\mathrm{b}=$ valor do coeficiente de regressão \pm seu desvio padrão

In $a=$ valor, em logarítmo natural, da constante de regressão \pm seu desvio padrão $\mathrm{r}^{2}=$ coeficiente de determinação

\begin{tabular}{|c|c|c|c|c|}
\hline \multicolumn{5}{|l|}{ B } \\
\hline Teste & entre & $\mathrm{n}$ & $t(b)$ & $t(a)$ \\
\hline Q I & $X \quad \delta I$ & 11 & 0,09 & 0,10 \\
\hline QII & $x \quad \delta I I$ & 14 & 0,31 & 0,45 \\
\hline Q I & $x$ QII & 13 & 0,07 & 0,16 \\
\hline$\delta I$ & $x \quad \delta I I$ & 12 & 0,25 & 0,65 \\
\hline Área I X & Ārea II & 13 & 0,15 & 0,31 \\
\hline
\end{tabular}

$\mathrm{n}=$ número total de exemplares 
TABELA XIII - A) Dados das regressões entre logarítmo do peso total ( $1 n$ Wt) e logarítmo do comprimento total ( $1 \mathrm{n} \mathrm{L}_{\mathrm{t}}$ ) de $M$. furnieri por sexo e para o total, para as äreas I e II;

\begin{tabular}{|c|c|c|c|c|c|c|c|}
\hline A & & $\begin{array}{l}\text { Res } \\
\text { xos }\end{array}$ & $\mathrm{r} \frac{\mathrm{d}}{\mathrm{a}}$ & $\begin{array}{l}\text { s do } \\
\text { rea, }\end{array}$ & $\begin{array}{l}\text { "t" aplicac } \\
\text { re äreas par }\end{array}$ & $\begin{array}{l}\text { às regressoes } \\
\text { total. }\end{array}$ & \\
\hline \multirow[t]{4}{*}{ Area } & Sexo & $\mathrm{N}$ & $\mathrm{A}_{\mathbf{x}}$ & (mm) & b & $\ln a$ & $r^{2}$ \\
\hline & Q & 271 & 130 & -628 & $3,0010 \pm 0,0220$ & $-11,4945 \pm 1,2807$ & 0,98 \\
\hline & o & 204 & 155 & -560 & $3,0023 \pm 0,0339$ & $-11,4913 \pm 1,8656$ & 0,96 \\
\hline & Total & 513 & 130 & -628 & $2,9996 \pm 0,0226$ & $-11,4822 \pm 0,9206$ & 0,96 \\
\hline \multirow{3}{*}{ I I } & Q & 165 & 236 & -749 & $3,0570 \pm 0,0368$ & $-11,7500 \pm 1,8139$ & 0,96 \\
\hline & $\delta$ & 107 & 219 & -586 & $3,0705 \pm 0,0429$ & $-11,8318 \pm 2,9206$ & 0,96 \\
\hline & Total & 300 & 219 & -749 & $3,0677 \pm 0,0259$ & $-11,8173 \pm 1,3737$ & 0,98 \\
\hline
\end{tabular}

$\mathrm{N}=$ número de exemplares

$A_{x}=a m p l i t u d e$ da variável x (menor - maior)

$\mathrm{b}=$ valor do coeficiente de regressão \pm seu desvio padrão

ln a = valor, em logarítmo natural, da constante de regressão \pm seu desvio padrão $\mathrm{r}^{2}=$ coeficiente de determinação

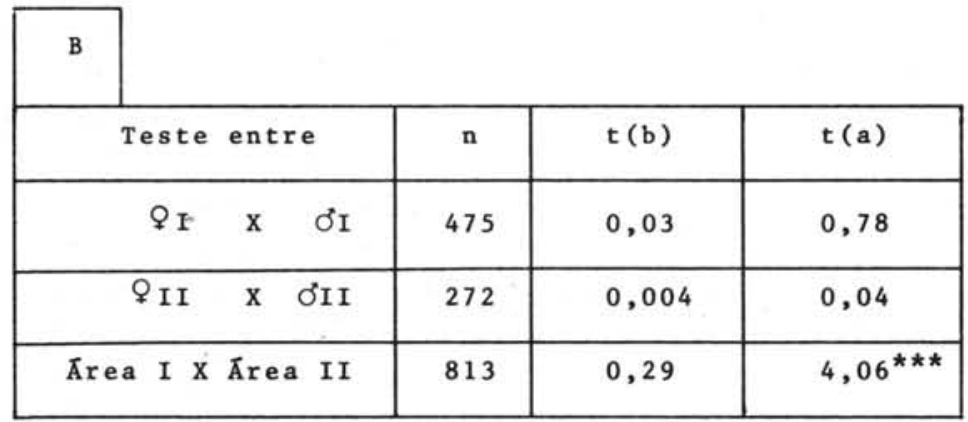

$\mathrm{n}=$ número total de exemplares

*** = significativo ao nivel de $0,1 \%$

Para número de séries de escamas acima da linha lateral e número de vértebras não foram construidos histogramas das distribuições de frequência, dada a grande diferença na frequência das duas classes que ocorrem, mostrada abaixo:

\begin{tabular}{crrr}
\hline \multirow{2}{*}{ Caráter } & \multirow{2}{*}{ No } & \multicolumn{2}{c}{ Frequência (no) } \\
& & Area I & Area II \\
\hline \multirow{2}{*}{ NsE1 } & 6 & 3 & 16 \\
\multirow{2}{*}{ NV } & 7 & 443 & 282 \\
& 23 & 1 & 1 \\
& 24 & 146 & 78 \\
\hline
\end{tabular}

IV - Os dados relativos às proporções corporais foram estudados através de anālise de regressão simples (Marr, 1955). Foram analisadas as regressões entre cabeça $x$ tronco, olho $x$ cabeça, focinho x cabeça, altura $x$ tronco, distância pré-anal x comprimento total, distância prē-dorsal x comprimento total e 
TABELA XIV - A) Distribuição bimensal de frequência de exemplares portadores de formaçôes ósseas anômalas;

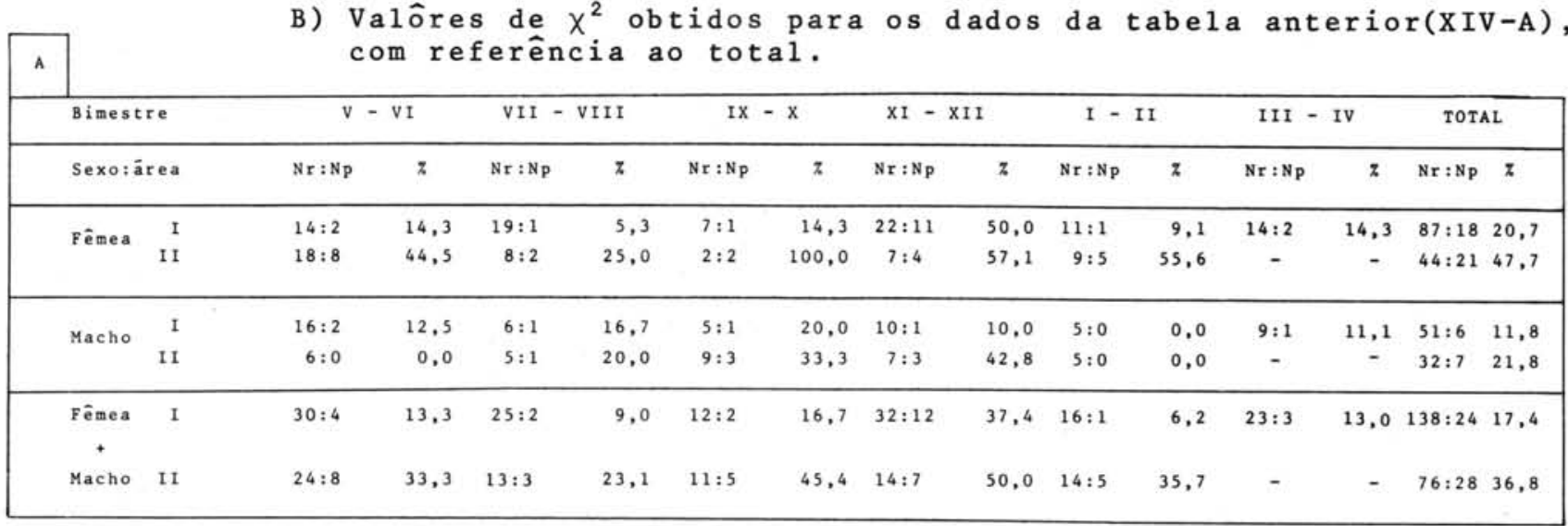

Nr:Np = número de exemplares radiografados : nümero de portadores de formaçōes ósseas anômalas.

\begin{tabular}{|c|c|c|}
\hline B & & \\
\hline Teste & entre & $x^{2}$ \\
\hline$\wp_{I}$ & $x \quad \delta I$ & 1,860 \\
\hline 911 & $x \delta 11$ & 3,336 \\
\hline$Q_{I}$ & $x Q_{11}$ & 4,400 * \\
\hline$\delta I$ & $x \sigma_{1 I}$ & 0,548 \\
\hline R̃rea I X & Ārea II & $5,160^{\star}$ \\
\hline
\end{tabular}

* - significativo ao nivel de $5 z$

TABELA XV - A) Distribuição bimensal do nümero médio de formações ōsseas anômalas por exemplar portador, por sexo, para as áreas I e II;

B) Valôres de $X^{2}$ obtidos para os dados da tabela anterior $(\mathrm{XV}-\mathrm{A})$, com referência ao total.

\begin{tabular}{|c|c|c|c|c|c|c|c|c|c|c|c|c|c|c|c|}
\hline \multirow{2}{*}{\multicolumn{2}{|c|}{$\begin{array}{l}\text { Bimestre } \\
\text { Area:Sexo }\end{array}$}} & \multicolumn{2}{|c|}{$V-V I$} & \multicolumn{2}{|c|}{ vII - vIII } & \multicolumn{2}{|c|}{$x I-x$} & \multicolumn{2}{|c|}{$X I-X I I$} & \multicolumn{2}{|c|}{$I-I I$} & \multicolumn{2}{|c|}{$I I I-I V$} & \multicolumn{2}{|c|}{ TOTAL } \\
\hline & & $N f: N p$ & $\overline{\mathrm{x}}$ & $N f: N p$ & $\overline{\mathrm{x}}$ & $N f: N p$ & $\bar{x}$ & $N f: N_{p}$ & $\overline{\mathrm{x}}$ & $N f: N p$ & $\overline{\mathrm{x}}$ & $\mathrm{Nf}: \mathrm{Np}$ & $\overline{\mathrm{x}}$ & $\mathrm{Nf}: \mathrm{Np}$ & $\overline{\mathrm{x}}$ \\
\hline \multirow{2}{*}{ I } & Fêmea & $3: 2$ & 1,5 & $1: 1$ & 1,0 & $1: 1$ & 1,0 & $40: 11$ & 3,6 & $2: 1$ & 2,0 & $3: 2$ & 1,5 & $50: 18$ & 2,8 \\
\hline & Macho & $2: 2$ & 1,0 & $1: 1$ & 1,0 & $2: 1$ & 2,0 & $4: 1$ & 4,0 & - & - & $3: 1$ & 3,0 & $12: 6$ & 2,0 \\
\hline & Fêmea & $27: 8$ & 3,4 & $6: 2$ & 3,0 & $5: 2$ & 2,5 & 11,4 & 2,8 & $26: 5$ & 5,2 & - & - & $75: 21$ & 3,6 \\
\hline & Macho & - & - & $2: 1$ & 2,0 & $4: 3$ & 1,3 & $4: 3$ & 1,3 & - & - & - & - & $10: 7$ & 1,4 \\
\hline \multirow{2}{*}{ Tota 1} & I & $5: 4$ & 1,2 & $2: 2$ & 1,0 & $3: 2$ & 1,5 & $44: 12$ & 3,7 & $2: 1$ & 2,0 & $6: 3$ & 2,0 & $62: 24$ & 2,6 \\
\hline & II & $27: 8$ & 3,4 & $8: 3$ & 2,7 & $9: 5$ & 1,8 & $15: 7$ & $2, i$ & $26: 5$ & 5,2 & - & - & $85: 28$ & 3,0 \\
\hline
\end{tabular}

Nf:Np - número de formaçōes ósseã anômalas : número de exemplares portadores

$\overline{\bar{x}}$ - número médio de formaçōes ósseas anômalas, por exemplar portador.

\begin{tabular}{|c|c|}
\hline \multicolumn{2}{|c|}{} \\
\hline Teste entre & $x^{2}$ \\
\hline QI $\times$ OI & 0,079 \\
\hline II $\times$ OOII & 1,944 \\
\hline QI X OII & 0,752 \\
\hline OI X OII & 0,017 \\
\hline R̃ea I X Ärea II & 0,436 \\
\hline
\end{tabular}


TABELA XVI - Resultados da anālise estatística dos diferentes caracteres merísticos de $M$. furnieri das āreas I e II

\begin{tabular}{|c|c|c|c|c|c|c|c|c|c|c|c|c|}
\hline Caräter & \multicolumn{2}{|c|}{$N_{r 2 d}$} & \multicolumn{2}{|c|}{$\mathrm{N}_{r} \mathrm{P}_{\mathrm{e}}$} & \multicolumn{2}{|c|}{$N \quad R$} & \multicolumn{2}{|c|}{$N_{e} L_{1}$} & \multicolumn{2}{|c|}{$\mathrm{N}_{\mathrm{s}} \mathrm{E}_{1}$} & \multicolumn{2}{|c|}{$\mathrm{N} V$} \\
\hline Ārea & I & II & I & II & 1 & II & I & II & I & II & I & II \\
\hline N & 511 & 318 & 508 & 308 & 485 & 304 & 391 & 278 & 446 & 298 & 147 & 79 \\
\hline A & $26-31$ & $25-32$ & $15-19$ & $15-19$ & $20-28$ & $21-28$ & $49-55$ & $50-55$ & $6-7$ & $6-7$ & $23-24$ & $23-24$ \\
\hline M & $\begin{array}{c}28,89 \\
\quad \pm \\
0,076\end{array}$ & $\begin{array}{c}28,80 \\
\pm \\
0,118\end{array}$ & $\begin{array}{c}17,34 \\
\pm \\
0,059\end{array}$ & $\begin{array}{c}17,26 \\
\pm \\
0,086\end{array}$ & $\begin{array}{c}24,60 \\
\pm \\
0,112\end{array}$ & $\begin{array}{c}24,86 \\
\pm \\
0,135\end{array}$ & $\begin{array}{c}52,39 \\
\pm \\
0,112\end{array}$ & $\begin{array}{c}52,22 \\
\pm \\
0,116\end{array}$ & $\begin{array}{c}6,99 \\
\pm \\
0,008\end{array}$ & $\begin{array}{c}6,49 \\
\pm \\
0,025\end{array}$ & $\begin{array}{c}23,99 \\
\pm \\
0,041\end{array}$ & $\begin{array}{c}23,99 \\
\pm \\
0,024\end{array}$ \\
\hline v & 3,08 & 3,72 & 3,92 & 4,40 & 5,04 & 4,87 & 2,14 & 1,86 & 1,20 & 3,31 & 1,08 & 0,46 \\
\hline$F$ & \multicolumn{2}{|c|}{1,82} & \multicolumn{2}{|c|}{2,04} & \multicolumn{2}{|c|}{$8,69^{\star *}$} & \multicolumn{2}{|c|}{$4,06^{\star}$} & \multicolumn{2}{|c|}{$16,66^{* \star *}$} & \multicolumn{2}{|c|}{0,00} \\
\hline
\end{tabular}

\footnotetext{
$\mathrm{N}=$ nümero de exemplares

$A=$ amplitude observada (menor-maior)

$M=$ média $t t$ (Student) vêzes seu desvio padrāo

$V=$ coeficiente de variabilidade

$F=$ valor de "F" obtido no teste entre äreas

* = significativo ao nivel de $5 z$

** = significativo ao nivel de 17

$* * *=s i g n i f i c a t i v o$ ao nivel de $0,1 \%$
}

TABELA XVII - Dados das regressões entre proporções corporais de M. furnieri das āreas I e II

\begin{tabular}{|c|c|c|c|c|c|c|c|c|}
\hline Regressão & Área & $\mathrm{N}$ & $A_{x}(m m)$ & & b & & a & $\mathrm{r}^{2}$ \\
\hline \multirow{2}{*}{$\mathrm{Lc} \times \mathrm{Tr}$} & I & 341 & $116-466 \mid$ & 0,3510 & $\pm 0,0035$ & | $-3,5804$ & $\pm 0,2149$ & 0,96 \\
\hline & I I & 315 & $167-565$ & $0,3586=$ & $\pm 0,0043$ & $-8,2165$ & $\pm 0,2408$ & 0,94 \\
\hline \multirow{2}{*}{ Do $x$ Lc } & I & 341 & $35-162$ & 0,1289 & $\pm 0,0026$ & 3,2956 & $\pm 0,2339$ & 0,86 \\
\hline & II & 315 & $52-184$ & 0,1194 & $\pm 0,0023$ & 3,1664 & $\pm 0,2355$ & 0,92 \\
\hline \multirow{2}{*}{ Lf $x$ Lc } & I & 341 & $35-162$ & 0,3492 & $\pm 0,0031$ & $-2,0792$ & $\pm 0,0236$ & 0,96 \\
\hline & II & 315 & $52-184$ & 0,3551 & $\pm 0,0030$ & $-2,5468$ & $\pm 0,2189$ & 0,96 \\
\hline \multirow[t]{2}{*}{$L d x L t$} & I & 341 & $151-628$ & 0,2823 & $\pm 0,0039$ & $-6,9397$ & $\pm 0,2125$ & 0,92 \\
\hline & I I & 315 & $219-749$ & $0,2937=$ & $\pm 0,0028$ & $-13,2997=$ & $\pm 0,2358$ & 0,96 \\
\hline \multirow{2}{*}{$\mathrm{La} \times \mathrm{Lt}$} & I & 341 & $151-628$ & 0,5782 & $\pm 0,0044$ & $-10,1028 \pm$ & $\pm 0,2125$ & 0,98 \\
\hline & I I & 315 & $219-749$ & 0,5855 & $\pm 0,0059$ & $-12,3926 \pm$ & $\pm 0,2358$ & 0,96 \\
\hline \multirow{2}{*}{$E \times L t$} & I & 323 & $151-628$ & 0,0122 & $\pm 0,0005$ & $0,4912 \pm$ & $0,2169 \mid$ & 0,67 \\
\hline & II & 272 & $219-749$ & 0,0107 & $\pm 0,0007$ & $1,9271 \pm$ & 0,25541 & 0,49 \\
\hline
\end{tabular}

$N=$ número de exemplares

$A_{x}=$ amplitude da variável x (menor-maior)

$b=$ valor do coeficiente de regressão \pm seu desvio padrão

$a=$ valor da constante de regressão \pm seu desvio padrão

$\mathrm{r}^{2}=$ coeficiente de determinação 
TABELA XVIII - Resultados do teste de "t" aplicado às regressões entre pares de proporções corporais, entre as áreas I e II

\begin{tabular}{|c|c|c|c|}
\hline Regressão & $\mathrm{n}$ & $\mathrm{t}(\mathrm{b})$ & $\mathrm{t}(\mathrm{a})$ \\
\hline Lc $\times \mathrm{Tr}$ & 656 & 0,27 & $11,89^{* *}$ \\
\hline Do $\times$ Lc & 656 & 0,83 & 0,91 \\
\hline Lf $\times$ Lc & 656 & 0,21 & $2,01^{*}$ \\
\hline Ld $\times$ Lt & 656 & 0,49 & $15,51^{* *}$ \\
\hline La $\times$ Lt & 656 & 0,16 & $3,94^{* * *}$ \\
\hline E $\times$ Lt & 595 & 1,23 & $14,77^{* * *}$ \\
\hline
\end{tabular}

$\mathrm{n}=$ número total de exemplares

* = significativo ao nivel de $5 \%$

$* * *=$ significativo ao nível de $0,1 \%$

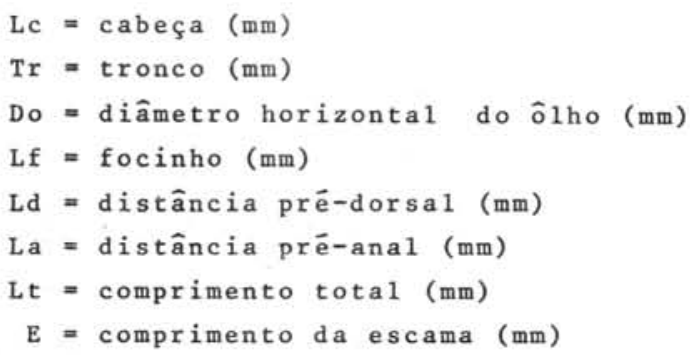

comprimento da escama $x$ comprimento total. Foram ajustadas aos dados equações do 19 e 29 grau, pelo método dos mínimos quadrados. A análise de variância provou serem todas as regressões, lineares (19 grau). As regressões foram calculadas por sexo, bimestre e sub-ärea; através do teste de "t" foram testadas entre sexos por bimestre e sub-área, entre sub-äreas dentro de cada bimestre e entre bimestres dentro de cada sub-área. Com base nos resultados, os dados foram grupados para a área I e ārea II (Tabs.XVII e XVIII, Figs. 33 a 38 ).

A Figura 39 representa a variação das temperaturas médias a 10 metros de profundidade, durante o ano, nas āreas I e II. Os dados para a ārea I foram obtidos de Leinebl (1969) e referem-se às temperaturas médias na posição 25007,9's - 47048,4'W (Bom Abrigo) no período janeiro de 1958 a janeiro de 1961; para a área II, os dados foram obtidos de Miranda (1969) e referem-se à amplitude de variação da temperatura na região entre $29^{\circ}-33^{\circ} \mathrm{S}$ (Torres-Chui), tendo sido coletados no período de abril de 1968 a março de 1969.

\section{RESULTADOS}

\section{I - REPRODUÇÃO E CRESCIMENTO}

A - REPRODUÇÃo - Para as duas āreas consideradas, a maior frequência de indivíduos com gônadas esvaziadas (estádio D) não ocorre logo após a época 
de maior frequência de indivíduos maduros (estádio $C$ ), mas sim após a máxima de indivíduos em maturação (estādio B). Nessa época há acentuada queda de frequência de $B$, e não ocorre aumento da de $C$, portanto, não há desenvolvimento de B para C (Fig. 14). Tal observação ratifica conclusão anterior (Vazzoler, 1970) de que Micropogon furnieri apresenta desova parcelada, ou seja, que ocorre mais de uma desova dentro de cada período de reprodução. A gônada matura,ocorre eliminação de uma parte dos óvulos (os que atingiram densenvolvimento tota1) e a gônada retorna para o estádio B, ocorrendo a seguir a maturação da outra parte dos óvulos, que são eliminados, passando a gônada para o estádio D. A desova, assim, ocorre em lotes.
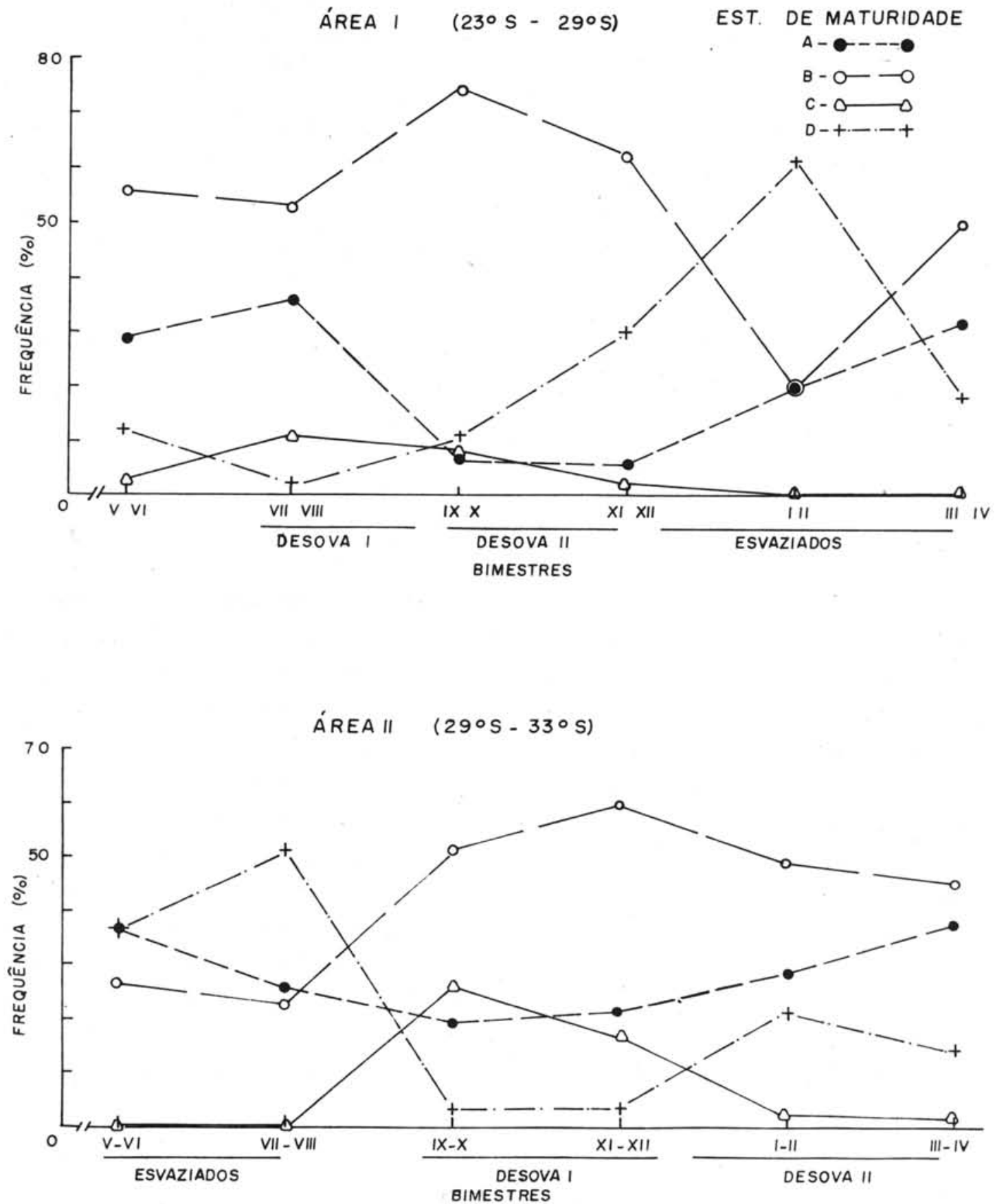

FIG. 14 - Distribuições bimensais de frequência (\%) dos quatro estádios de maturidade, para os dois sexos grupados, para as áreas I e II 
As gônadas que já sofreram uma desova parcial (e que ainda irão eliminar outro lote de óvulos) não apresentam-se com as características descritas em "Material e Métodos" (p. 16) para o estádio C; por isso estão classificadas como pertencentes ao estádio B. Devido a esse fato é que a frequência máxima de D ocorre após a máxima de B. Na ocasião do início da coleta dos dados não tínhamos indicações que pudessem sugerir uma escala com mais estádios,que resultariam do desdobramento dos estádios B e C em B1 e B2 e C1 e C2, respectivamente. Assim, o que ocorre durante o desenvolvimento das gônadas, pode ser esquematizado como segue:

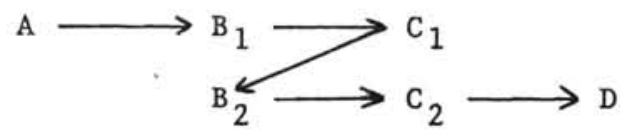

(Desova I)

(Desova II)

Entretanto, tal fato não impossibilita conclusões sobre o período de reprodução de Micropogon furnieri nas duas äreas consideradas.

Para a ārea I a desova inicia-se no bimestre VII-VIII, estendendo-se até XI-XII, ocorrendo indivíduos com gônadas esvaziadas (D) no período XI-XII a III-IV, atingindo a frequência máxima em I-II. Para a área II a desova iniciase no bimestre IX-X estendendo-se até III-IV, sendo que os indivíduos com gônadas em estádio D ocorrem no período V-VI/VII-VIII, com frequência máxima neste bimestre (Fig. 14).

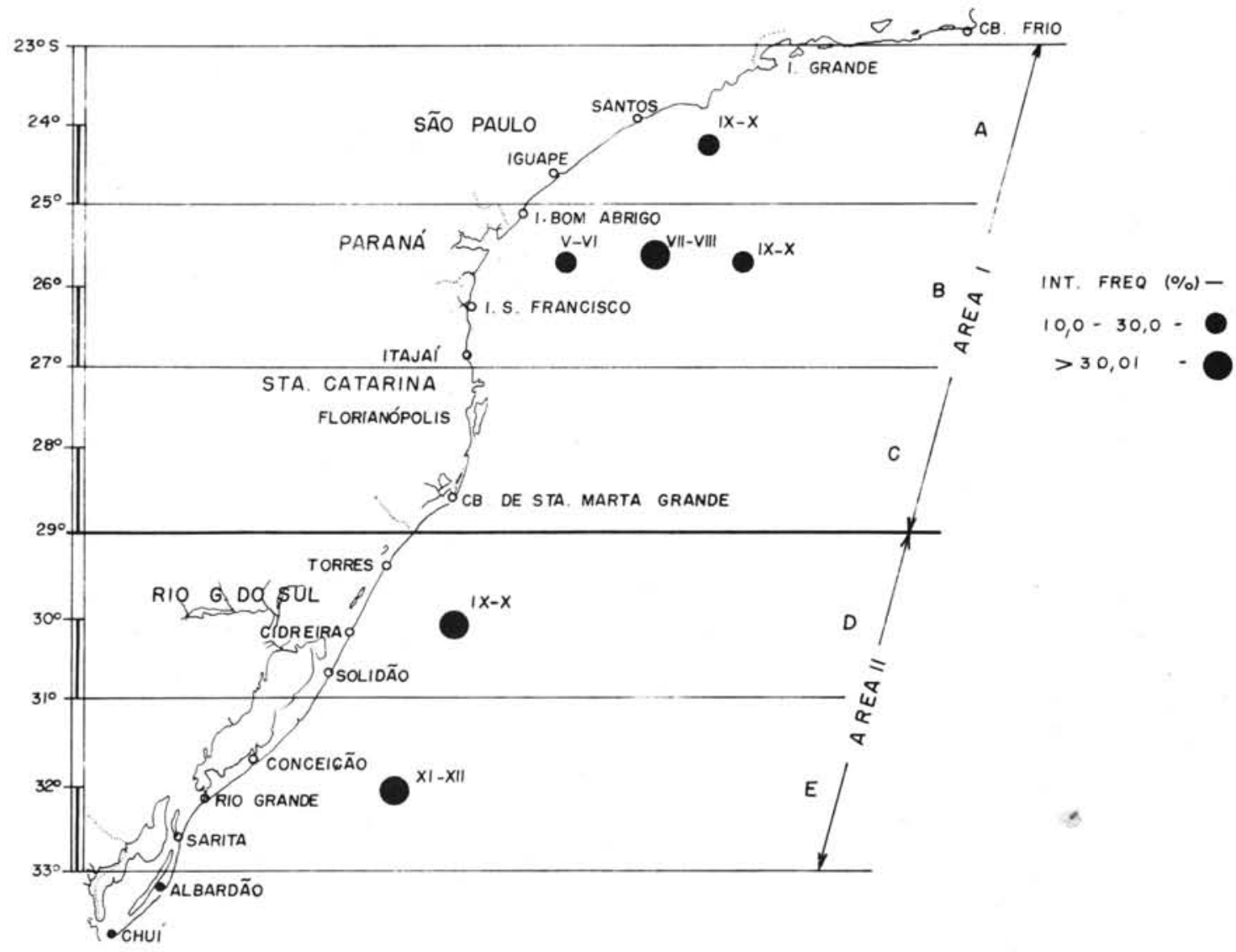

FIG. 15 - Distribuição de frequência ( $>10 \%$ ) dos indivíduos com gônadas maduras (estádio C), no espaço (sub-áreas) e no tempo (bimestres)

Bolm Inst. oceanogr. S Paulo, 20 (2): 1-70, 1971 
vê-se que Micropogon furnieri, apresenta períodos de reprodução distintos nas duas áreas, segundo o esquema abaixo:

Brimestre II

Desse modo, a reprodução ocorre na ärea I durante o inverno e primavera, e na ārea II durante a primavera e verão.

Na ārea I a maior frequência de indivíduos com gônadas maduras ocorre no bimestre VII-VIII, na sub-ärea B (ilha do Bom Abrigo, ilha de São Francisco), enquanto que na área II ocorre durante IX-X/XI-XII, nas sub-äreas $D$ e E, sendo que esses indivíduos ocorrem em IX-X na sub-área D e em XI-XII na sub-área E (região da barra do Rio Grande). Na sub-ärea C não ocorreunenhumindivíduo maduro (estádio C) durante todo o período estudado (Fig. 15). Os indivíduos com gônadas esvaziadas (estádio D) ocorrem ao longo das cinco sub-áreas consideradas, com maior frequência, dentro da área I, nos bimestres XI-XII/I-II, na subārea B e, dentro da ārea II, nos bimestres V-VI/VII-VIII, na sub-ärea D. Pela época do ano em que ocorrem indivíduos em estádio D na sub-área C ( bimestre XI-XII e III-IV), conclue-se que são indivíduos que desovam dentro da ärea I (desova de inverno-primavera); observa-se ainda que não ocorre penetração na sub-ārea C de indivíduos em estádio D provenientes da área II (desova de primavera-verão) (Fig. 16).

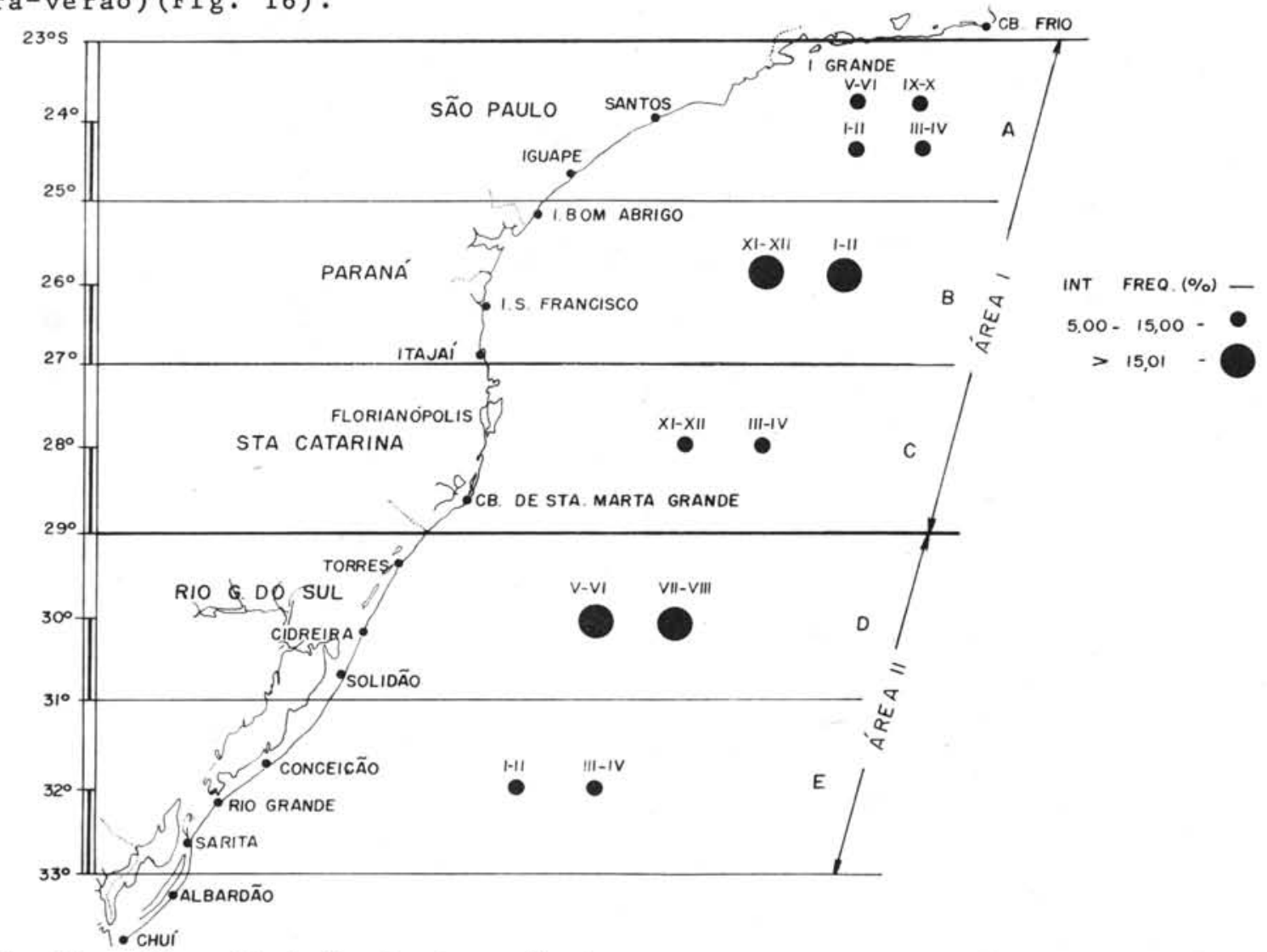

FIG. 16 - Distribuição de frequência ( $>5 \%$ ) dos indivíduos com gônadas esvaziadas (estádio D), no espaço (sub-äreas) e no tempo (bimestres) 
Os comprimentos totais médios (mm) nos quais $50 \%$ da população inicia a primeira maturação sexual ( $\mathrm{L}_{\mathrm{m}}$ ) e os comprimentos totais (mm) nos quais toda a população está adulta $\left(L_{100 \%}\right)$ são, respectivamente (Fig. 17):

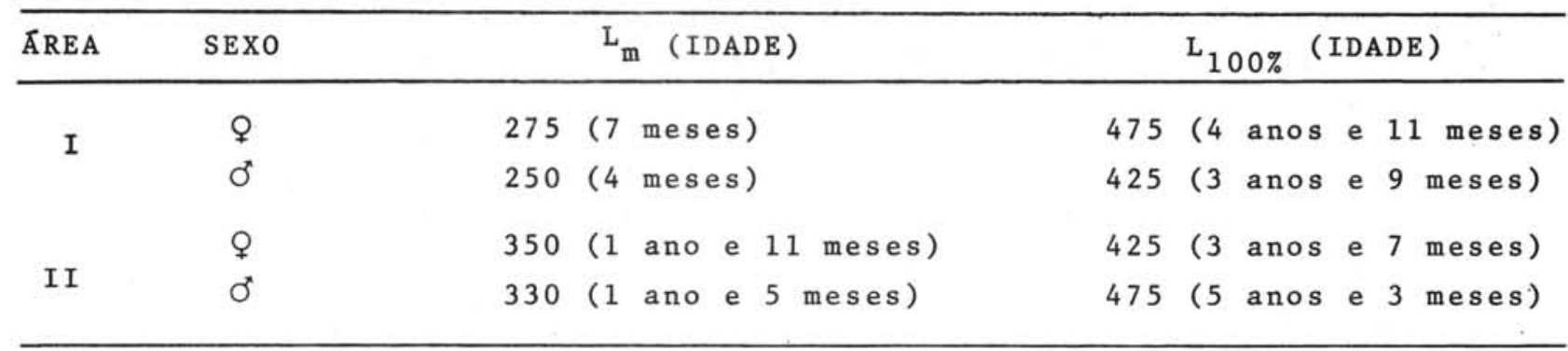

Comparando-se os valores obtidos para $\mathrm{L}_{\mathrm{m}}$ e $\mathrm{L}_{100 \%}$, com os obtidos no estudo sobre crescimento (Fig. 22), vemos que o processo inicia-se em idades distintas para os dois sexos nas duas äreas, completando-se em intervalos diferentes, sendo que para as fêmeas da área II o processo é acentuadamente mais rāpido.

Os resultados mostram claramente a diferença existente entre o gue ocorre com M. furnieri das āreas I e II; na ärea I a primeira maturação inicia-se em exemplares mais jovens que na II. Entretanto, o processo de maturação da população é mais rápido na ārea II, principalmente para fêmeas.

A entrada de jovens ocorre na ärea I, principalmente, no bimestre V-VI (outono), com outra entrada pouco intensa nos bimestres IX-X/XI/XII, enquanto que na ärea II o período principal são os bimestres III-IV/V-VI (verão-outono), com um período secundārio em IX-X. A ocorrência de várias modas é devida à desova parcelada (Fig. 18).

Há variação semelhante no peso dos ovários por classe de comprimento, nos quatro estādios de maturidade, para as duas āreas; há um aumento no peso com o desenvolvimento dos ovários (maturação) e com o crescimento do peixe, e uma queda com a desova (Fig. 19). Tal fato mostra que, apesar de terem sido considerados apenas quatro estádios e de ocorrer desova parcelada, a caracterização feita para cada estádio é vālida, pois se as gônadas parcialmente esvaziadas tivessem sido classificadas no estádio D, não haveria queda tão acentuada no peso para esse estádio.

B - CRESCIMENTo - Os anéis de crescimento das escamas formam-se em épocas distintas nas duas äreas (Fig. 20). Na área I formam-se durante o verão (bimestres I-II/III-IV), enquanto que na ärea II formam-se durante o fim do outono e inverno (bimestres V-VI/VII-VIII). Nota-se ainda que a ocorrência de indivíduos da classe de 0 anel verifica-se na ārea I, do fim do verão ao início da primavera (III-IV a IX-X), e na ärea II, do fim do inverno ao início do outono (IX-X a III-IV).

A Figura 21 mostra as relações entre $L_{t+1}$ e $L_{t}$ (entre o comprimento para uma determinada idade e o comprimento na idade anterior) entre sexos por área 


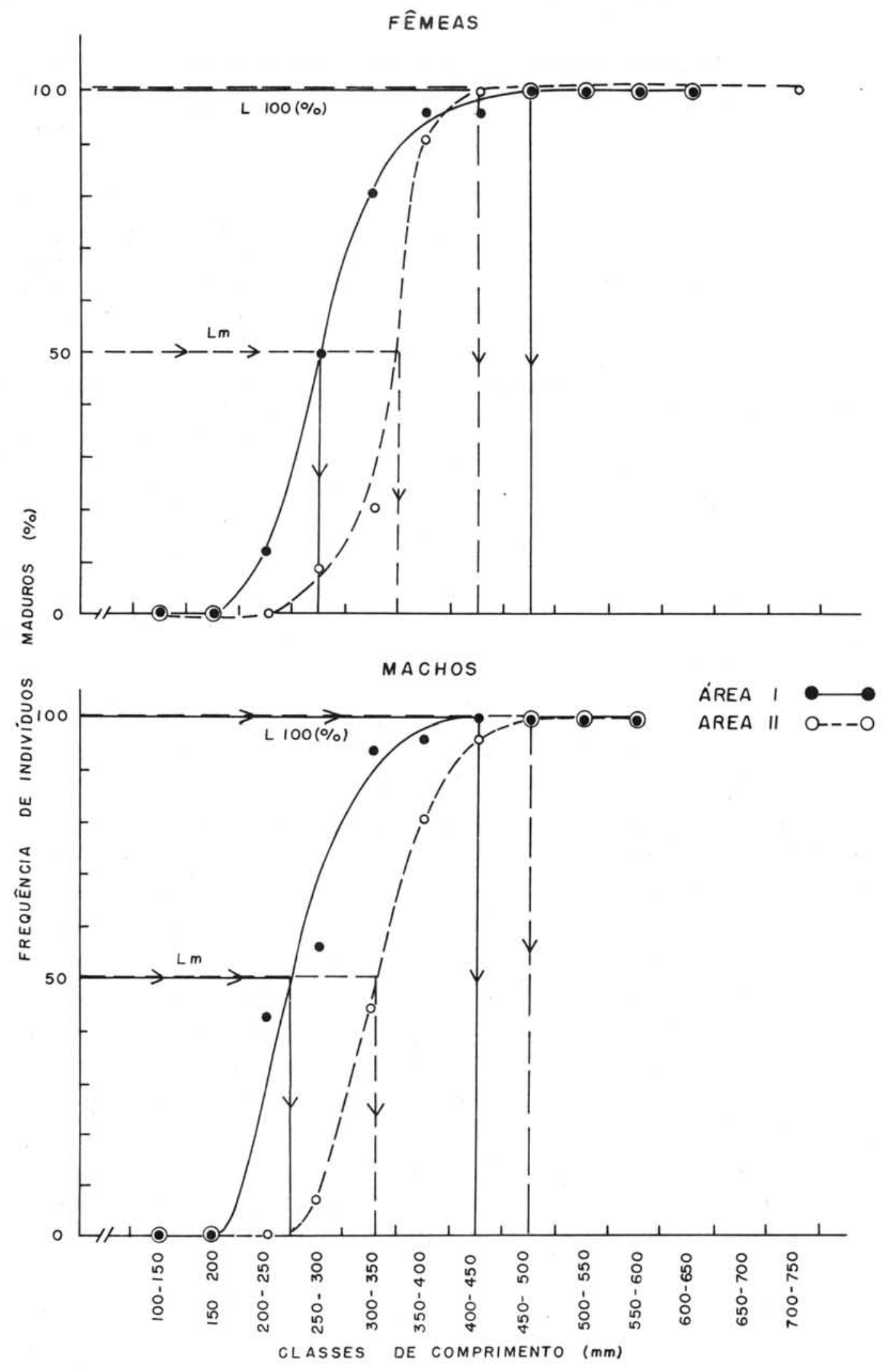

FIG. 17 - Distribuição por classe de comprimento da frequência de fêmeas e machos adultos (estádio B, C, D), para as áreas I e II 


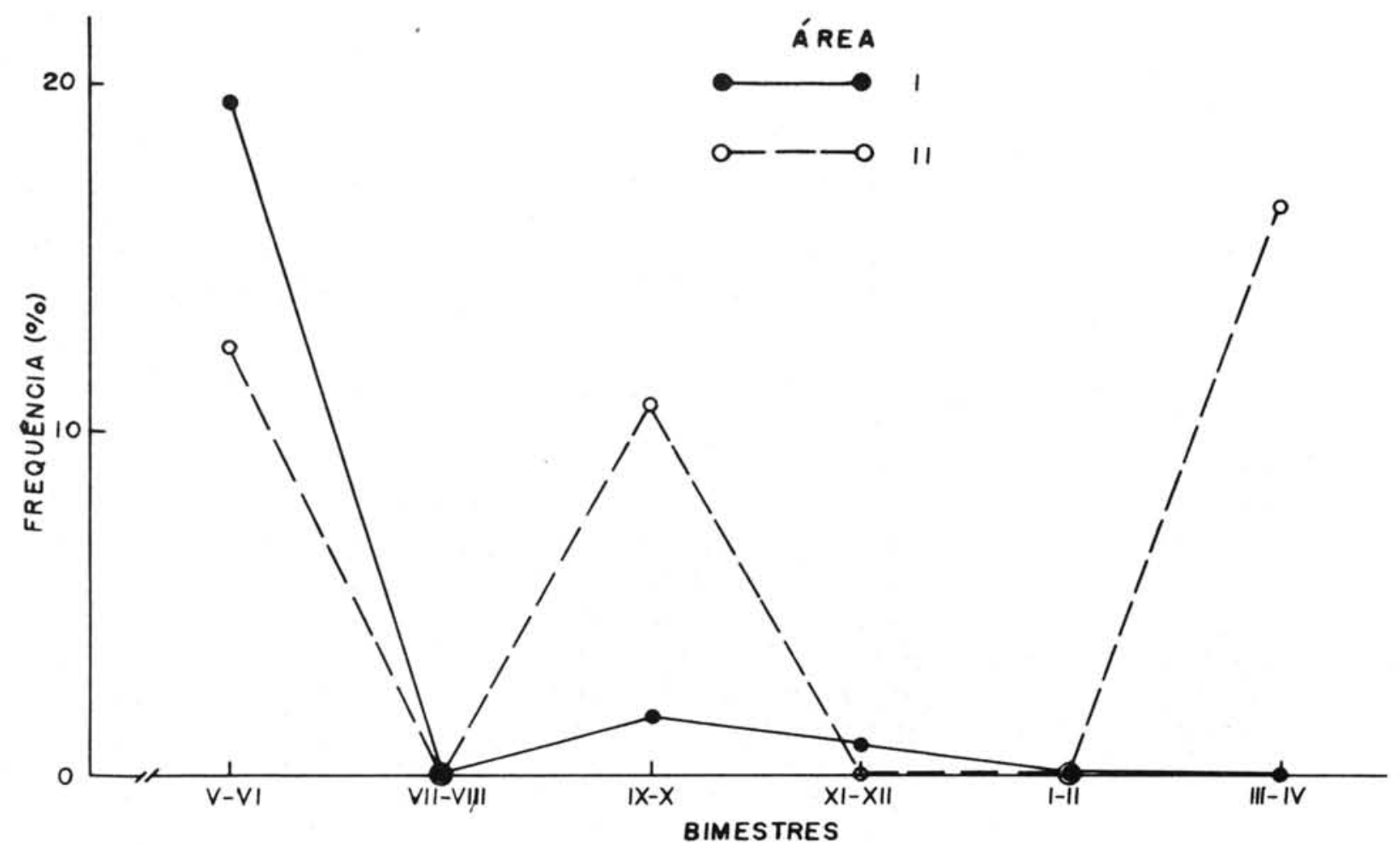

FIG. 18 - Distribuição de frequência de indivíduos jovens (gônadas indiferenciadas) em relação ao número total de indivíduos amostrados, por bimestre e por àrea

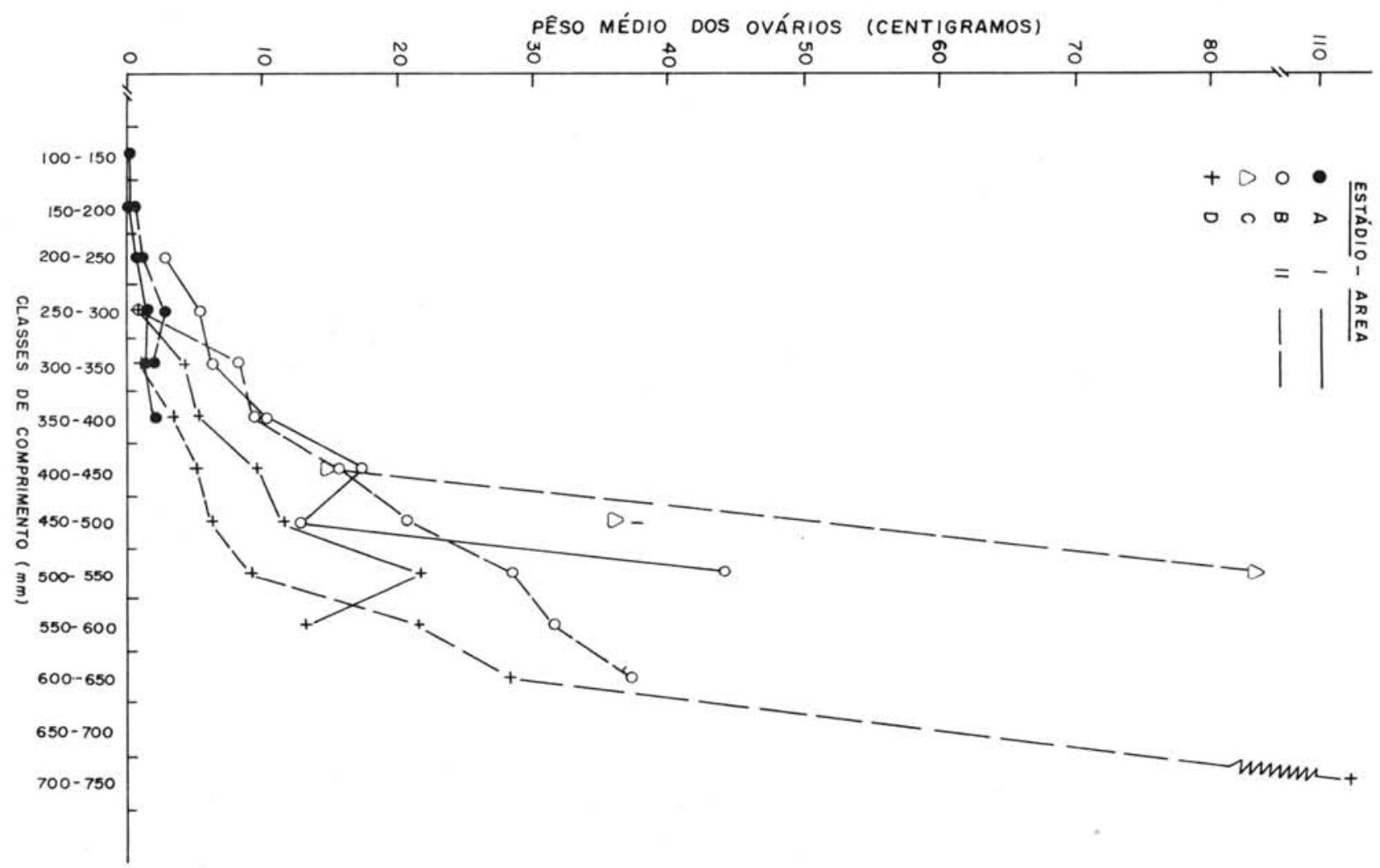

FIG. 19 - Distribuição gráfica da variação do pêso dos ovários nos quatro estádios de maturidade, por classe de comprimento e área 

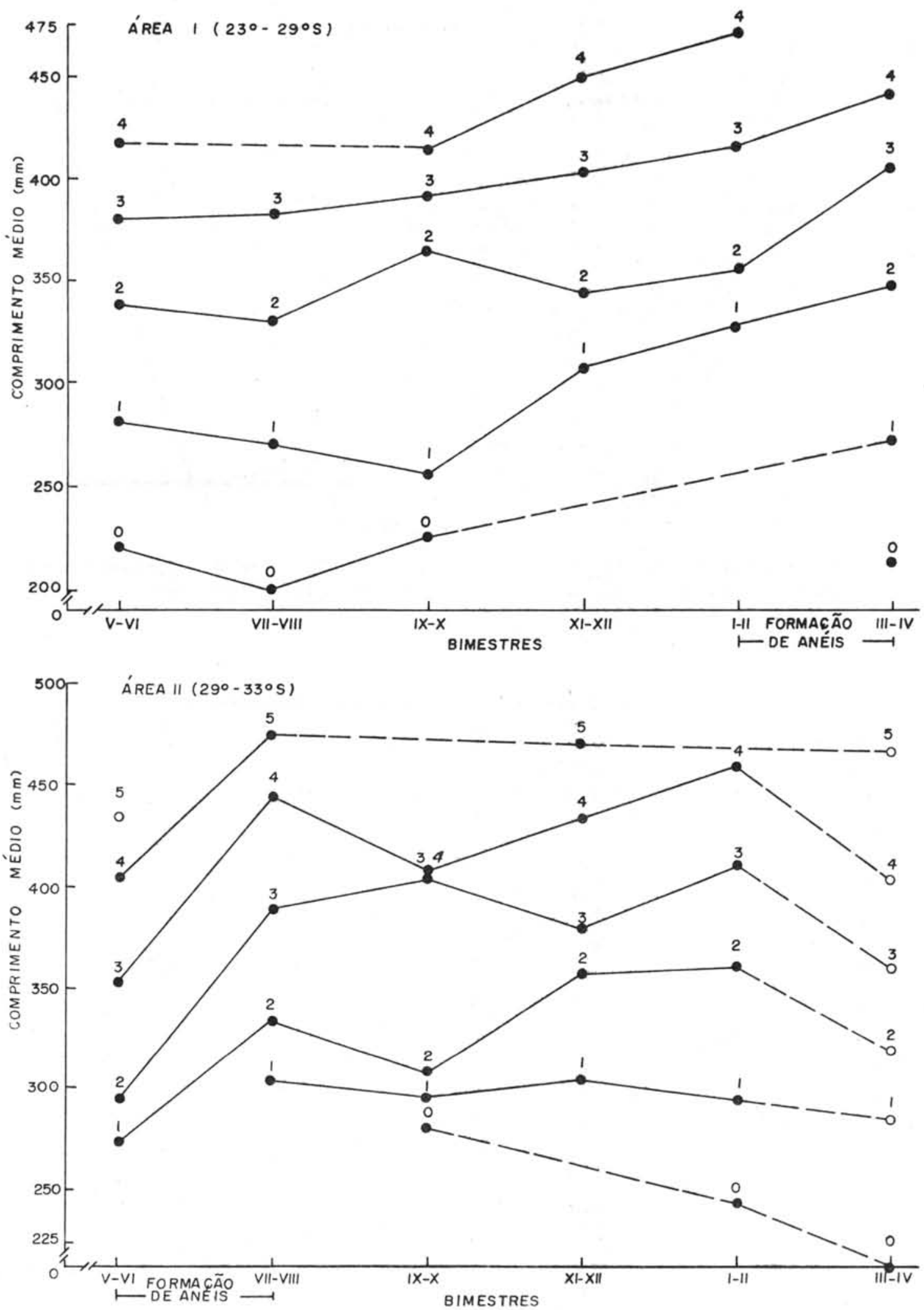

FIG. 20 - Distribuição bimensal das médias de comprimento total ( $\left.\overline{\mathrm{L}}_{\mathrm{t}}\right)$
por classe de idade, para as ăreas I e II 
e entre āreas por sexo. Observa-se que nas duas área as fêmeas apresentam relação mais elevada que os machos, nas fases iniciais. Comparando-se as regressões de um sexo entre āreas, observamos que as fêmeas da àrea I apresentam relação mais elevada nas, fases iniciais, enquanto que para machos a relação é sempre mais elevada para os da ārea I. Ocorrem diferenças significativas entre sexos dentro de cada área, e entre äreas para cada sexo, Assim, cada sexo, em cada ārea, apresenta suas próprias características de crescimento (Tab.X-B).

Calculadas as curvas de crescimento, obtivemos os seguintes resultados:

$\begin{array}{cccccc}\text { Area } & \text { Sexo } & \mathrm{N} & \mathrm{L}_{\infty}(\mathrm{mm}) & \mathrm{k} & \mathrm{t}_{\circ} \\ \text { I } & \text { O } & 236 & 601,0 & 0,219 & -2,08 \\ & \sigma^{*} & 188 & 829,0 & 0,106 & -2,97 \\ & \text { O } & 122 & 693,3 & 0,149 & -2,79 \\ \text { II } & \sigma^{*} & 102 & 895,7 & 0,076 & -4,64\end{array}$

$\mathrm{N}=\mathrm{nu}$ üero de exemplares considerados

$\mathrm{L}_{\infty}=$ assintota do comprimento corporal, quando a idade aumenta indefinidamente

$\mathrm{k}=\mathrm{taxa}$ de crescimento

$t_{0}=$ idade inicial

As curvas de crescimento (Fig. 22) mostram que para a ārea I as fêmeas apresentam crescimento mais intenso que os machos desde idade inferior a um ano; na ārea II os machos, até 2 anos, apresentam crescimento mais intenso, invertendo-se a situação a partir dessa idade. Comparando-se estes resultados com os obtidos para comprimento médio do início da primeira maturação sexual $\left(L_{m}\right)$, vemos que as mudanças no crescimento ocorrem durante a primeira maturação sexual (Barlow, 1961).

Os valores obtidos para k mostram que M. furnieri da ärea I apresenta crescimento mais intenso, o que determina um período de vida mais curto (idades menos avançadas) e valores de $L_{\infty}$ mais baixos que na ärea II.

A anālise das regressões entre logarítmo dos pesos totais médios e logarítmo da idade (Fig. 23) mostra não ocorrerem diferenças significativas entre exemplares das duas áreas (Tab. XII-B). Assim, o crescimento em pesoé seme1hante para $M$. furnieri de toda ärea estudada (230s a $33^{\circ} \mathrm{S}$ ).

A anāilse das regressões entre logarítmo do peso total e logarítmo do comprimento total mostra ocorrerem diferenças significativas entre exemplares das duas äreas (Tab XIII-B); para uma mesma classe de comprimento os exemplares da ārea II possuem peso mais elevado que os da ārea I (Fig. 24).

\section{II - FORMAÇÕES OSSEAS ANÔMALAS DO ESQUELETO}

As formações ósseas anômalas em $M$. furnieri ocorrem sobre o corpo de uma ou mais vértebras, fundindo-as (Figs.9A e 10B-a), nos pterigióforos da nadaBolm Inst. oceanogr. S Paulo, 20 (2): 1-70, 1971 

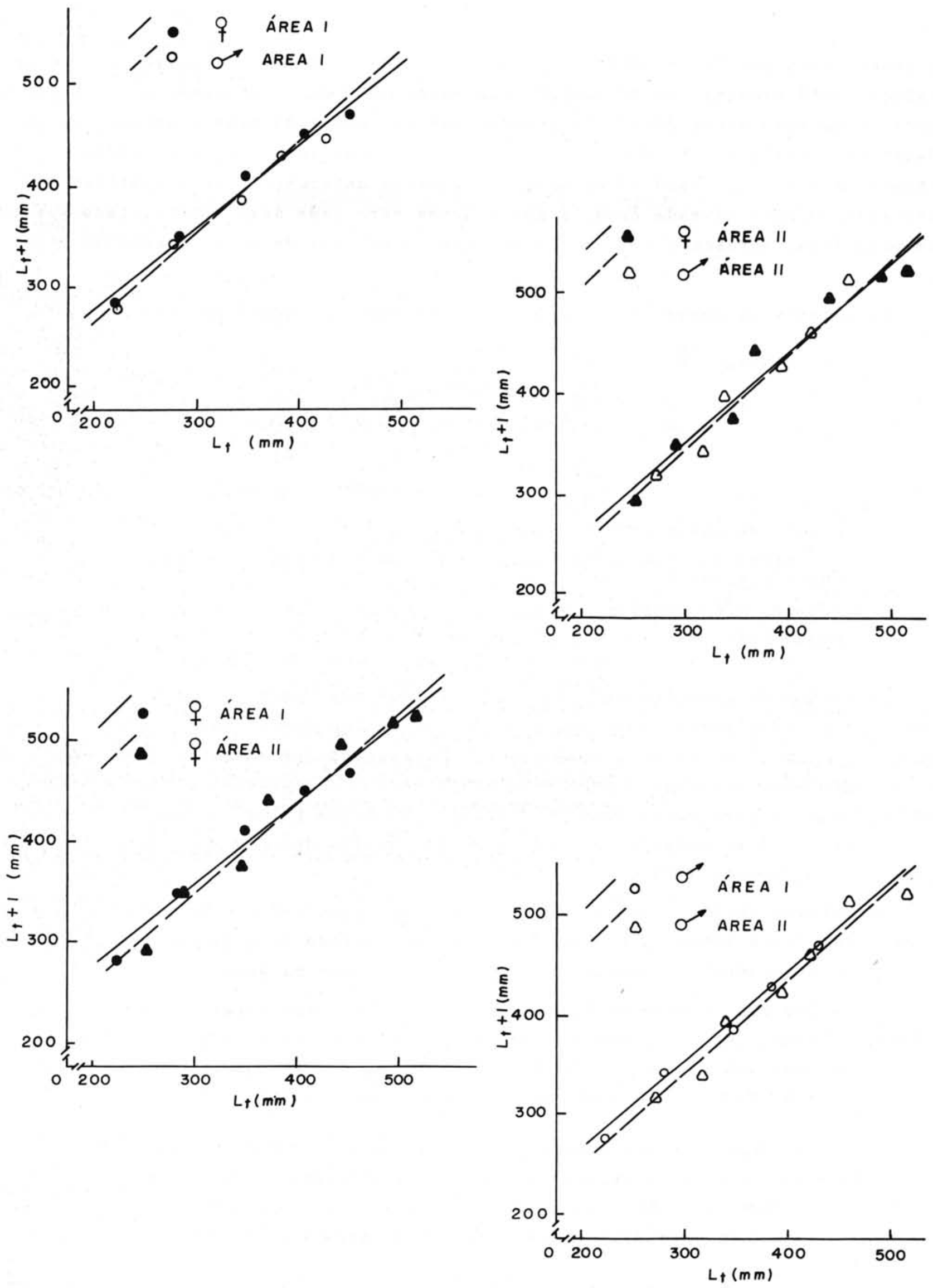

FIG. 21 - Representação gráfica da relação entre $\mathrm{L}_{\mathrm{t}+1}$ e $\mathrm{L}_{\mathrm{t}}$ de $M$. furnieri, entre sexos por área, e entre áreas por sexo 

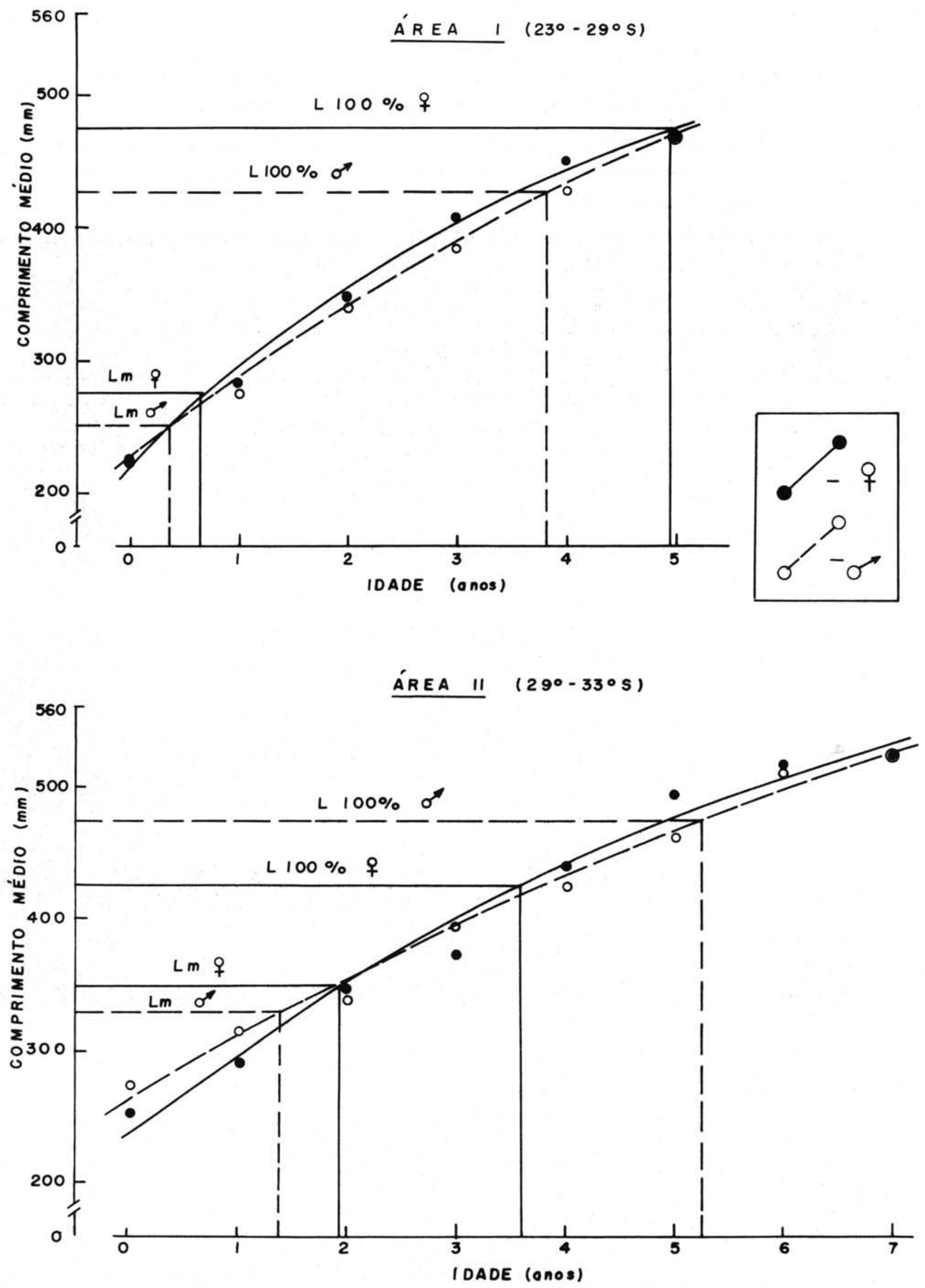

FIG. 22 - Curvas de crescimento em comprimento de fêmeas e machos de M. furnieri das äreas I e II, e indicação dos comprimentos totais médios do início ( $\left.\mathrm{L}_{\mathrm{m}}\right)$ e conclusão ( $\mathrm{L}_{100 \%}$ ) do processo de maturação sexual, por sexo e ārea 
deira dorsal (Figs.9B e 10A) e como formaçóes ósseas que partem do corpo da vértebra nas costelas epipleurais (Figs. 5, 9B, 10A, 10B-b).

Radiografias de exemplares portadores de tais formações mostram que nas fases iniciais de desenvolvimento, estas apresentam-se como um tecido esponjoso que circunda o osso sobre o qual se desenvolvem(Fig. 10A-pterigióforos ), tornando-se mais denso com o crescimento (Fig. 10A - formação partindo do corpo da vértebra) mas, mantendo estrutura esponjosa (Fig. 10B-c).

Quando sobre o corpo da vértebra, ocorrem sempre em vértebras abdominais; nas costelas epipleurais localizam-se sempre nas que partem do corpo da 8 a

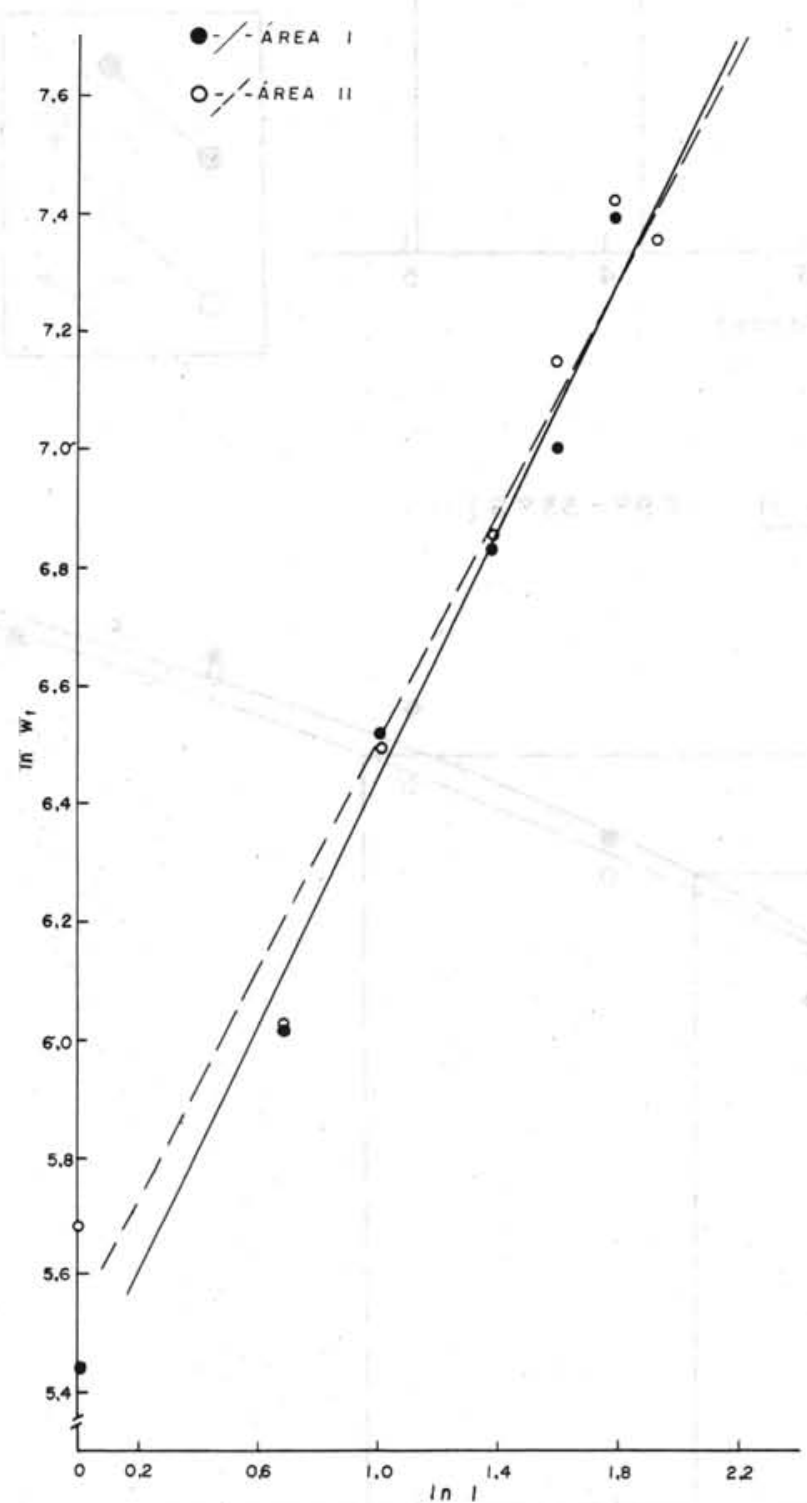

FIG. 23 - Representação gräfica da relação entre logarítmo do pêso mëdio ( $\ln \bar{W}_{t}$ ) e logaritmo da idade (In I), para $M$. furnieri das äreas I e II

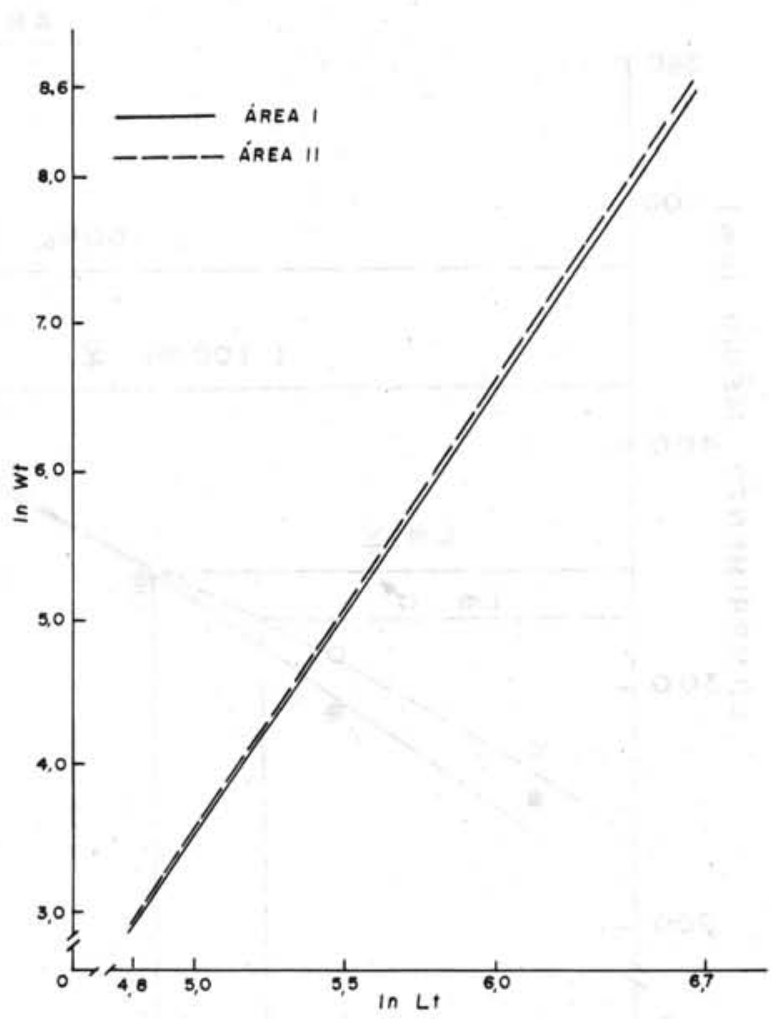

FIG. 24 - Representação gräfica da rellação entre logarítmo do pêso total ( 1 n $W_{t}$ ) e logaritmo do comprimento total ( $1 \mathrm{n} L_{t}$ ) de $M$. furnieri das äreas ${ }^{t} I$ e II 
vērtebra (inclusive o atlas), de um ou de ambos os lados, sendo estas as que atingem maiores tamanhos. Sua forma e número em cada exemplar, são extremamente variāveis.

A frequência de exemplares portadores dessas anomalias aumenta com o comprimento (Fig. 25), não tendo sido constatadas em exemplares de comprimentos inferiores ao da primeira maturação sexual. Entretanto, não há relação entre o comprimento do exemplar e o número de formações (Fig. 26).

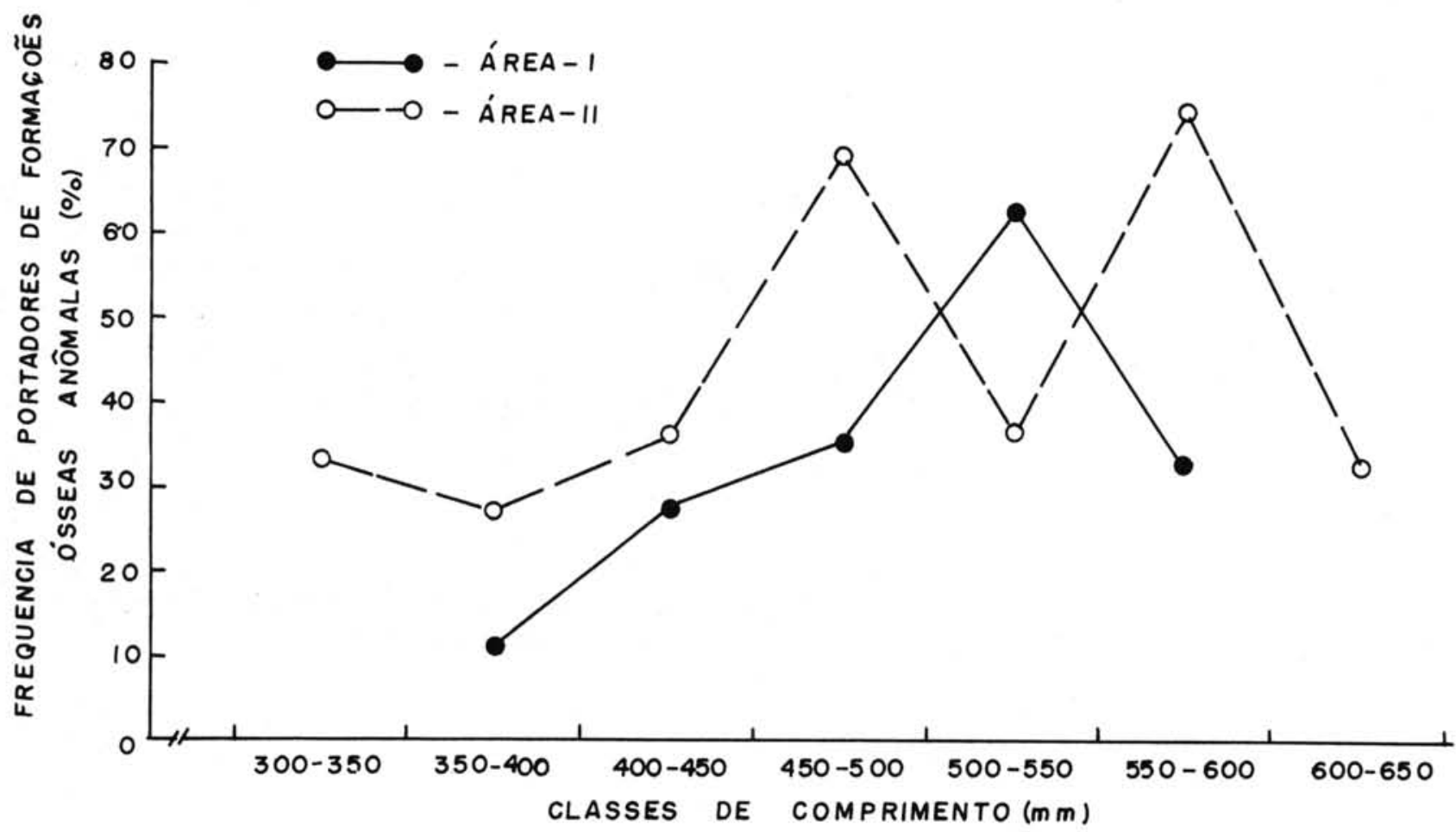

FIG. 25 - Frequência (\%) de portadores de formações ósseas anômalas, por classe de comprimento e por área

Não há diferença significativa entre a frequência de fêmeas e de machos portadores dentro de cada área; considerando-se os sexos grupados, a frequência de portadores é significativamente mais elevada na ārea II $(36,8 \%)$ que na ārea I $(17,4 \%)$, devido à diferença significativa entre a frequência de fêmeas portadoras, nas duas áreas (Fig. 27; Tab. XIV-B).

A anālise do número médio de formações por exemplar portador mostra não ocorrerem diferenças significativas (Tab. XV-B). Entretanto, o número médio de formações por exemplar portador é ligeiramente mais elevado para a área II $(2,6: 3,0)$. Relativamente aos sexos, esse número é mais elevado para fêmeas, e dentre estas para as da área II $(2,8: 3,6)$ enquanto que para machos é mais elevado para os da área I (2,0:1,4) (Fig. 28).

Bolm Inst. oceanogr. S Paulo, 20 (2): 1-70, 1971 
A anālise da frequência de portadores durante o ano nas duas áreas (Tab. XIV-A; Fig. 29), mostra que esta é sempre superior para a ärea II, havendo um paralelismo nas variações das duas āreas; isso sugere não ocorrer penetração de exemplares de uma área para outra.

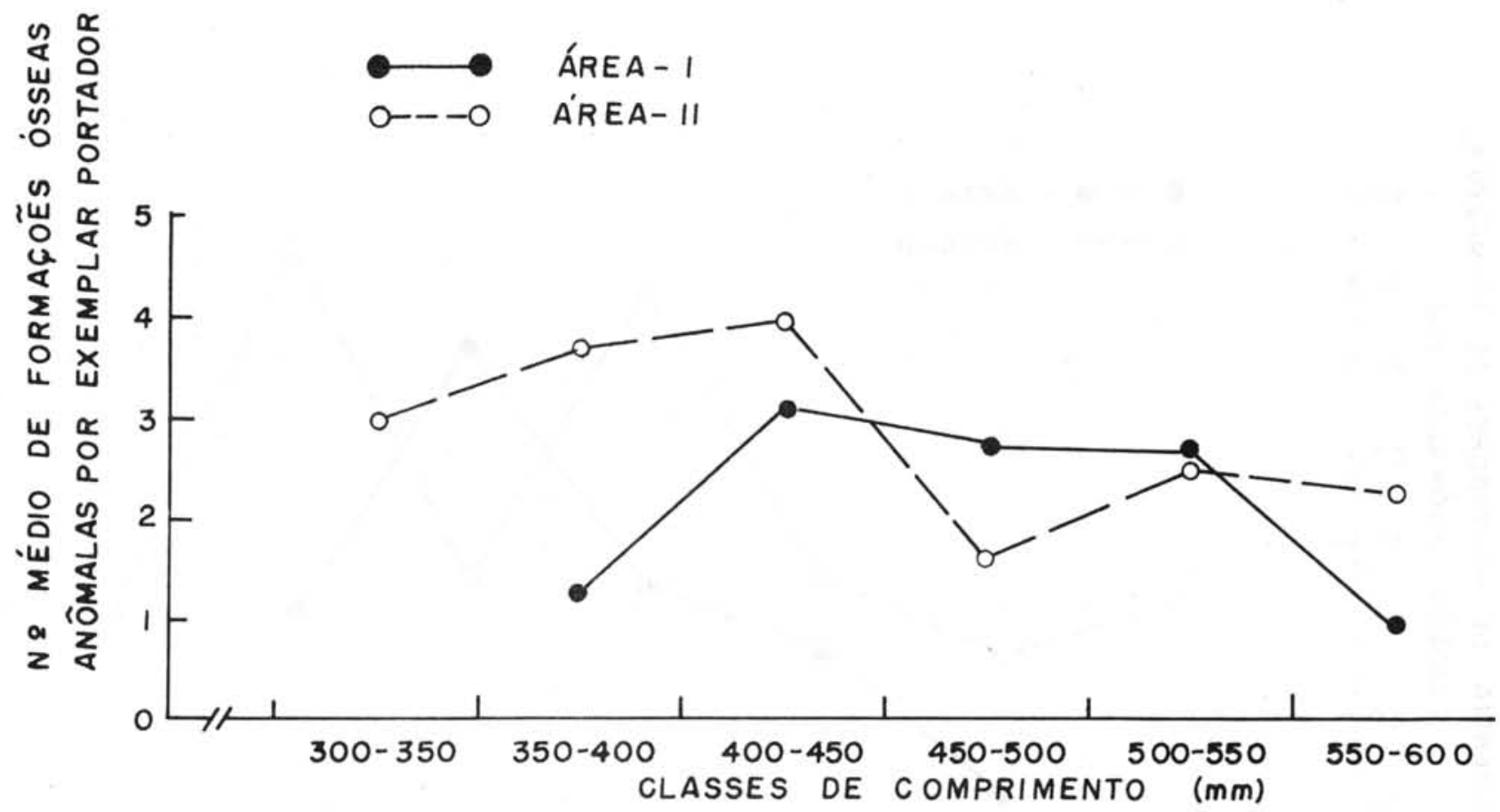

FIG. 26 - Número médio de formações ósseas anômalas por exemplar, por classe de comprimento e por ärea

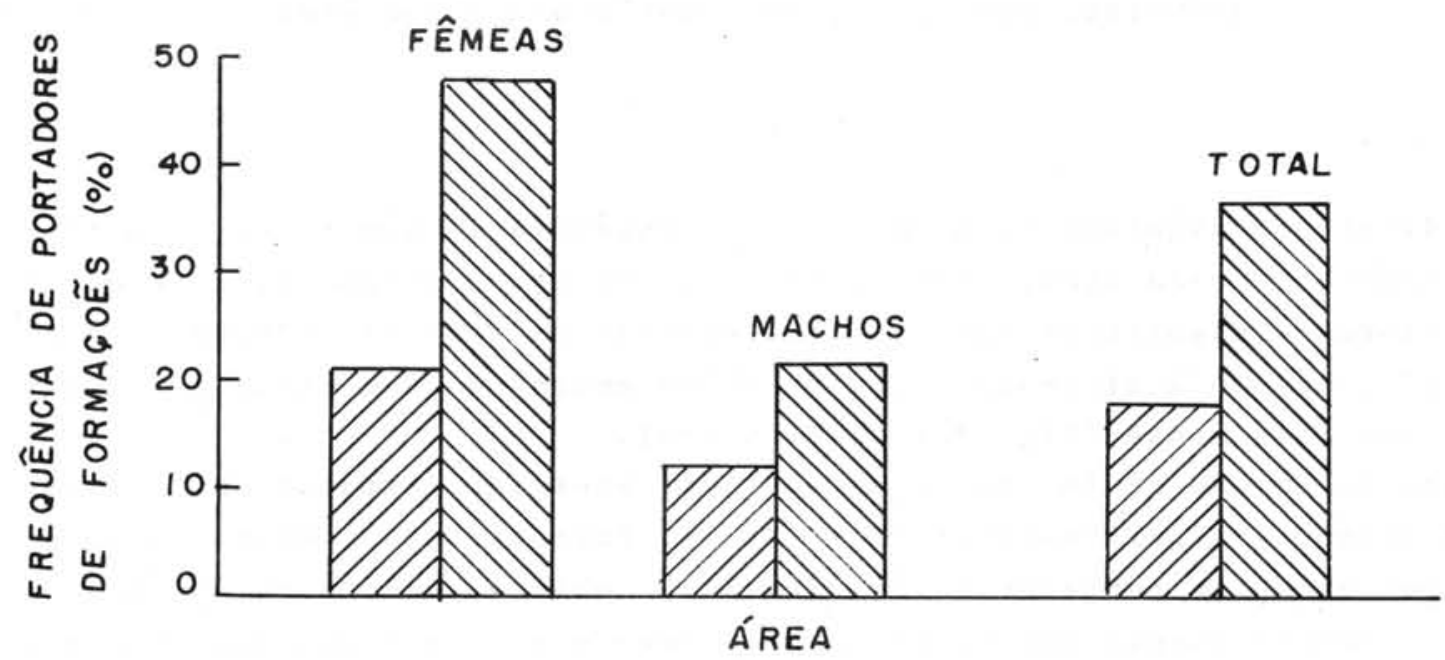

FIG. 27 - Frequência (\%) de portadores de formações ósseas anômalas por sexo e área, e para o total, por área 
o número de raios da segunda nadadeira dorsal, da peitoral esquerda e de vértebras, são homogêneos para toda a área estudada (230s-33os) (Tab. XVI; Figs. 30 e 32 ).

Quanto ao número de escamas na linha lateral, total de rastros no primeiro arco branquial esquerdo e de séries de escamas acima da linha lateral, ocorrem diferenças significativas entre exemplares da ārea I e da área II (Tab. XVI; Figs. 31 e 32). O número de rastros é mais elevado para $M$. furnieri da área II, enquanto que o nümero de escamas na linha lateral e o de série de escamas acima da linha lateral são mais elevados em exemplares da ärea I.

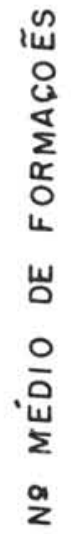

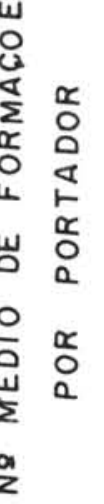

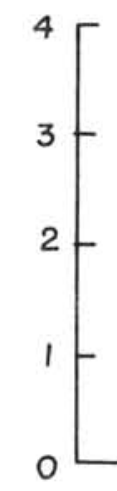

F $\widehat{E} M E A S$
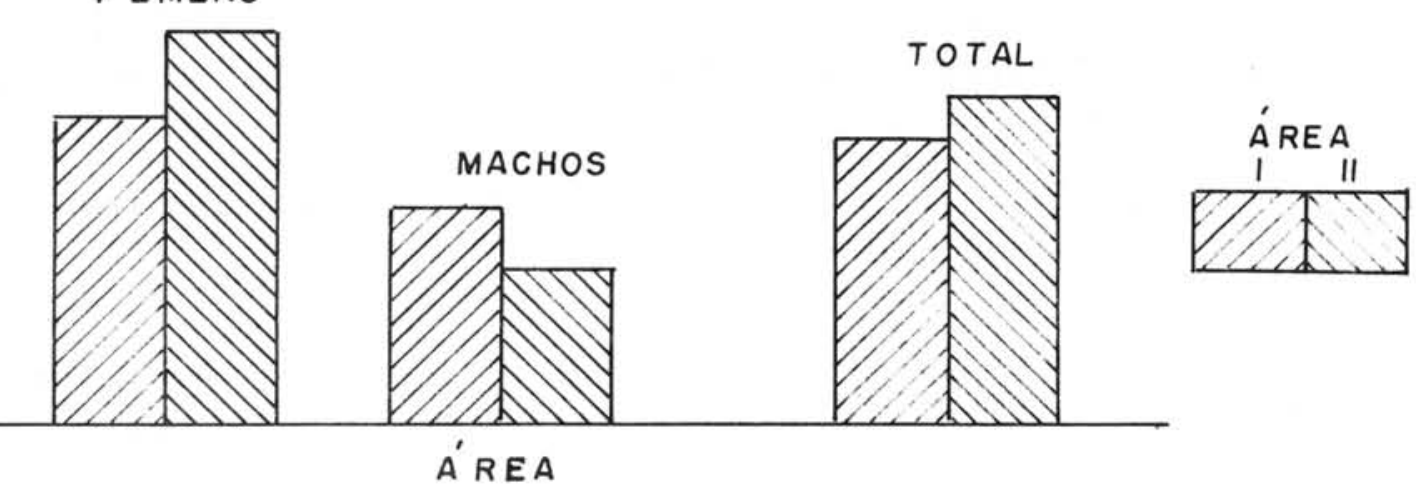

FIG. 28 - Nümero médio de formações ósseas anômalas por portador,

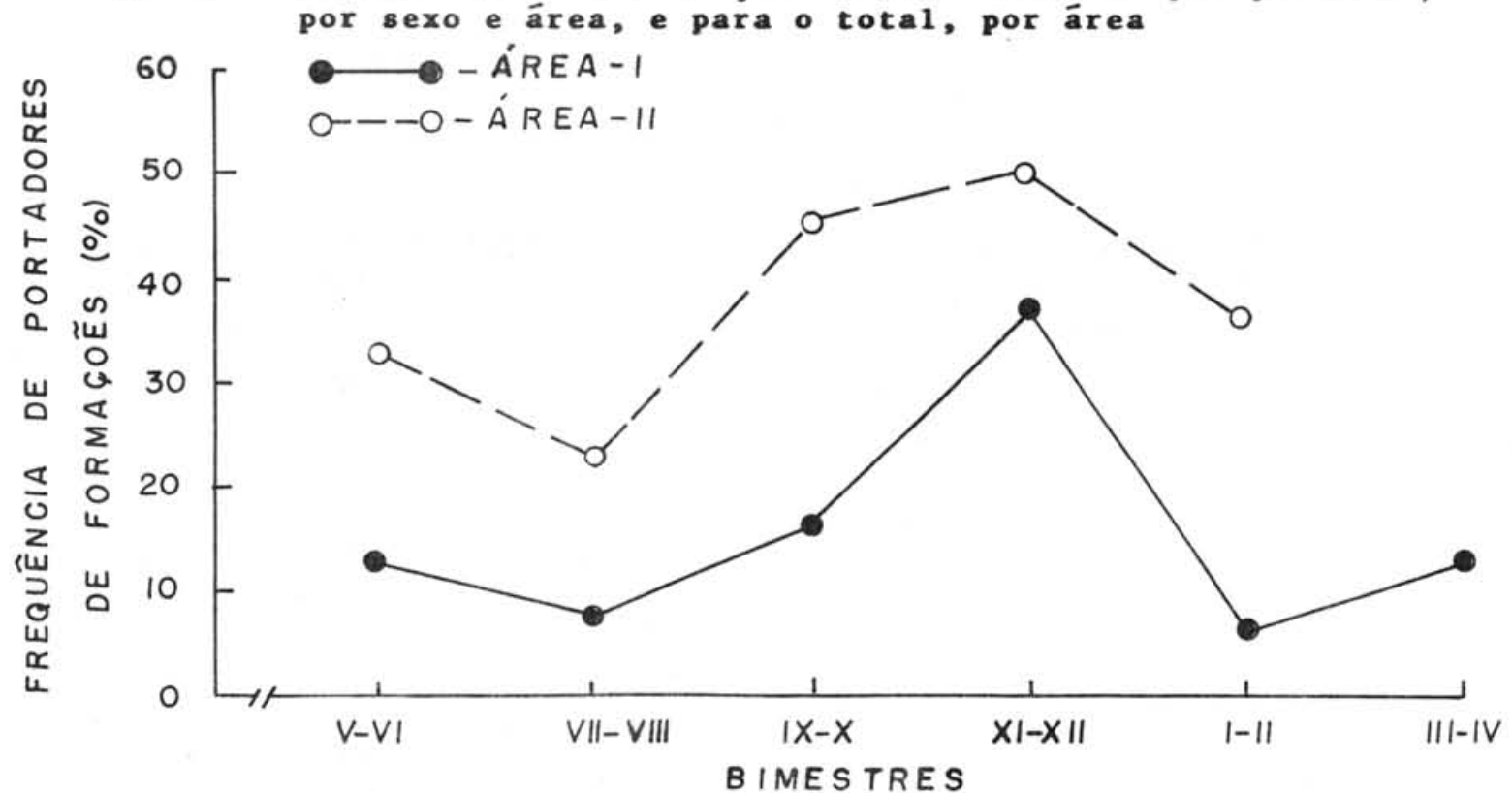

FIG. 29 - Frequência (\%) de portadores de formações ósseas anômalas por bimestre e ärea 

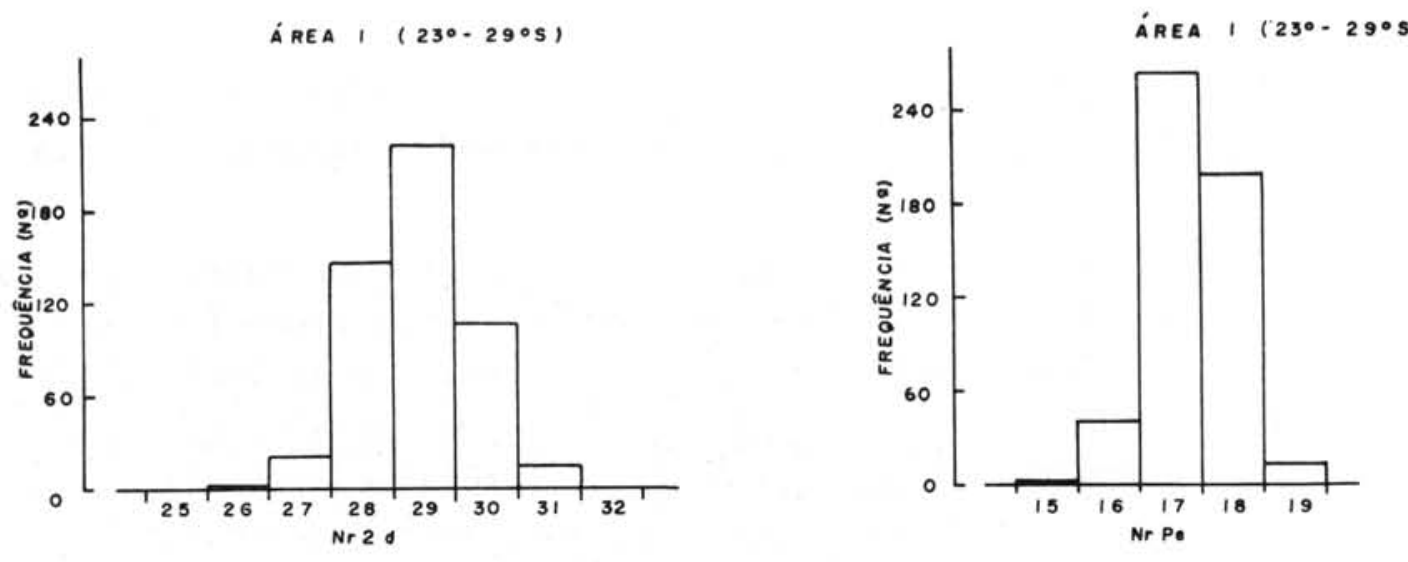

AREA $\|\left(29^{\circ}-33^{\circ} \mathrm{S}\right)$
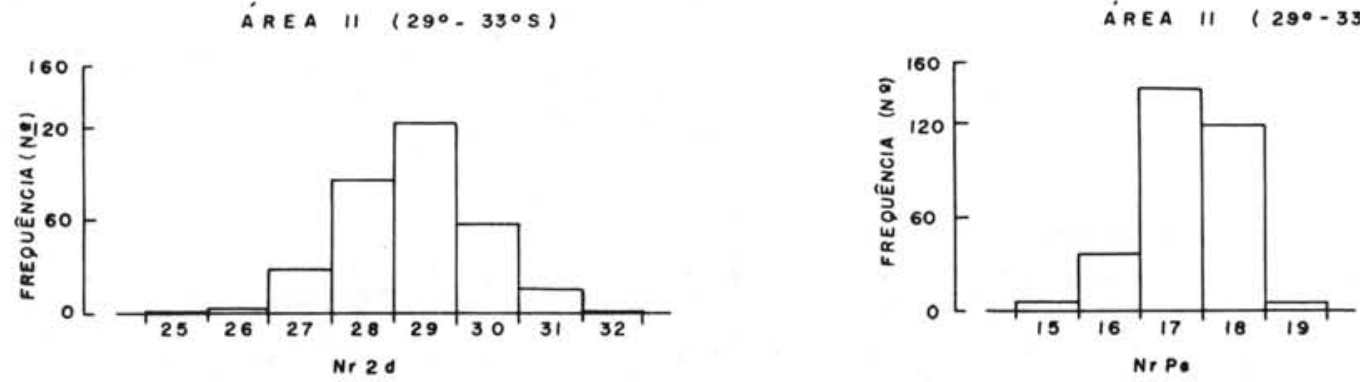

FIG. 30 - Variação nos números de raios da segunda nadadeira dorsal e da peitoral esquerda de $M$. furnieri das áreas I e II
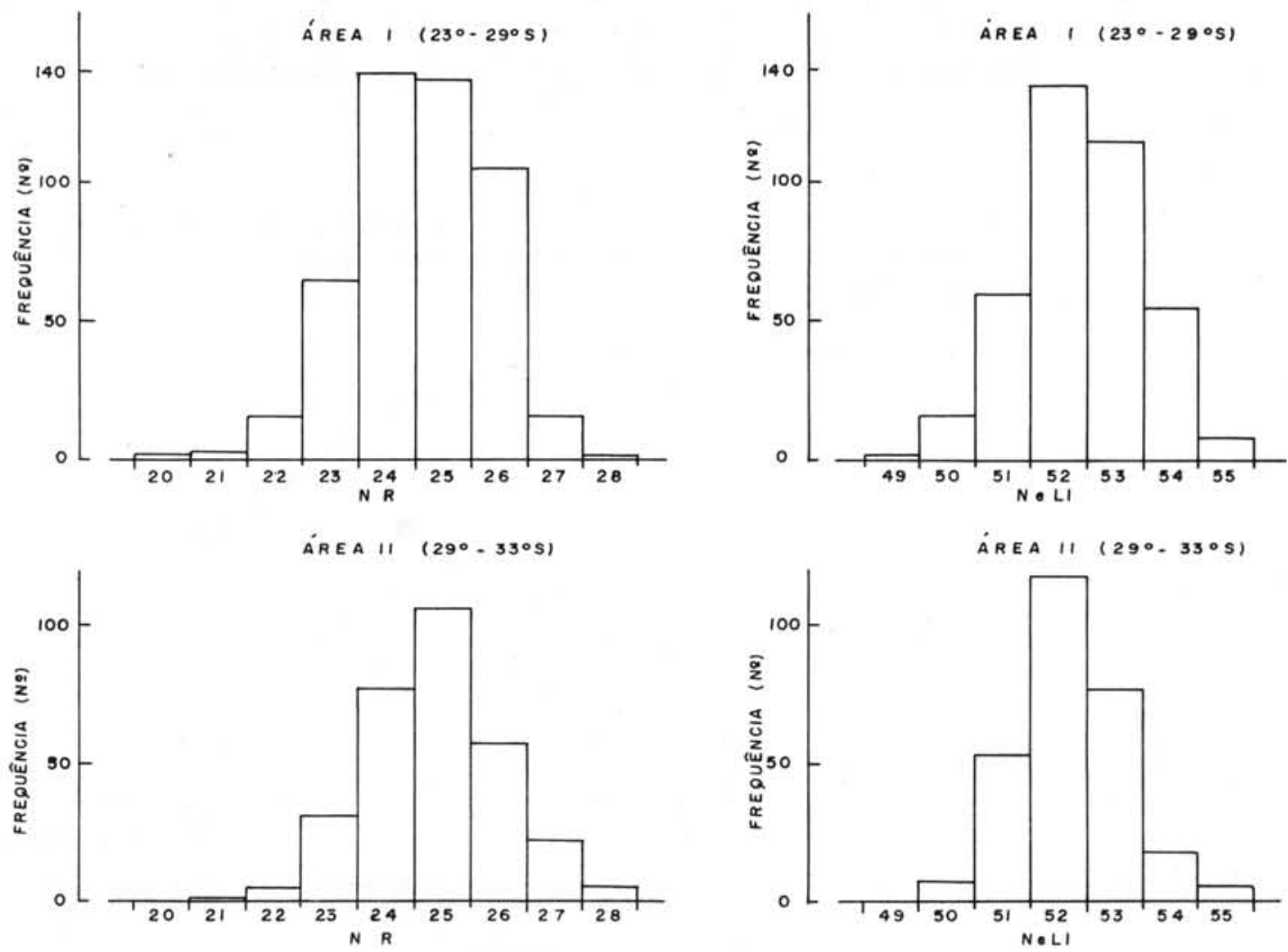

FIG. 31 - Variação nos números total de rastros do primeiro arco branquial esquerdo e de escamas na linha lateral de $M$. furnieri das áreas I e II 


\section{IV - PROPORÇÕES CORPORAIS}

Para a comparação de exemplares dentro da ārea estudada eliminamos as regressões relativas a altura x tronco, por termos constatado que o desenvolvimento dos ovārios provoca deformações da região ventral das fêmeas, introduzindo um importante fator de erro na medida da altura.
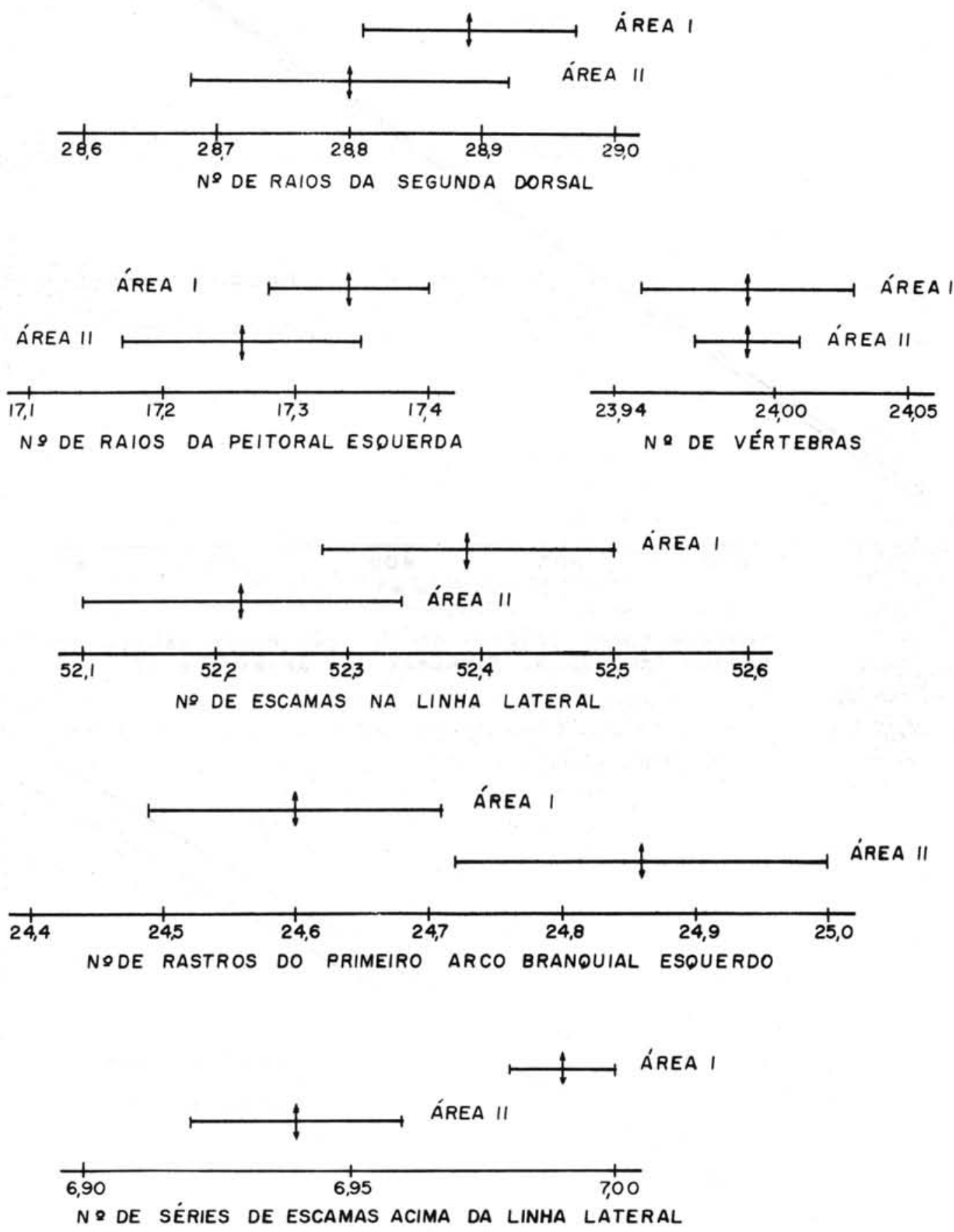

FIG. 32 - Representação gräfica da média e dos seus intervalos de confiança, para os caracteres merísticos estudados, por área

São significativamente diferentes (Tab. XVIII) as regressós entre cabeça x tronco (Fig. 33), focinho x cabeça (Fig. 35), distância prē-anal x comprimento total (Fig. 36), distância pré-dorsal x comprimento total (Fig. 37 ) e comprimento da escama x comprimento total (Fig. 38), para as áreas I e II.

Bolm Inst. oceanogr. S Paulo, 20 (2): 1-70, 1971 
Os exemplares da ārea II possuem olho relativamente menor que os da área I, apesar da diferençã não ser significativa (Fig. 34; Tab. XVIII).

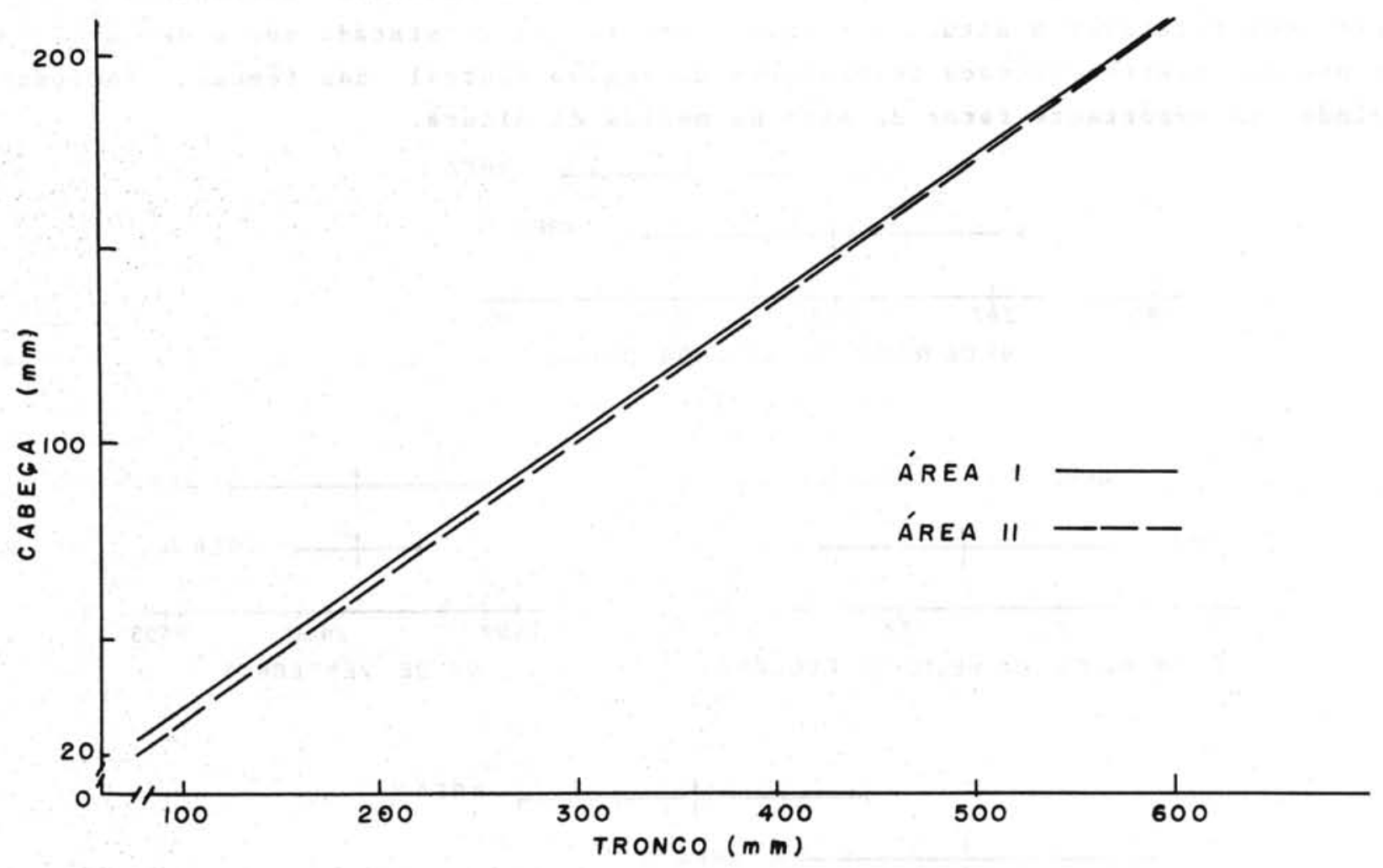

FIG. 33 - Representação grāfica da relação entre cabeça (mm) e

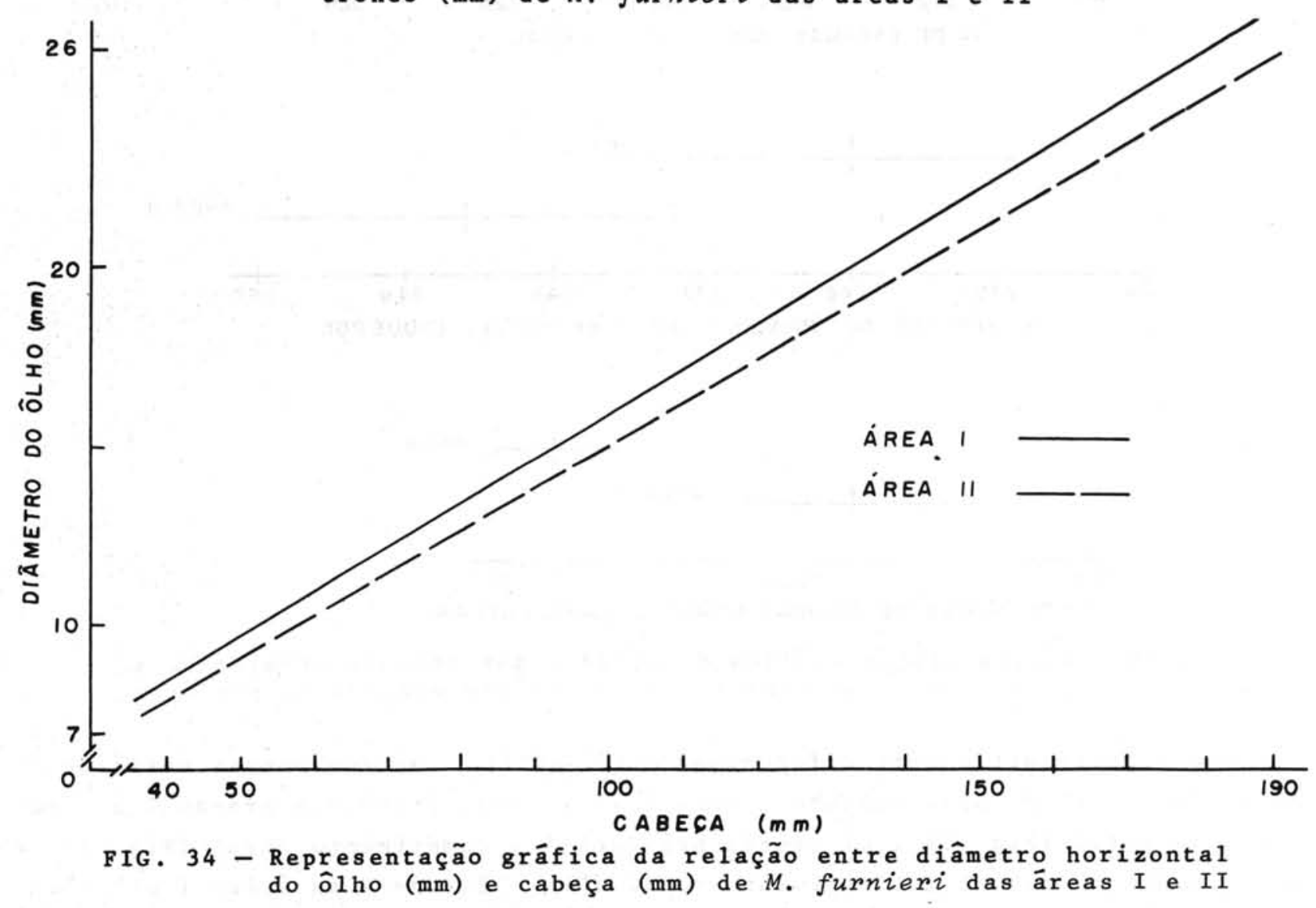


Os exemplares da ārea II possuem cabeça relativamente menor (Fig. 33) e escamas relativamente maiores (Fig. 38) que os da ärea I.

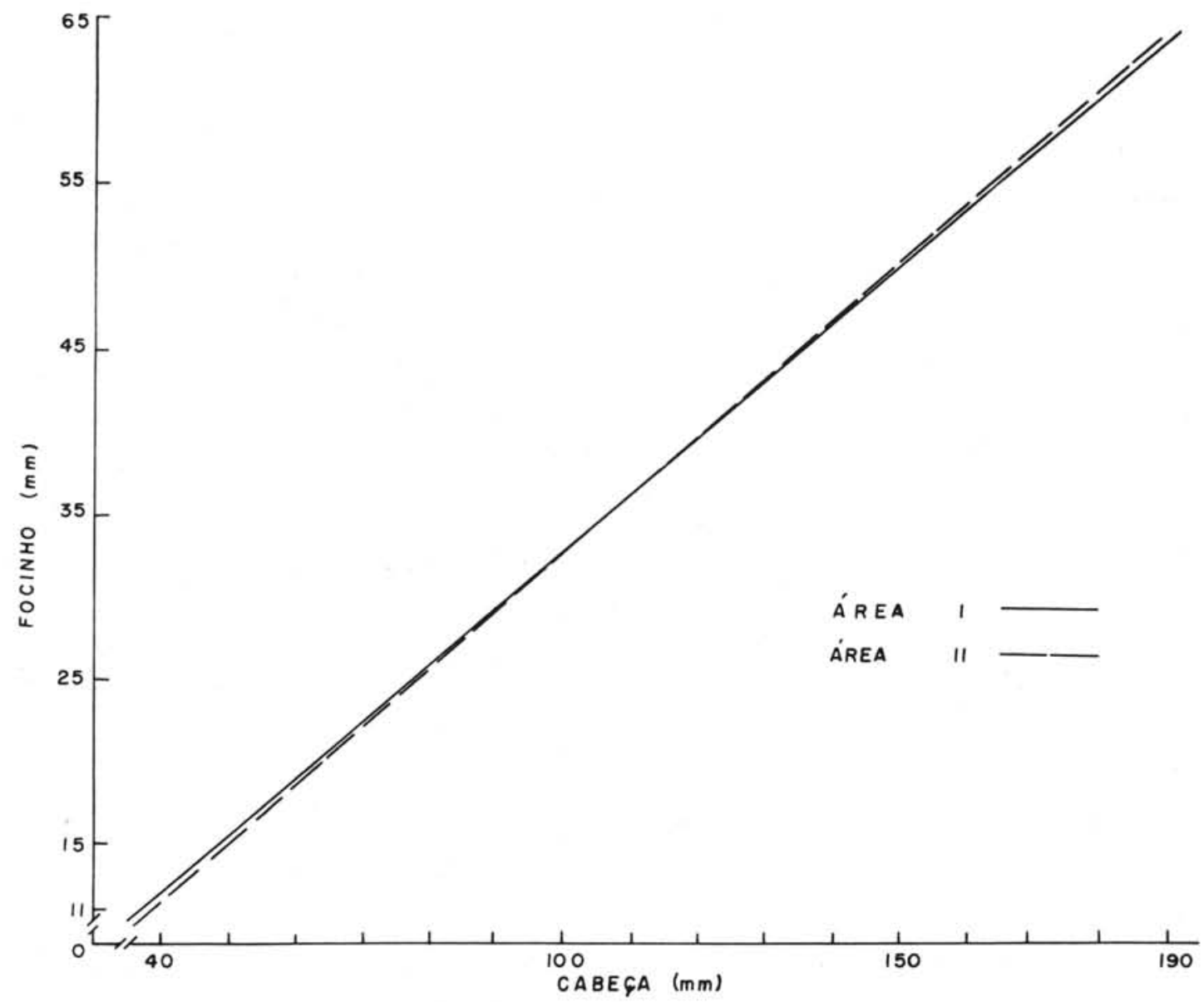

FIG. 35 - Representação gräfica da relação entre focinho (mm) e cabeça (mm) de $M$. furnieri das äreas I e II

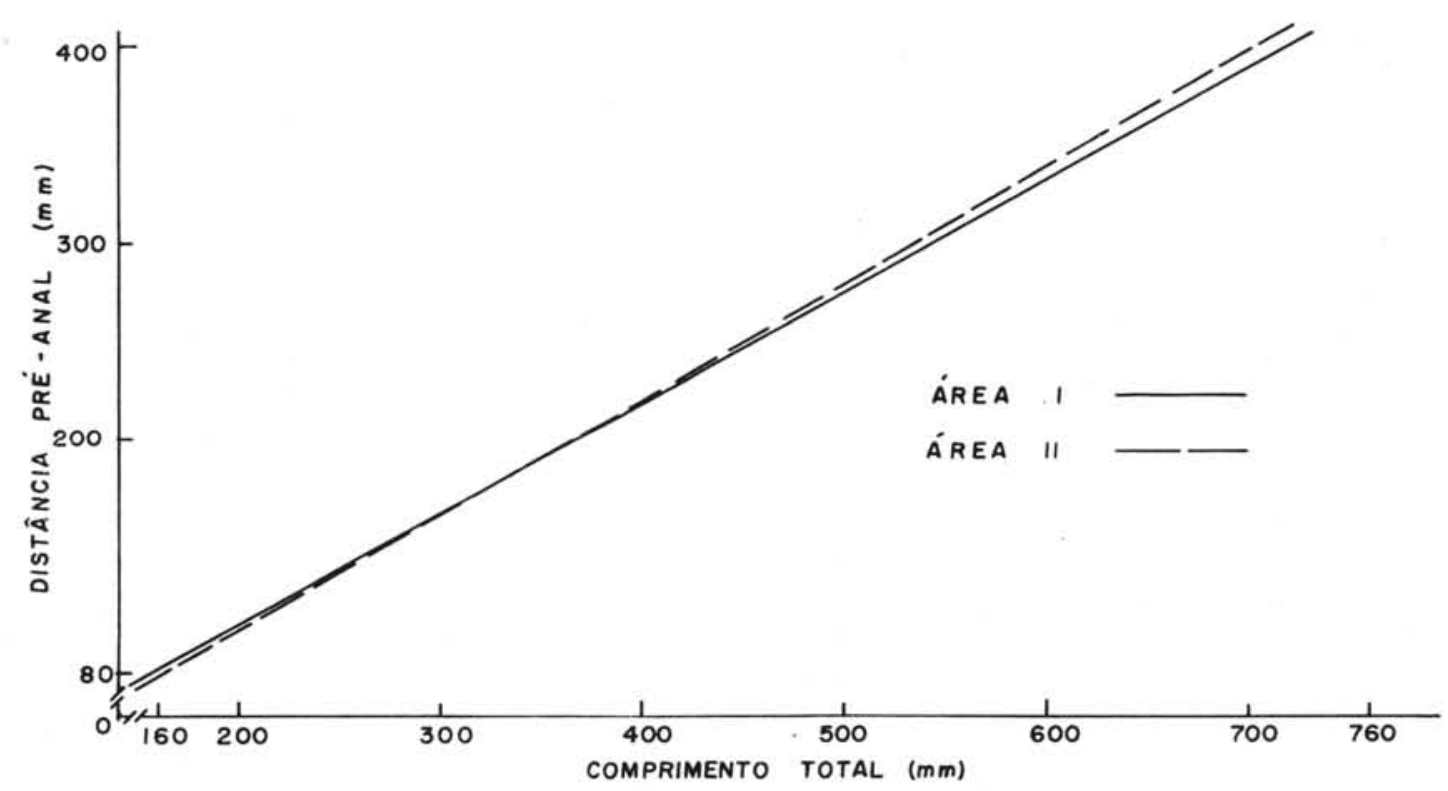

FIG. 36 - Representação gräfica da relação entre distância pré-anal (mm) e comprimento total (mm) de $M$. furnieri das äreas I e II 
Para as outras três relações (Figs. 35,36 e 37) hā interseç̧ão das retas, sendo que na fase inicial ocorrem valores mais elevados para os exemplares da área I.

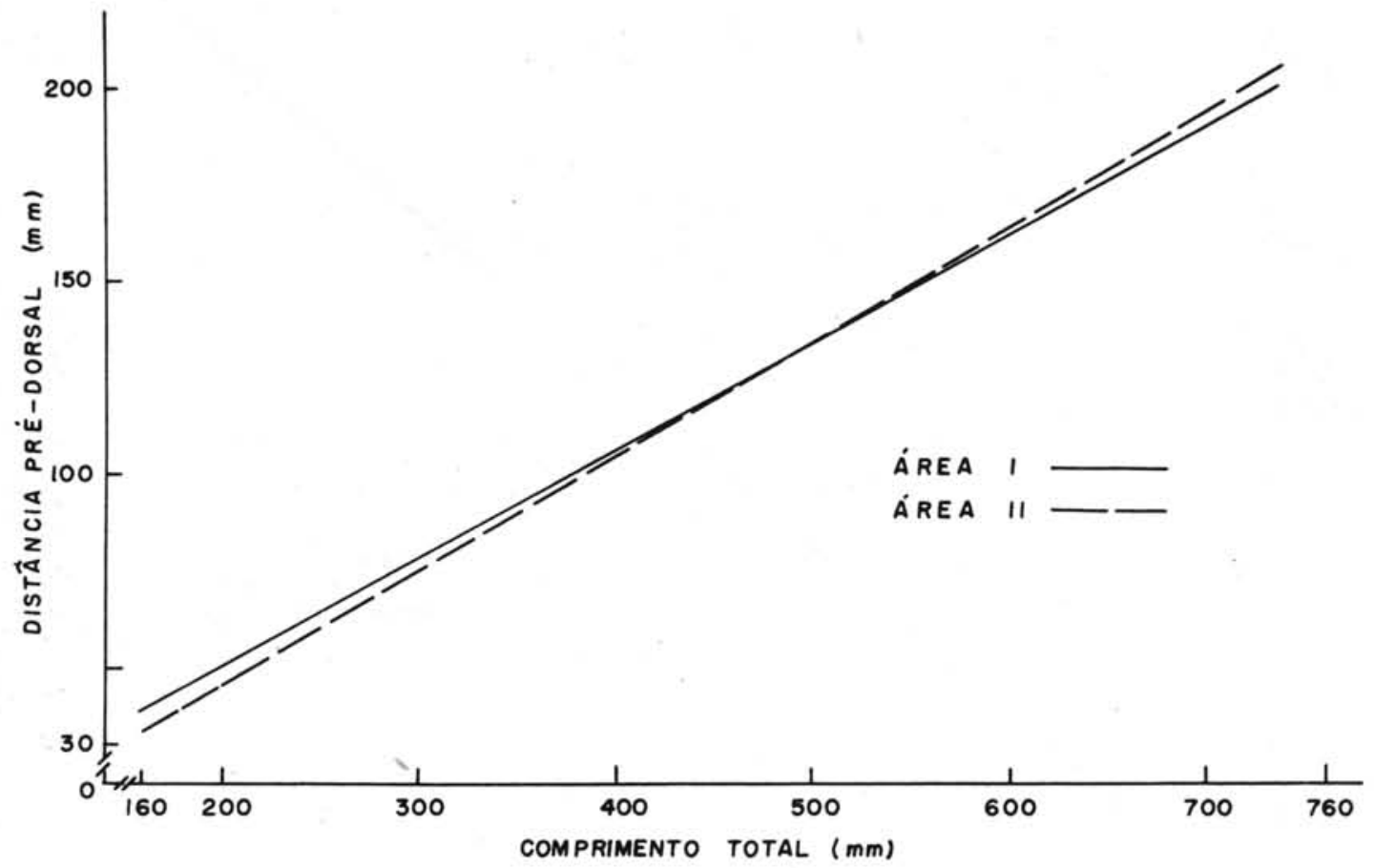

FIG. 37 - Representação gráfica da relaçäo entre distância pré-dorsal (mm) e comprimento total (mm) de $M$. furnieri das áreas I e II

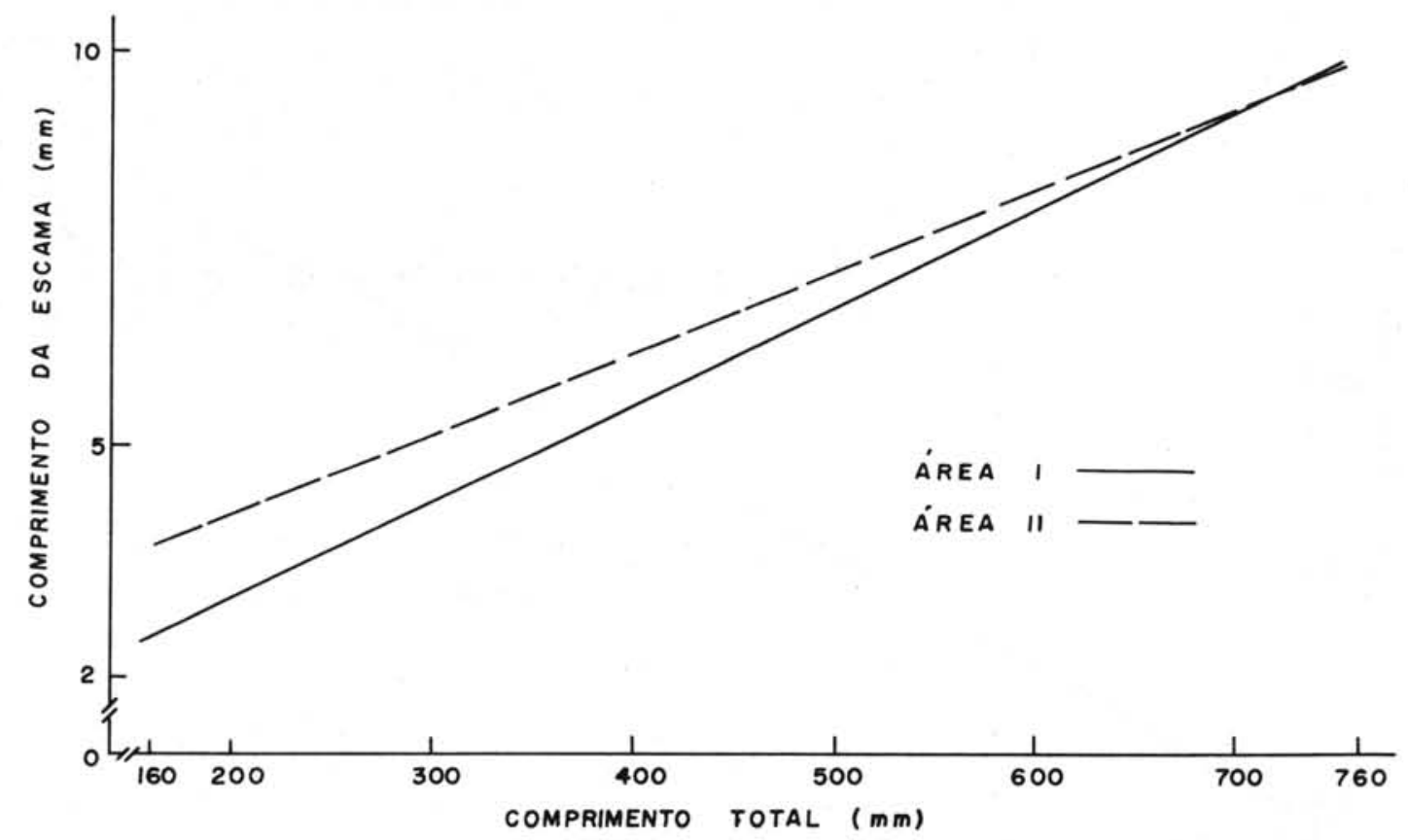

FIG. 38 - Representação gräfica da relação entre comprimento da escama (mm) e comprimento total (mm) de M. furnieri das áreas I e II 


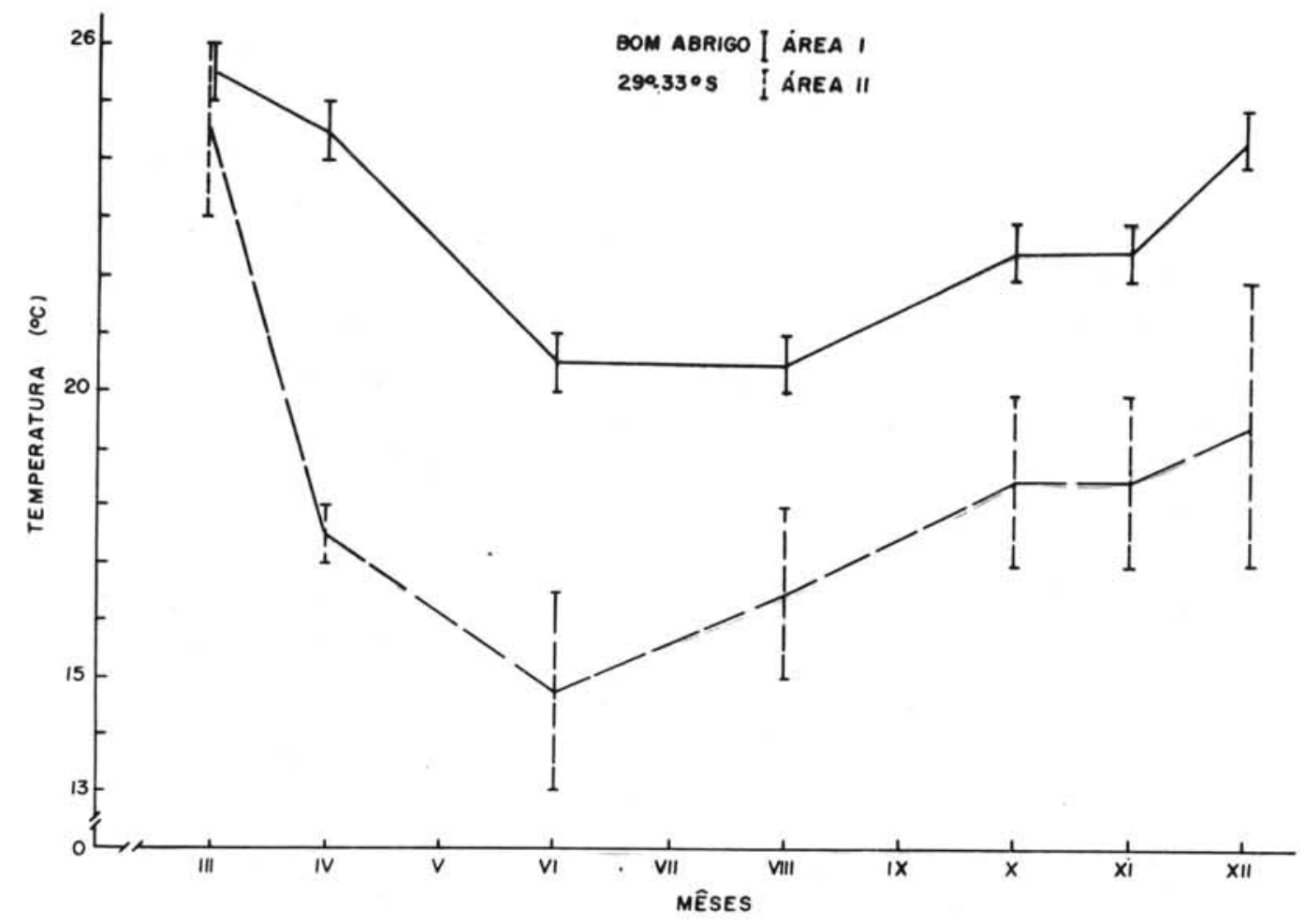

FIG. 39 - Variação das temperaturas médias, a $10 \mathrm{~m}$ de profundidade, durante o ano, nas áreas I e II

\section{DISCUSSÃO}

Constatou-se que, realmente, $M$. furnieri não se comporta como um todo uniforme, ficando evidenciada a existência de duas populações: a da área I $(230-290 \mathrm{~S})$ e a da ắrea II (290-330S), diferenciadas quanto a proporções corporais, caracteres merísticos e padrões de crescimento e de reprodução.

Nos organismos marinhos, como nos terrestres, as variações morfológicas são induzidas por um conjunto complexo de fatores. A experiência mostra, entretanto, que a temperatura desempenha, nos primeiros, papel preponderante, atuando sobre a distribuição geral, comportamento e processos metabólicos da espécie.

A diversidade pode ser devida a variações fenotípicas provocadas por variações ambientais, agindo sobre o indivíduo (ecofenotipos) sem significado evolutivo, ou ter uma base genética (diferenciação geogräfica). Neste caso fatores genéticos e ecológicos operam como mecanismos inter-atuantes, a amplitude da variação resultante dependendo da norma de reação do genotipo em questão (Dobzhansky, 1955). Fatores abióticos podem atuar como seletivos, limitando a distribuição da espécie e determinando sua divisão em categorias infraespecíficas.

Bolm Inst. oceanogr. S Paulo, 20 (2): 1-70, 1971 
Na maioria das espécies de peixes marinhos, a temperatura é o fator 1 imitante da distribuição e é, também, um dos principais fatores que determinam a época de reprodução, a qual só se verifica dentro de um intervalo de temperatura bem delimitado. Variações de temperatura ao longo da ārea de distribuição da espécie podem condicionar diversificação quanto a essa época.

Condições hidrológicas podem limitar os deslocamentos de indivíduos da espécie, dentro da ärea. Não ocorrendo mistura completa entre populações (panmixia), inicia-se um isolamento temporal e espacial (especiação geogräfica e alocrônica). Quando as variações refletem influências de gradação nas condições ambientais, constituindo apenas variações fenotípicas, sem alterar a estrutura da espécie, é de se esperar a ocorrência de "clines" ( Mayr ,1966; Vanzolini, 1968).

Por outro lado, em alguns casos a presença de uma espécie ocasiona modificações morfológicas em outras ("character displacement" Brown \& Wi1son, 1956). Um caso dessa natureza, em peixes, foi estudado por Vanzolini et al. (1964).

0 tipo de diferenciação que constatamos para $M$. furnieri, distribuindo-se em dois grupos distintos, e em āreas com características hidrogrāficas diferentes; não indica tratar-se apenas de variação fenotípica. Não temos dados sobre espécies concorrentes, mas os elementos disponíveis sobre fatores físicos do ambiente são muito sugestivos. A ārea I não sofre influência da corrente das Malvinas, pelo menos não de maneira acentuada, sendo limitada ao norte por uma zona de ressurgência; a temperatura nessa ārea é mais elevada que na área II, como pode ser observado na Figura 39. A área II sofre influência dire ta da corrente das Malvinas, recebendo ainda um grande contingente de água doce, proveniente da lagoa dos Patos. Separando as duas äreas ocorre a convergên cia Sub-tropical, que no caso parece atuar como barreira oceanogräfica. A ārea I pode ser considerada como sub-tropical e a área II como temperada quente.

Os estudos sobre variações morfológicas ligadas ao meio, realizados em peixes, mostram que, no Hemisfério Norte, como regra geral, os representantes setentrionais de uma espécie são maiores, com taxa de crescimento menor, período de vida mais longo e com cabeça, olhos e outras estruturas, menores que nos representantes meridionais. Mostram também que a maturação sexual é mais precoce nestes ūitimos.

Sendo as condições de circulação das massas de água inversas no Hemisfério Sul (Sverdrup et al., 1960), apresentando, portanto, um gradiente nas condições ambientais inverso ao observado para o Hemisfério Norte, deve-se esperar que ocorra um padrão inverso de variação morfológica das espécies. Isso ocorre realmente, nos poucos casos estudados no Hemisfério Sul (Hubbs, 1926; V1adykov, 1934 ).

\section{CARACTERES MERISTICOS}

E bem conhecida a variação do número de elementos em caracteres merísticos com a distribuição latitudinal; para o Hemisfério Norte foi mostrado, por vā- 
rios autores, haver boa correlação entre ambientes de temperaturas mais frias e números merísticos mais elevados. Os trabalhos experimentais de Tảning (1944), Molander \& Molander-Swedmark (1957), Orska (1962), demonstram claramente serem esses caracteres influenciados por condições ambientais, sendo o principal a temperatura. O número de elementos seriados estā relacionado à taxa de desenvolvimento, a qual é influenciada pela temperatura. Temperaturas baixas, retardando o desenvolvimento, determinam um maior número de elementos seriados. Outros fatores ambientais, como altas salinidades e baixas tensós de oxigênio retardam o desenvolvimento (Hubbs, 1926; Tảning, 1952; Seymour, 1956). Fatores bióticos, tais como nutrição também podem determinar diferenças raciais (Hubbs, 1941).

O estágio de desenvolvimento em que cada caráter é fixado é importante; os caracteres mais lábeis são os que aparecem por último durante a ontogenia. Tal estágio varia de caráter para caráter e de espécie para espécie. Por exemplo, para Salmo truta (Táning, 1952) e Pleuronectes platessa (Molander \& MolanderSwedmark, 1957), as vértebras são determinadas mais cedo que os raios das nadadeiras. Para Macropodus opercularis (Lindsey, 1954) as vértebras abdominais são fixadas considerávelmente mais cedo, no desenvolvimento, que os demais caracteres merísticos; o número de elementos das nadadeiras é determinado quase que ao mesmo tempo que o de vértebras caudais.

o padrão de variação com a temperatura, entretanto, não é absoluto. Para algumas espécies certos caracteres variam de modo inverso ao considerado como regra geral. Blaxter (1957) constatou que, para Clupea harengus, as contagens de vértebras eram progressivamente mais altas quando os peixes eram criados em temperaturas progressivamente mais baixas. O mesmo foi verificado por Gabriel (1944) para Fundulus heteroclitus. Outros padrões de variação também foram constatados como por exemplo, o verificado por Lindsey (1954) para Macropodus opercularis: vértebras, elementos basais da nadadeira dorsal, raios segmentados da anal e raios da peitoral, apresentavam valores mínimos em uma temperatura intermediária, sendo as contagens mais elevadas em temperaturas superiores e inferiores a essa intermediária, resultando uma relação em v entre número de elementos seriados e temperatura.o número de espinhos da anal foi progressivamente mais elevado em temperaturas baixas; o número de espinhos da dorsal, e também o de raios moles da dorsal, foi aproximadamente o mesmo em todas as temperaturas.

Orska (1962) estudando a influência da temperatura sobre o número de vértebras em Salmo irideus, concluiu que a temperatura altera o número de somitos, ao qual o de vértebras está intimamente ligado. Essa ação efetua-se através do tamanho dos somitos: temperaturas baixas determinam a formação de somitos pequenos, portanto em maior número,enquanto que em temperaturas altas os somitos são mais desenvolvidos, decrescendo seu número.

Tester (1937) baseando-se na gradação do número médio de vértebras e escamas carenadas com a latitude, e em diferenças significativas constantes entre arenques (Clupea pallasii) de diferentes localidades da costa da Columbia Bri- 
tânica, com referência ao número total de vértebras, número de vértebras abdominais, "sex ratio", taxa de crescimento, comprimento da cabeça e distância pré-dorsal, concluiu que o estoque total é sub-dividido em um número de unidades essencialmente discretas ou populações locais; não exclui a possibilidade de que ocorra uma leve mistura entre grupos adjacentes ou proximamente situados.

McHugh (1951) estudando a variação de cinco caracteres merísticos da anchova (Engraulis mordax mordax) da costa pacífica da América do Norte, separou-a em três populações, admitindo não haver mistura completa entre elas. 0 número de vértebras manteve-se constante em toda a ārea estudada; o número de rastros decresce, de modo mais ou menos regular, do norte para o sul; o número de raios das nadadeiras anal e peitoral aumenta do norte para o sul, enquanto que o da dorsal aumenta do norte para o sul até o sul da California e decresce daí em direção ao sul (Baixa Califórnia).

Quast (1964) estudou a variação de caracteres merísticos em oito espécies de Hexagrammidae, considerando as variações geográfica e local,dentro de cada espécie e entre espécies. Constatou ocorrer variação principalmente nas espécies que apresentavam ampla distribuição norte-sul. Verificou que as contagens de vértebras foram as que apresentaram a menor variação, enquanto as de rastros, a maior. Conclui que a variação intra-específica nos Hexagrammidae é relacionada à temperatura.

Purdon \& Wyatt (1969) demonstraram que as diferenças raciais entre o linguado(Pleuronectes platessa) do mar da Irlanda e mar do Norte, com referência ao número de vértebras, têm base genética, podendo refletir diferenças em sua distribuição e hábitos reprodutivos.

Nossos resultados mostram ocorrer diferenças significativas entre Micropogon furnieri das áreas I e II, quanto ao nümero total de rastros no primeiro arco branquial esquerdo, de escamas na linha lateral e de séries de escamas acima da linha lateral. Não foram constatadas diferenças quanto ao númerode vértebras e raios das nadadeiras estudadas. O número de vértebras é fixado durante o desenvolvimento embrionário ou logo após a eclosão; assim, está sujeito à influência de variações do meio ambiente sobre o genotipo durante um período muito curto, e é de se esperar que seja o menos variável dos caracteres merísticos. Os rastros, que parecem ser o último caráter merístico fixado em muitos peixes, e continuam a formar-se durante todo o desenvolvimento, estão sujeitos a variaçóes ambientais durante longo período, sendo de se esperar que seja o mais variável. Isso foi observado por nós, em concordância com vários autores citados na literatura: a variação observada obedece o padrão geral, ou seja, nümero mais elevado para o sul (área II), onde as águas sãofrias (vide Fig.39). O número de escamas também é fixado tarde durante a ontogenia, estando sujeito, portanto, à influência do meio ambiente. Observamos que seu número varia seguindo, entretanto, um padrão inverso ao estabelecido como geral para caracteres merísticos em peixes. Tanto para escamas na linha lateral, como para séries de escamas acima desta, o número observado foi superior na região 
mais ao norte (ärea I), com águas mais quentes.

Se analisarmos a variação dos caracteres estudados, nas duas āreas, observamos que, de modo geral, ela é mais acentuada para a área II. Sendo os sciaenideos, peixes de distribuição primariamente tropical (Myers, 1960) é de se esperar que estejam menos adaptados a regiões temperadas, como a ārea II por nós estudada, pois estariam agora invadindo ambientes mais frios. Desse modo a observação de Quast (1964), de que a variação pode ser usada como um índice do gráu de adaptação da população a condições ambientais durante os estágios embrionários, seria válida para nosso caso.

\section{PROPORÇÕES CORPORAIS}

Existe extensa bibliografia sobre variação de proporções corporais com a variação das condições ambientais, sugerindo, em alguns casos, que algumas diferenças têm base genética (Martin, 1949). Barlow (1961) resume e discute os de maior importância.

Schaefer (1955) estudando algumas proporções corporais dos atuns (Neothunnus macropterus) das costas da Polinésia sul-oriental, América Central e Hawai, concluiu que os atuns do Pacífico estão separados em populaçóes independentes ou semi-independentes, não podendo ser excluida a possibilidade de ocorrer certa mistura.

Lund Jr. (1957) analisando seis proporções corporais de Roccus saxatilis ao longo da costa at 1 ântica da América do Norte, concluiu que ocorrem pelo menos quatro populações dessa espécie na baía de Chesapeake e seus tributários. Verificou que alguns caracteres morfométricos apresentam variação latitudinal.

Constatamos haver diferenças significativas em cinco das seis proporções corporais estudadas para Micropogon furnieri das duas áreas. Para a relação entre cabeça e tronco verificamos que os dados concordam com o padrão geral observado para peixes, ou seja, exemplares das äreas mais frias possuem cabeças menores (área II). Para a relação comprimento da escama x comprimento total, foi observado que os exemplares da região mais quente (área I) são os que possuem escamas menores. Para as outras três relações em que ocorrem diferenças significativas, há interseç̧ão das linhas, o que indica mudanças nos padrões de crescimento das partes, causadas, provavelmente, pela maturação sexual. Es sabido que o crescimento não se dá, durante todo o desenvolvimento, com a mesma intensidade; ocorrem várias "stanzas", sendo que a variação no instante de transição de uma "stanza" para outra é que determina as diferenças nas proporções corporais. Tais mudanças no crescimento relativo geralmente ocorrem durante a maturação sexual, mas raramente depois.

FORMAÇÕES OSSEAS ANÔMALAS NO ESQUELETO

Deformidades no esqueleto de peixes são relativamente frequentes; as causas de tais deformidades, nos casos estudados, estão relacionadas a um número 
de condições defavoráveis, incluindo constantes temperaturas altas e desfavoráveis durante a ontogenia (Mottley, 1937 ; Gabriel, 1944). Outros fatores, como concentração de sólidos dissolvidos e gases, também podem causar anormalidades; anormalidades correlacionadas com altas temperaturas podem, na realidade, ser causadas em parte pela concentração de oxigênio elou dióxido de carbono em solução, nessas temperaturas. Bailey \& Gosline (1955) relatam a ocorrência de anormalidades vertebrais em Percidae de Oklahoma, Kansas e México, que talvez sejam devidas às altas temperaturas durante o verão nessas áreas. Hubbs (1959) estudando exemplares de duas populações de Gambusia affinis constatou que ambas vivem em condições ecológicas semelhantes e apresentam frequência semelhante de anormalidades vertebrais. A temperatura nos dois locais era elevada $\left(34,8^{\circ} \mathrm{C}\right.$ e $\left.35-35,5^{\circ} \mathrm{C}\right)$; o autor admite que temperaturas altas constantes, mais do que águas quentes ocasionais, sejam a causa de alta incidência de deformidades, pois indivíduos normais ocorrem em águas mais quentes que $35^{\circ} \mathrm{C}$, ocasionalmente $39,5^{\circ} \mathrm{C}$, sendo entretanto tais "habitats" sujeitos a grandes flutuações sazonais de temperatura. Hubbs admite ainda que outros fatores químicos da água (que não gases dissolvidos, os quais podem estar relacionados com altas temperaturas), dificilmente possam causar anormalidades, pois em regiões frias de uma mesmo curso de ägua, os peixes são normais.

Molander \& Molander-Swedmark (1957) estudando experimentalmente a variação em Pleuronectes platessa, constataram uma variação no número de vértebras anormais ("complex vertebrae") com a temperatura; o número foi maior embaixa temperatura e menor em temperaturas elevadas. Os referidos autores citam as observações de Kändler (1932, 1935) sobre a ocorrência comum de anormalidades morfológicas na coluna vertebral de linguados em extensas partes de sua área de distribuição; estudando populações do Bāltico e do mar do Norte, verificou a ocorrência, em grande escala, de tais anormalidades, as quais "constitute important characteristics of the stocks". Indivíduos portadores correspondem a $15 \%$ da população do mar do Norte, $23 \%$ no Báltico Ocidental e $58 \%$ no Báltico Orienta1.

Tảning (1944) estudando experimentalmente a influência da temperatura sobre salmo trutta trutta verificou que o nümero de anormalidades na coluna vertebral variava com a temperatura; o maior número de anormalidades ocorria em temperaturas mais baixas, e o menor número em temperaturas elevadas e intermediārias .

Nem todas as deformações vertebrais, entretanto, são causadas apenas por condições ambientais adversas. Algumas foram estudadas em laboratório e determinou-se serem controladas geneticamente (Aida, 1930; Rosenthal \& Rosenthal, 1950; Rosentha1, Myers \& Brunings, 1958). Schults (1963) relata a ocorrência e mecanismo genético de transmissão de uma deformidade vertebral em Poeciliopsis prolifica, denominada "stubby" (regiões de fusão de vértebras); os portadores, mutantes recessivos, apresentam um encurtamento da coluna vertebral que determina mudança relativa na posição de värias partes do esqueleto, havendo um aumento no esqueleto interno de suporte ao gonopódio, o que torna os machos, apesar de férteis, incapazes de copular. 
As anomalias encontradas no esqueleto de $M$. furnieri jā haviam sido registradas por Barcellos (1962) em exemplares das costas do Rio Grande do Sul, Uruguai e Argentina. Esse autor constatou sua ocorrência apenas em indivíduos com comprimento acima de $28,0 \mathrm{~cm}$, tendo verificado que $30,4 \%$ dos exemp 1 ares examinados eram portadores de anomalias. Essa frequência é seme lhante à que verificamos para $M$. furnieri da ärea II $(36,8 \%)$. A localização das anomalias foi a mesma por nós verificada; entretanto, Barcellos refere-se a anomalias "em um ou nos dois arcos superiores da quinta costela posterior", enquanto nós a encontramos apenas nas costelas epipleurais da 8 ạ vértebra, e não nas da 5 ă, como referido pelo autor. 0 autor também não verificou relação entre o número de anomalias e o tamanho ou sexo dos exemplares. Barcellos cita a presença de fungos no tecido ósseo (observação de cortes histológicos), mas admite a possibilidade de sua penetração ter sido posterior, e não cita qual o fungo encontrado. A análise de cortes histológicos de tais anomalias, em material por nós coletado em condições de relativa assepsia, não mostrou agente estranho; indicou tratar-se de exostoses, sem nenhum aspecto anormal, sendo apenas um super-crescimento de tecido ósseo. A causa de tal desenvolvimento, no presente caso, não foi pesquisada porque julgamos não ser essencial ao nosso objetivo at ua 1 .

No caso de $M$. furnieri a maior frequência de portadores foi observada na área II, onde a temperatura do meio ambiente é mais baixa que a da ārea I (ver Fig. 39). A observação da variação de frequência em indivíduos portadores durante o ano, mostra que ocorre um paralelismo entre as variaçóes nas duas āreas, sendo a frequência sempre superior para a ārea II. Isso sugere não ocorrer penetração de exemplares de uma ärea para outra, o que constitui uma indicação de que as duas populações são isoladas, não ocorrendo mistura mesmo fora da época de reprodução.

\section{CRESCIMENTO}

Constatamos que os exemplares de $M$. furnieri da região mais ao sul ( ärea II) apresentam taxa de crescimento menor, atingem tamanhos máximos maiores e idades mais avançadas que os da área I, mais ao norte. Tais observações estão de acordo com a tendência latitudinal comumente relatada para peixes, na literatura. Tendo taxa de crescimento menor, os exemplares da área II possuem cabeça e olhos menores que os da área I.

Martin (1949) estudando a variação da truta (SaZmo gairaneri) verificou, também, que os peixes com cabeças menores eram aqueles que cresciam mais lentamente; sugeriu que tal diferença, provavelmente, é genética.

Vazzoler, G. (1962) estudando M. furnieri da costa sul do Brasil(Cabo FrioChuí), portanto, da mesma ārea por nós estudada,encontrou um valor de $63,36 \mathrm{~cm}$ para a assíntota do comprimento $\left(\mathrm{L}_{\infty}\right)$. O referido autor não analisou o crescimento para cada sexo em separado. Apesar de termos constatado que há diferenças significativas entre o crescimento de fêmeas e machos, grupamos ambos os sexos para obter valores que pudessem ser comparados com os do citado au-

Bolm Inst. oceanogr. S Paulo, 20 (2): 1-70, 1971 
tor; constatamos que o valor de $L_{\infty}$, para sexos grupados, é $632,3 \mathrm{~mm}$ para a ärea I e $823,0 \mathrm{~mm}$ para a ārea II. Vemos que o valor encontrado pelo citado autor é muito próximo àquele por nós obtido para $M$. furnieri da área I. 0 material sobre o qual foi baseado o estudo acima referido foi coletado de barcos da frota comercial nacional, no Entreposto de Pesca de Santos, durante o período de agosto de 1958 a agosto de 1959 ; tais barcos, nessa época, muito raramente operavam ao sul de Santa Catarina. Assim sendo, os dados são mais representativos da área norte (Cabo Frio-Santa Catarina). Hā grande concordância entre os resultados do referido estudo e os por nós obtidos para M. furnieri da ärea I: valores semelhantes de $L_{\infty}$, bem próximos para k (obtivemos um valor de $k=0,19$ para a ärea I e 0,098 para a ärea II, considerando os sexos grupados) e formação dos anēis de crescimento das escamas durante o verão.

Rodrigues (1968) estudando o crescimento de $M$. furnieri das costas do Ceará encontrou valores para $L_{\infty}$ de $68,80 \mathrm{~cm}$ para machos e $67,60 \mathrm{~cm}$ para fêmeas. Tais valores, entretanto, foram calculados com base em dois tipos de dados, considerados conjuntamente: para exemplares com mais de quatro anos de idade, foi feita leitura direta da idade através das escamas e para exemplares mais jovens foram considerados dados obtidos através de retro-cālculo; assim sendo, tais valores não podem ser considerados como representativos do crescimento da espécie nessa ārea:

Lowe-McConnel (1966) cita que os comprimentos mäximos verificados para $M$. furnieri da Guiana Inglesa estavam entre 43,0 e 48,0 cm, sendo os exemplares do noroeste geralmente maiores. Levanta ainda a possibilidade de existirem duas populações e sugere diferença no padrão de crescimento de fêmeas e machos maduros.

Os resultados por nós obtidos sobre época de formação dos anéis de crescimento nas escamas na ārea II, concordam com o verificado para Macrodon ancy Zodon, outro sciaenídeo que ocorre na mesma ärea; Yamaguti \& Santos (1966) verificaram que os anéis de crescimento dos otolitos, estrutura utilizada para determinação da idade nessa espécie, formam-se entre os bimestres V-VI/VII-VIII, portanto, fim do outono, início do inverno.

Vārios estudos foram feitos sobre a existência de populações dentro de uma espécie, com base em variações nos padrões de crescimento.

o bacalhau (gênero Gadus) apresenta ampla distribuição geogräfica, em águas com características as mais variadas possíveis, ocorrendo várias espēcies e sub-espēcies desse gênero (Svetovidov, 1948; Moiseev, 1953).

Segundo Quast (1966) os bacalhaus do Pacífico, Atlântico e Groenlândia diferem apenas sub-especificamente, sendo que os dados sobre crescimento e reprodução indicam que o do Pacífico apresenta, de modo geral, taxa de crescimento mais elevada, matura em idades mais baixas e possui período de vida mais curto que o do Atlântico. Para o bacalhau do Pacífico (Gadus macrocephalus) ocorrem diferenças de acordo com sua distribuição latitudinal; os exemplares de regiões mais quentes, ao sul (costa do Canadá), apresentam taxa de crescimento mais elevada, período de vida mais curto e maturam mais cedo que os de 
regiões mais frias, ao norte (mar de Bering; Okhotsk Sea) (Ketchen, 1961; Moiseev, 1953). Mesmo em āguas canadenses ocorrem diferenças, se bem que menos acentuadas, entre exemplares do sul (Strait of Georgia) e de āguas de mar aberto, mais ao norte (Hecate Strait); para G. macrocephalus do sul foram encontrados valores de $k=0,56$ e $L_{\infty}=75,0 \mathrm{~cm}$ (Ketchen, 1961), enquanto que para - do norte, $k=0,27$ e $L_{\infty}=94,0 \mathrm{~cm}$ (Ketchen, 1964). Assim, para a população de Strait of Georgia, onde as águas são relativamente mais quentes, a taxa de crescimento é mais elevada e o comprimento máximo é inferior aos da população de Hecate Strait, com àguas mais frias.

Micropogon undulatus, espécie que ocorre na costa atlântica da América Central e do Norte, tambëm apresenta diferenças quanto ao comprimento: os maiores exemplares coletados na baía de Chesapeake mediam 508 mm (Hildebrand \& Schroeder, 1927), enquanto que os da costa do Texas, mediam 370 mm (Gunter, 1945 ).

Gunter (1950) compara os tamanhos máximos coletados para 26 espécies dessa região e mostra que 18 espécies apresentam tamanhos maiores na baía de Chesapeake. Vemos que os exemplares mais do norte apresentam tamanhos máximos maiores que os do sul (Hemisfério Norte). O mesmo autor (1945, 1950) cita a ocorrência de duas populações de Micropogon undulatus; uma que se distribui nas costas dos estados do Atlântico Central, que suporta grande intensidade de exploração e outra nas costas do golfo do México, cuja exploração é acidental. Tal observação é semelhante ao por nós constatado para Micropogon furnieri nas costas brasileiras (Vazzoler \& Sá, 1963; Vazzoler, 1965), apenas que no nosso caso, a população mais abundante é a mais meridional.

REPRODUÇÃO

Os resultados obtidos com referência a reprodução para M. furnieri nas duas áreas, mostrando que os dois grupos desovam emáreas e em épocas distintas, que não há ocorrência de indivíduos com gônadas maduras durante todo o ano na sub-área $C$, entre os dois locais de desova, e que não há penetração, nessa sub-ārea, de indivíduos com gônadas esvaziadas provenientes da ārea II, aliadas às diferenças contrastantes com relação aos comprimentos médios e idades do início e fim do processo de maturação sexual para exemplares das duas äreas, fornecem fortes indicações de que ocorre isolamento reprodutivo espacial, além do temporal.

Pode ocorrer mistura entre os dois grupos, pelo deslocamento de individuos, de uma área para outra, fora das épocas de reprodução; entretanto, se tal mistura ocorre, deve ser em pequena proporção, pois o paralelismo observado com relação à frequência de indivíduos portadores de exostoses, durante o ano, não sugere ocorrer mistura. Se tal acontecesse em frequência elevada, as diferenças não seriam tão constantes, mas haveria alternâncias entre as frequências, nas duas áreas.

Bolm Inst. oceanogr. S Paulo, 20 (2): 1-70, 1971 
Constatamos que a maturação ocorre em exemplares mais jovens na ārea $I$, sendo, entretanto, o processo de maturação mais rāpido na área II(completa-se num intervalo de tempo menor que na ärea I).

Em estudo preliminar que realizamos (Vazzoler, 1962) sobre a primeira maturação sexual de quatro espécies de peixes da mesma ārea, entre elas Micropogon furnieri, encontramos para esta um valor para o comprimento do início da primeira mąturação sexual de $28,0 \mathrm{~cm}$; vemos que tal valor é bem próximo ao verificado para $M$. furnieri da ārea I. Isto tambëm é devido ao fato discutido com relação ao trabalho de Vazzoler, G. (1962), das amostras serem mais representativas da área entre Cabo Frio e Santa Catarina.

Para M. furnieri da Guiana Inglesa foi constatado (Lowe-McConne11, 1966) que a primeira maturação inicia-se em tamanhos diferentes para cada sexo, sendo $18-21 \mathrm{~cm}$ e 23-26 cm, ainda no primeiro ano de vida.

Para Macrodon ancyzodon da ärea II, Yamaguti (1967) constatou que a desova ocorre de novembro a abril, com picos em dezembro e março-abril (sugerindo desova parcelada), na região da barra de Rio Grande(RGS), o mesmo que verificamos para $M$. furnieri dessa ärea. A ocorrência de desova parcelada em $M$. ancyZodon jā havia sido sugerida anteriormente (Vazzoler, 1963b). Tal tipo de desova também ocorre para M. furnieri da região entre $29{ }^{\circ} \mathrm{S}$ e $33^{\circ} \mathrm{S}$ (Vazzoler, 1969).

Verificamos ocorrer desova parcelada tanto para $M$. furnieri da área I, como da ārea II; tal tipo de desova foi constatado para outras espécies do Atlântico Sul Ocidental (Angelescu et al., 1958; Ciechomski, 1967) e admite-se que é característica de regiões com ambientes relativamente estāveis, onde as condições exigidas para a reprodução e desenvolvimento dos primeiros estāgios não ocorrem apenas em um período bem estabelecido, durante o ano. Devido a essa relativa estabilidade do meio ambiente é que o período é longo, abrangendo vārios meses, nessas regiões.

Lowe-McConne11 (1966) cita que alevinos e jovens de $M$. furnieri vivem em àguas salobras sendo, às vêzes, capturados na desembocadura de rios mas nunca em estuários. Observando os locais de desova de $M$. furnieri nas duas āreas por nós consideradas, constata-se que são próximos a fontes de ägua doce: região de Bom Abrigo-Paranaguá-são Francisco na ārea I e desembocadura da lagoa dos Patos, na área II. Citações relativas a esse fato jā foram feitas anteriormente (Ihering, 1897; Lemos, 1956).

As diferenças constatadas para Micropogon furnieri da ärea I e da área II são suficientes para afirmarmos tratar-se de duas populaçós reprodutivamente isoladas. A presença de diferenças constantes e significativas em caracteres raciais, entre duas populações, sugere que não deve ocorrer livre cruzamento entre membros de ambas. Se isso não fosse verdadeiro, diferenças causadas apenas por variações ambientais seriam rapidamente dissolvidas. No caso por nós estudado, os resultados obtidos quanto à reprodução e frequência de portadores de exostoses enfatizam tal afirmação. Entretanto, não podemos concluir que as 
duas populações sejam completamente isoladas, $\grave{a}$ luz dos presentes resultados, pois um inter-cruzamento em baixo grau, pouco intenso, pode ocorrer.

A nosso ver, as diferenças ecológicas existentes entre as duas áreas consideradas,explicam as causas da diversificação dessa espécie dentro da área total estudada.

Tais resultados indicam que, enquanto estudos mais detalhados sobre a existência ou não de fluxo gênico entre as duas populações não forem realizados, trabalhos orientados no sentido de estimar o tamanho dos estoques de $M$. furnieri, na área entre $23^{\circ} \mathrm{S}$ e $33^{\circ} \mathrm{S}$, devem ser conduzidos considerando-se cada população como uma unidade isolada.

Estudos futuros, de novos caracteres determinados geneticamente nos possibilitarão estabelecer o grau de isolamento dessas duas populaçóes.

Dado que estudamos $M$. furnieri apenas em parte de sua área, deixamos de fazer hipóteses sobre o seu padrão geral de diferenciação geográfica (isto é, eventual existência de sub-espécies) e,assim, de atribuir "status" sistemático e nomes às populações aqui identificadas.

\section{CONCLUSÕES}

A anālise de variação de caracteres merísticos, proporções corporais e aspectos relativos ao crescimento e à reprodução de Micropogon furnieri, em parte de sua área de distribuição, mostrou que na região da costa brasileira compreendida entre as latitudes $23^{\circ} \mathrm{S}$ e $33^{\circ} \mathrm{S}$, ocorre diversificação dessa espécie que se constitui em duas populações: uma ocupando a área entre $23^{\circ} \mathrm{S}$ e $29^{\circ} \mathrm{S}$, que denominamos área I (sub-tropical) e outra ocupando a ärea entre $29 \circ \mathrm{S}$ e $33^{\circ} \mathrm{S}$, denominada ärea II (temperada quente).

As duas populações diferem quanto a:

1) REPRODUÇÃo - $M$. furnieri da área I desova durante o inverno-primavera na região de Bom Abrigo, enquanto que na área II a desova ocorre durante a primavera-verão na região da barra de Rio Grande;

2) EPOCA DE RECRUTAMENTo - Considerando-se as épocas em que ocorre recrutamento mais intenso, temos que na área I a entrada de jovens se dá durante o outono, e na ārea II durante o verão-outono;

3) INICIO DA PRIMEIRA MATURAÇÃo SEXUAL - Para $M$. furnieri da ārea I, as fêmeas iniciam a maturação sexual com $275 \mathrm{~mm}$ aos 7 meses de idade e os machos com $250 \mathrm{~mm}$ aos 4 meses; na área II as fêmeas encontram-se com $350 \mathrm{~mm}$ com 1 ano e 11 meses e os machos com $330 \mathrm{~mm} \operatorname{com} 1$ ano e 5 meses de idade;

4) MATURAÇÃo COMPleta da POPULAÇÃo - $100 \%$ dos indivíduos da população completam o processo de maturação sexual em tamanhos e idades diferentes nas duas äreas; para a área I as fêmeas atingiram $475 \mathrm{~mm}$ aos 4 anos e 11 meses e os machos $425 \mathrm{~mm}$ aos 3 anos e 9 meses, enquanto que na área II as fêmeas atingiram $425 \mathrm{~mm}$ aos 3 anos e 7 meses e os machos $475 \mathrm{~mm}$ aos 5 anos e 3 meses; assim veBolm Inst. oceanogr. S Paulo, 20 (2): 1-70, 1971 
mos que a duração do processo de maturação das populações das duas áreas, também difere;

5) ÉPOCA DE FORMAÇÃo dOS ANEIS DE CRESCIMENTO DAS ESCAMAS - Na ärea I os anéis formam-se no verão, enquanto que na área II, entre o fim do outono e inverno;

6) TAXA DE CRESCIMENTO - A taxa de crescimento difere entre sexos numa mesma área e entre as áreas para um mesmo sexo; é, entretanto, mais elevada, para M. furnieri da área I. Ocorrem mudanças na taxa de crescimento relativo para os dois sexos, nas duas āreas, sendo que difere o momento em que tais mudanças se verificam, estando relacionadas à maturação sexual: na área I ocorre logo no início do desenvolvimento, durante o primeiro ano de vida, enquanto que na ārea II ocorre bem mais tarde, durante o terceiro ano de vida;

7) DURAÇÃO DO PERIODO DE VIDA - Apesar da taxa de crescimento ser mais baixa para $M$. furnieri da área II, a espécie aí atinge comprimentos assintóticos superiores aos verificados para a área I; isso porque o período de vida da espécie é mais elevado na área II. Vemos que na amostragem realizada para a área I ocorreu nümero representativo de indivíduos até 5 anos de idade,enquanto que na ärea II a idade de 7 anos foi bem representada;

8) RELAÇÃo PESO TOTAL x COMPRIMENTO TOTAL - Os exemplares da área II, para uma mesma classe de comprimentto, apresentam peso total superior aos da área I (diferença significativa);

9) FREQUENCIA DE PORTAdORES DE FORMAÇÕES OSSEAS ANÔMALAS NO ESQUeleto Verificamos ser significativamente diferente a frequência de portadores nas duas áreas: na área II a frequência é bem superior $(36,8 \%)$ à da área I $(17,4 \%)$. Essa diferença mantém-se constante durante todo o ano;

10) NUMERO TOTAL DE RASTROS NO PRIMEIRO ARCO BRANQUIAL ESQUERDO - 0 número médio de rastros difere significativamente nas duas äreas, sendo mais elevado para exemplares da ārea II, onde as temperaturas ambientais são mais baixas;

11) NÚmero de eSCAMAS NA LINHA LATERAL - o número médio de escamas na 1inha lateral varia significativamente entre exemplares das duas āreas,sendo mais elevado para os da ārea I;

12) NUMERO DE SERIES DE ESCAMAS ACIMA DA LINHA LATERAL - Ocorrem diferenças significativas com referência a esse caráter, entre exemplares das duas áreas, sendo mais elevado para aqueles da ärea I;

13) RELAÇÃo CABEÇA $x$ TRONCO - Os exemplares da área II apresentam cabeças significativamente menores que os da área $I$;

14) RELAÇÃO COMPRIMENTO DA ESCAMA x COMPRIMENTO TOTAL - acorre diferença significativa, sendo que os exemplares da ārea II possuem escamas maiores que os da ārea I; 
15) RELAÇÕES FOCINHO X CABEÇA, DISTÂNCIA PRE-DORSAL x COMPRIMENTO TOTAL e DISTÂNCIA PRE-ANAL x COMPRIMENTO TOTAL - Ocorrem diferenças significativas entre exemplares das duas áreas, sendo que há intersecção das linhas representativas dessas relações; nas fases inicias os valores são mais elevados para exemplares da área I. Isso indica ocorreremalterações na taxa de crescimento relativo das partes, durante o desenvolvimento.

As conclusões alistadas acima, constituem provas suficientes para afirmar mos tratar-se de duas populações reprodutivamente isoladas sugerindo ainda que se ocorre fluxo gênico entre ambas, a troca se verifica em taxa bem reduzida. Entretanto, este fato só poderá ser confirmado por estudos futuros, de outros caracteres cuja determinação genética seja incontrovertível, como sejam, grupos sanguineos e padrões de hemoglobina.

\section{AGRADECIMENTOS}

Quero expressar meus sinceros agradecimentos à Instituição a que pertenço, sem o apoio da qual este estudo não teria sido realizado.

Ao prof. dr. Paulo Emílio Vanzolini, meu orientador, que durante a elaboração desta tese foi incansável como mestre, tendo contribuido ainda, de modo decisivo, em minha formação geral como pesquisadora, seria pouco expressar meus mais profundos agradecimentos por meio de palavras. Tenho a certeza de que é conhecedor de minha admiração e gratidão. Quero apenas dizer-lhe que espero, ao longo de minha carreira futura, poder contribuir, ainda que de maneira não tão brilhante, para a formação de novos elementos, retribuindo assim um pouco do muito que recebi.

Quero ainda expressar meus agradecimentos à Fundação de Amparo à Pesquisa do Estado de São Paulo, pelo auxílio concedido para a aquisição do material necessário ao estudo radiológico do material; ao dr. Jarbas Gomes da Cunha, diretor do Instituto de Rádio-diagnóstico, de Santos, pela cessão do equipamento de raio $\mathrm{x}$; ao dr. João Plutarco Rodrigues Lima, pelo estudo histológico das anomalias ósseas; ao sr. Alfredo Martins Paiva Filho, pela programação e execução de parte da análise estatística dos dados efetuada no Computador B3500 do Centro de Computação Eletrônica do Instituto de Pesquisas Matemáticas da Universidade de São Paulo; à srta. Lucy Teixeira, pela padronização das citações bibliográficas e, ainda, representando toda a Divisão de Informação e Documentação Científica do Instituto Oceanográfico da Universidade de São Pau1o, pela assistência irrestrita durante todas as ocasiões em que sua colaboração foi solicitada; ao sr. Zairo de Freitas Pinto, pela preparação final dos gráficos; à 1ic. Virgínia N. Villaça da Veiga, pela revisão linguística do manuscrito; ao sr. Oscar Barbosa pela datilografia das tabelas e do texto. Meus agradecimentos são extensivos ainda a todos aqueles que de maneira direta ou indireta colaboraram na coleta das amostras e nos trabalhos de laboratório, em particular ao srs. Wilson Ribas, Alfredo Martins Paiva Filho e à srta. Izaura Gonçalves Bezerra.

Bolm Inst. oceanogr. S Paulo, 20 (2): 1-70, 1971 
Finalmente, mas não em ültimo lugar, quero externar meus mais profundos e sinceros agradecimentos ao lic. Gelso Vazzoler, por sua contribuição como colega e, ainda mais, como espôso; sem sua colaboração, compreensão, estímulo e dedicação esta tese nunca teria sido realizada.

Êste trabalho é dedicado à memória de meu Pai e de meus Avós Emília e Caetano Amato, e à minha Mãe, meus Filhos e meu Espôso.

\section{B I BL IOGRAF IA}

AIDA, T. 1930. Further genetical studies of Aplocheilus Zatipes. Genetics, Princeton, vol. 15, no 1, p. 1-6.

ANGEleSCU, V., GNERI, F.S. \& NANI, A. 1958. La merluza del mar argentino. Argentina, Secr. Mar., Serv. Hidrogr. Nav., H 1004, 224 p.

BAILEY, R.M. \& GOSLINE, W.A. 1955. Variation and systematic significance of vertebral counts in the American fishes of the Percidae. Misc. Publs Mus. Zoo1. Univ. Mich., vo1. 93, p. 1-44.

BALECH, E. 1954. Division zoogeografica del litoral sulamericano. Revta Bio1. mar., vol. 4, p. 184-195.

1964. Caracteres biogeograficos de la Argentina y Uruguay.Boln Inst. Biol. mar., vol. 7, p. 107-111.

BARCELlos, B.N. 1962. Anomalias do esqueleto da corvina. Ciênc. Cult., S Paulo, vol. 14, no 2, p. 111-113.

BARLOW, G.W. 1961. Causes and significance of morphological variation in fishes. Syst. Zoo1., vo1. 10, no 3, p. 105-117.

BEVERTON, R.J.H. \& HOLT, S.J. 1957. On the dynamics of exploited fish popu1ations. Fishery Invest., Lond., ser. 2, vo1. 19, p. 1-553.

BLAXTER, J.H.S. 1957. Herring rearing. III. The effect of temperature and other factors on myotome counts. Mar. Res., vol. 1, p. 1-16.

BOLTOVSKOY, E. 1959. La corriente de Malvinas (un estudio en base a $1 a$ investigacion de foraminíferos). Argentina, Secr. Mar., Serv. Hidrogr. Nav., H 1015 , p. 1-96.

1964. Provincias zoogeograficas de America del Sur y su sector antartico segun los foraminiferos bentonicos. Boln Inst. Biol. mar., vol.7, p. 93-99.

1968. Hidrologia de las aguas superficiales en la parte occidental del Atlantico sur. Revta Mus. Argent. Cienc. nat. Bernardino Rivadavia Inst. nas. Invest. Cienc. nat, Hidrobio1., vo1. 2, no 6, p. 199-224.

BOSCHI, E. 1964. Los peneidos de Brasil, Uruguay y Argentina. Boln Inst. Bio1. mar., vo1. 7, p. 37-42.

BROWN Jr., W.L. \& WILSON, E.O. 1956. Character displacement. Syst. Zool., vo1. 5, n? 2 , p. $49-64$.

BUCKMANN, A. 1929. Die methodik fischereibiologischer Untersuchungen an Meeresfischen. Handb. bio1. ArbMeth., vol. 9, pte 6, no 1, 194p. 
CARCElles, A. 1944. Catalogo de los moluscos marinos de Puerto Quequén. Revta Mus. La Plata, n.s., Zoo1., vol. 3, p. 233-309.

CIECHOMSKI, J.D. de 1967. Caracter del desove y fecundidad de la merluza argentina, Merluccius merluccius hubbsi, del sector bonaerense. Boln Inst. Bio1. mar., vo1. 13, p. 1-30.

CUSHING, J.E. 1964. The blood groups of marine animals. In: RUSSELL, F.S., ed. Advances in marine biology. New York, Academic Press, vo1. 2, p.85131.

DOBZHANSKY, T. 1955. Genetica y el origen de las especies. Revta Occid., Madrid, p. 1-391.

EMILSSON, I. 1961. The shelf and costal waters off southern Brazil. Bolm Inst. oceanogr. S Paulo, vo1. 11, no 2, p. 101-112.

ETCHICHURY, M.C. \& REMIRO, J.R. 1963. La corriente de Malvinas y los sedimentos Pampeano-patagónicos. Comun. Mus. nas. Hist. nat. Bernardino Rivadavia, Geol., vol. 1, no 2, p. 1-11.

FRANCO, G.T. 1959. Nota preliminar sôbre alimentação de alguns peixes comerciais brasileiros. Anais Acad. bras. Ciênc., vol. 31, nọ 4, p. 589-593.

FRYDENBERG, $\varnothing .$, M $\emptyset$ LLER, D. , NAEVDAL, G. \& SICK, K. 1965. Haemoglobin po1ymorfism in Norwegian cod populations. Hereditas, vol. 53, no 21, p. 257271.

GABRIEL, M.L. 1944. Factors affecting the number and form of vertebrae in Fundulus heteroclitus. J. exp. Zool., vol. 95, p. 105-143.

GORDON, M. 1957. Physiological genetics of fishes. In: BROWN, M.E., ed.- The physiology of fishes. New York, Academic Press, vol. 2, p. 431-501.

GUNTER, G. 1945. Studies on marine fishes of Texas. Publs Inst. mar. Sci. Univ. Tex., vol. 1, no 1, p. 1-190.

1950. Correlation between temperature of water and size of marine fishes on the Atlantic and Gulf coasts of the United States. Copeia, no 4, p. 298-304.

HEUTS, M.J. 1947a. Experimental studies on adaptative evolution in Gasterosteus aculeatus (L). Evolution, Lancaster, Pa., vol. 1, p. 89-102. 1947b. The phenotypical variability of Gasterosteus aculeatus (L.) populations in Belgium. Verh. K. ned. Akad. Wet., vo1. 9, p. 1-63. 1949. Racial divergence in fin ray variation patterns in Gasterosteus aculeatus. J. Genect., vol. 49, p. 183-191.

- 1956. Temperature adaptation in Gasterosteus aculeatus L..Pubb1.Staz. zool. Napo1i, vo1. 28, p. 44-61.

HILDEBRAND, S.F. \& SCHROEDER, W.C. 1927. Fishes of Chesapeake Bay. Bul1. U.S. Bur. Fish., vo1. 43, no 1, p. 1-366.

HUBBS, C.L. 1921. Geographic variation of Notemigonus crysoleucas: an American minnow. Trans. I11. St. Acad. Sci,, vol. 11, p. 147-151.

Bolm Inst. oceanogr. S Paulo, 20 (2): 1-70, 1971 
HUBBS, C.L. 1922. Variations in the number of vertebral and other meristic characters os fishes correlated with temperature of water during development. Am. Nat., vol. 56, p. 360-372.

- 1924. Studies on the fishes of the order Cyprinodontes. IV. The subspecies of Pseudoxiphophorus bimaculatus and Priapichthys annectens. Misc. Publs Mus. Zool. Univ. Mich., vol. 13, p. 17-23.

1926. The structural consequence of modifications of the developmental rate in fishes, considered in reference to certain problems of evolution. Am. Nat., vol. 60, p. 57-81.

1928. An hypothesis on the origin of graded series of local races in fishes. Anat. Rec., vo1. 51, p. 91 (Abastract).

1941. The relation of hydrological conditions to speciation in fishes. A symposium on hydrobiology. Univ. Wisconsin Press, p. 182-195.

1959. High incidence of vertebral deformities in two natural populations of fishes inhabiting warm springs. Ecology, vol. 40, no 1, p.154155 .

IHERING, H.von 1897. Os peixes da costa do mar do Rio Grande do Sul. Revta Mus. pau1., vo1. 2, p. 25-63.

KÄNDLER, R. 1932. Unsichercheiten bei Bestimmung der Wirbelzah1 infolge Verwaschsungserscheinungen. J. Cons. perm. int. Explor. Mer, vo1.7, p.373385 .

1935. Rassenkundiche Untersuchungen an Plattfischen. I. Variabilitthstudien and den Flossenstrahlen und Wirbelzahlen der 0stseeschollen. Ber. dt. wiss. Kommn Meeresforsch, N.F., vo1. 7, no 4, p. 381-493.

KETCHEN, K.S. 1961. Observations on the ecology of the Pacific cod (Gadus macrocephalus) in Canadian waters. J. Fish. Res. Bd Can., vo1.18, no 4, p. 513-558.

1964. Preliminary results of studies on growth and mortality of Pacific cod (Gadus macrocephalus) in Hecate Strait, British Columbia. J. Fish. Res. Bd Can., vol. 21, no 5, p. 1051-1067.

LAEVASTU, T. 1965. Manual of methods in fisheries biology. FAo Manuals in Fisheries Sci. no 1 (FIB/M 1), vol. 9, no 4, Research on fish stocks, p.151 .

LEINEBÖ, R. 1969. Study of coastal water on the Brazilian shelf at latitude $25^{\circ} \mathrm{S}$. Contrções Inst. oceanogr. Univ. S Paulo, sér. Ocean. fís., no 11, $14 \mathrm{p}$.

LEMOS, J. 1956. Relatório da missão portuguesa de pesca no Brasil. Introdução ao estudo das pescas no Brasi1. Lisboa, vo1. 1, p. 1-323.

LINDSEY, C.C. 1954. Temperature controlled meristic variation in the paradise fish Macropodus opercularis (L). Can. J. Zool., vol. 30, p. 87-98.

LOWE-MCCONNELL, R.H. 1966. The Sciaenidae fishes of British Guiana. Bul1. mar. Sci., vol. 16, no 1, p. 20-57. 
LUND Jr., W.A. 1957. Morphometric study of the striped bass Roccus saxatilis. Spec. scient. Rep. U.S. Fish Wild1. Serv. Fisheries, no 216, p. 1-24.

MARR, J.C. 1955. The use of morphometric data in systematic, racial and relative growth studies in fishes. Copeia, no 1, p. 23-31.

MARTIN, W.R. 1949. The mechanics of environmental control of body form in fishes. Univ. Toronto Stud. biol. Ser., no 58. Publs Ont. Fish. Res. Lab., n? 70, p. $1-91$.

MAYR, E. 1966. Animal species and evolution. Cambridge, Belknap Press,797p.. McHUGH, J.L. 1951. Meristic variations and populations of northern anchovy (Engraulis mordax mordax). Bull. Scripps Instn oceanogr. tech. Ser.,vol.6, no 3, p. 123-160.

MIRANDA, L.B. de 1969. Relatório sobre as condições oceanográficas na plataforma continental do Rio Grande do Sul (abril de 1968 a março de 1969 ). Primeira pesquisa oceanogrāfica sistemática do Atı̂ntico Sul entre Tôrres e Chuí. GEDIP-IOUSP, vol. 2 .

MOISEEV, P.A. 1953. Cod and flounders of far-eastern seas. Izv. tikhookean. nauchno-issled Inst. ryb. Khoz. Okeanogr., vol.40, p. 1-287. Fish. Res. Bd Can. Trans1. no 119 .

MOLANDER, A.R. \& MOLANDER-SWEDMARK, M. 1957. Experimental investigations on variation in plaice (Pleuronectes platessa L.). Rep.Fishery Bd Swed., ser. Biol., vol. 7, p. 1-45.

MøLlER, D. \& NAEVDAL, G. 1969. Studies on haemoglobins of some gadoid fishes. FiskDir. Skr., ser. Havundersфkelser, vol. 15, no 2, p. 91-97.

MOTtLEY, C. McC. 1937. The number of vertebrae in trout (Salmo). J. biol. Bd Can., vol. 3, no 2, p. 169-176.

MYERS, G.S. 1960. Restriction of the croakers (Sciaenidae) and anchovies (Engraulidae) to continental waters. Copeia, no 1, p. 67-68.

NOMURA, H. 1965. Bibliografia sôbre recursos marinhos do Brasil. Bolm Est. Biol. mar. Univ. Cearā, vol. 7, p. 1-53.

ORSKA, J. 1962. The influence of temperature on the development of meristic characters of the skeleton in Salmonidae. Part I. Temperature-controlled variations of the number of vertebrae in Salmo irideus Gibb...Zoologica Po1., vol. 12, no 3, p. 309-339.

PAIVA, M.P. 1958a. Notas biométricas sôbre corvina marisqueira, Micropogon furnieri (Desmarest, 1822) Jordan, 1884, Bolm Inst. oceanogr.s Paulo, vol. 9 , no $1 / 2$, p. 51-59.

1958b. Sôbre um caso de assimetria em ovārios de Micropogon furnieri (Desmarest, 1822) Jordan, 1884, Bolm Inst. oceanogr. S Paulo, vol.9, n? $1 / 2$, p. 23-29.

PIMENTEL, R.A. 1958. Taxonomic methods, their bearing on speciation. Syst. Zool., vol. 7, no 4, p. 139-156.

Bolm Inst. oceanogr. S Paulo, 20 (2): 1-70, 1971 
PURDON, C.E. \& WYATT, T. 1969. Racial differences in Irish Sea and North Sea plaice (Pleuronectes platessa). Nature, Lond., vol, 222, no 5195, p. 780781 .

QUAST, J.C. 1964. Meristic variation in the Hexagrammidae fishes. Fishery Bu11. Fish Wild1. Serv. U.S., vol. 63, no 3, p. 589-609.

1966. The Pacific cod systematic relatioships, biology and fisheries. Bib1. Arctique et Antarctique, III. Premier Congrèss Inter.de l'Industrie Morutiēre dans 1'Atlantique Nord, Rapport no 13.

RATTAZZI, M.C. \& PIK, C. 1965. Haemoglobin polymorphism in cod (Gadus morrhua): a single peptide difference. Nature, Lond., vo1. 208, p. 489-491.

RODRIGUES, M.S.S. 1968. Idade e crescimento da cururuca, Micropogon furnieri (Desmarest, 1822), nas águas cearenses. Arqs Est. Biol. mar. Univ. Fed. Cearā, vol. 8, no 1, p. 7-14.

ROSENTHAL, H.L., MYERS, P.R. \& BRUNINGS, N.K. 1958. Spinal curvature, a mutation in the swordtail, Xiphophorus. J. Hered., vo1.49, no 5, p. 238-242.

ROSENTHAL, H.L. \& ROSENTHAL, R.S. 1950. Lordosis, a mutation in the guppy. J. Hered., vol. 41, no 8, p. 217-218.

SCHAEFER, M.B. 1955. Morphometric comparison of yellowfin tuna from southest Polynesia, Central America, and Hawaii. Bull. inter-Am. Trop. Tuna Commn, vo1. 1, no 4, p. 91-136.

SCHMIDT, J. 1917. Racial investigations. I. Zoarces viviparus L. and $10 \mathrm{cal}$ races of the same. C. r. Trav. Lab. Carlsberg, vol. 13, p. 279-397.

1919. Racial studies in fishes. II. Experimental investigations with Lebistes reticulatus (Peters) Regan. J. Genet., vo1. 8, p. 147-153.

1921. Racial investigations.'vII.Annual fluctuations of racial characters in Zoarces viviparus L..C.r. Trav. Lab. Car1sberg, vol. 14, p. 1-24.

SCHULTZ, L.P. 1927. Temperature controlled variation in the golden shiner, Notemigonus crysoleucas. Pap. Mich. Acad. Sci., vol. 7, p. 417-432.

SCHULTZ, R.J. 1963. Stubby, a hereditary vertebral deformity in the viviparous fish Poeciliopsis prolifica. Copeia, no 2, p. 325-330.

SEYMOUR, A.H. 1956. Effects of temperature upon young chinnok salmon. Diss. Abstr., vol. 16, p. 2249.

SICK, K. 1961. Haemoglobin polymorphism in fishes. Nature, Lond., vol.192, n? 4805, p. 894-896.

1962. Haemoglobin pattern and chromosome number of American,European, and Japanese ee1s (AnguizZa). Nature, Lond., vol. 193, no 4819, p. 1001-1002.

1965a. Haemoglobin polymorphism of cod in the North Sea and the North Atlantic Oceans. Hereditas, vol. 54, no 3, p. 49-73.

Sea. Hereditas, vol. 54, no 2, p. 19-48. 
SICK, K., FRYDENBERG,. . \& NELSEN, J.T. 1963. Haemoglobin patterns of plaice, flounder and their natural and artificial hybrids. Nature, Lond., vol.198, n? 4878 , p. 411-412.

SINDERMANN, C.J. 1959. Serological studies of redfish. Int. Comm. for Northwest Atlantic Fish. Int. Counc. Expl. of the Sea, Redfish Symposium. 1961. Serological studies of At1antic redfish. Fishery Bull. Fish Wild1. Serv. U.S., vo1. 61, p. 351-354.

SINDERMANN, C.J. \& HONEY, K.A. 1963. Electrophoretic analysis of the haemoglobin of Atlantic clupeoid fishes. Copeia, no 3, p. 534-547.

STUARDO, B.J. 1964. Distribuición de los moluscos marinos litorales en Latino America. Boln Inst. Biol. mar., vol. 7, p. 79-91.

SVERDRUP, H.U., JOHNSON, M.W. \& FLEMING, R.H. 1960. The oceans: their physics, chemistry and general biology. New York, Prentice-Ha11, 1087p..

SVetovidov, A.M. 1948. Gadiformes. Fauna SSSR, Fishes, vol. 9, no 4, p.1217. Trans1. Off. tech. Serv. U.S., OTS 63-11071.

TANING, A.V. 1944. Experiments on meristic and other characters in fishes. I: Meddr. Kommn Danm. Fisk.-og Havunders., ser. Fiskeri, vo1. 11, no 3 , p. 1-66.

1952. Experimental study of meristic characters in fishes. Biol.Rev., vo1. 27 , p. 169-193.

TESTER, A.L. 1937. Populations of herring (Clupea palzasii) in the coastal waters of British Columbia. J. biol. Bd Can., vol. 3, no 2, p. 108-144.

VANNUCCI, M. 1963. Plâncton e ciclos alimentares. Contrções Inst. oceanogr. Univ. S Paulo, sér. Ocean. fís., nọ 5, p. 55-70.

VANZOLINI, P.E. 1968. Environmental temperature and number of body annuli in Amphisbena alba: notes on a cline (Sauria, Amphisbaenidae). Papéis Dep. Zoo1. S Pau1o, vo1. 21, no 23, p. 231-241.

de reconhecimento específico em três espēcies simpátricas de 1 ambaris do gênero Astyanax (Pisces, Characidae). Papéis Dep. Zool. S Paulo, vol. 16, n? 27 , p. 267-299.

VAZZOLER, A.E.A. de M. 1962. Sôbre a primeira maturação sexual e destruição de peixes imaturos. Bolm Inst. oceanogr. S Paulo, vo1. 12, no 2, p. 5-38.

1963a. Deslocamentos sazonais da corvina relacionados com as massas de ägua. Contrções Inst. oceanogr. Univ. S Paulo, sēr. Ocean. bio1., nọ 5, p. $1-8$.

1963b. Sôbre a fecundidade e desova da pescada foguete. Bolm Inst. oceanogr. S Paulo, vo1. 13, no 2, p. 33-40.

1965. Estimativa da abundância relativa da corvina, na costa centrosul do Brasil. Bolm Inst. oceanogr. S Paulo, vol. 14, no 1, p. 3-11.

1969. Micropogon furnieri: fecundidade e tipo de desova. Bolm Inst. oceanogr. S Paulo, vo1. 18, p. 27-32.

Bolm Inst. oceanogr. S Paulo, 20 (2): 1-70, 1971 
VAZZOLER, A.E.A. de M. \& SA, E.M. de 1963. Anälise da pesca da corvina na costa centro-sul do Brasil. Bolm Inst. oceanogr. S Paulo, vol. 13, no 2 , p. $61-70$.

\& SANTOS, E.P. dos 1965. Migração da corvina (Micropogon furnieri), na costa sul do Brasil. Bolm Inst. oceanogr. S Paulo, vol. 14, p. $115-128$.

VAzzoler, G. 1962. Sôbre a biologia da corvina da costa sul do Brasil. Bolm Inst. oceanogr. S Paulo, vol. 12, no 1, p. 53-102.

VLADYKOV, V.D. 1934. Environmental and taxonomic characters of fishes. Trans. R. Can. Inst., vol. 20, p. 99-140.

YAMAGUTI, N. 1967. Desova da pescada-foguete, Macrodon ancylodon. Bolm Inst. oceanogr. S Paulo, vol. 16, p. 101-106.

- \& SANTOS, E.P. dos 1966. Crescimento da pescada-foguete (Macrodon ancylodon): aspecto quantitativo. Bolm Inst.oceanogr. S Paulo, vol.15, p. $75-78$. 